\title{
THE ANTHROPOMORPHIZED ANIMAL IN CHILDREN'S CULTURE
}

by

Amy Ratelle

Bachelor of Fine Arts, Ryerson University, 2003

Master of Arts, Carleton University, 2006

\author{
A dissertation \\ Presented to Ryerson University and York University \\ in partial fulfillment of the \\ requirements for the degree of \\ Doctor of Philosophy \\ in the Program of \\ Communication and Culture
}

Toronto, Ontario, Canada, 2012

(C) Amy Ratelle 2012 


\section{AUTHOR'S DECLARATION FOR ELECTRONIC SUBMISSION OF A DISSERTATION}

I hereby declare that I am the sole author of this dissertation. This is a true copy of the dissertation, including any required final revisions, as accepted by my examiners.

I authorize Ryerson University to lend this dissertation to other institutions or individuals for the purpose of scholarly research.

I further authorize Ryerson University to reproduce this dissertation by photocopying or other means, in total or in part, at the request of other institutions or individuals for the purpose of scholarly research.

I understand that my dissertation may be made electronically available to the public. 


\begin{abstract}
The Anthropomorphized Animal in Children's Culture

Ph.D.

2012

Amy Ratelle

Communication and Culture

Ryerson University and York University
\end{abstract}

The reliance on animals in children's literature over the past two centuries has become a key means by which the civilizing process that children go through has been mediated by the animal body. Children are asked both implicitly and explicitly to identify with animals, but then to position themselves as distinctly human through the mode of their interactions with both lived animals and those depicted in literature and film. This core question of identity formation - child/adult, animal/human - forms the foundation of my dissertation, which investigates the overlapping, double-sided rhetorics addressing children, childhood and animals. My dissertation is organized into five areas of interest that pose complementary questions regarding the way in which relationships between animals and children inform and underscore adults' lived relationships with both of them.

Posthumanist scholarship, then, becomes a key means by which to de-prioritize a conception of an exclusively human subjectivity. Cary Wolfe in particular has recently worked to criticize liberal humanism and find ways to push cultural analysis beyond its 
inherent anthropocentrism in order to combat institutionalized speciesism, which continues to prioritize human beings, thereby excusing the exploitation or extermination of other species. What has been notably overlooked in posthumanism's challenge to anthropocentric human liberalism, however, is how the human is encultured through literature geared specifically towards a child audience. By examining culturally significant and widely popular works of children's culture through a posthumanist, or animality studies lens, I argue that Western philosophy's objective to establish a notion of an exclusively human subjectivity is continually countered in the very texts that ostensibly work to configure human identity. Literature geared toward a child audience reflects and contributes to the cultural tensions created by the oscillation between upholding and undermining the divisions between the human and the animal. My dissertation focuses on the ways in which these works present the boundary between humans and animals as, at best, permeable and in a state of continual flux. 


\section{Acknowledgements}

I would like to acknowledge the exceptional support of my supervisor, Dr. Dennis Denisoff of Ryerson University. His extraordinary contributions of time, expertise and encouragement enabled me to finish this dissertation.

I would also like to acknowledge Dr. Andrew O’Malley of Ryerson University and Dr. Kevin Dowler of York University for their contributions to my research. Their encouragement and accommodations are greatly appreciated.

I would also like to thank the external members of my committee, Dr. Tina Young Choi of York University and Dr. Barbara Seeber of Brock University, for their contributions to my dissertation.

Additional thanks to program administrator Jo Ann Mackie for her time and expertise over these past five years, and to the Ryerson Library for facilitating my many interlibrary loans. 


\section{Table of Contents}

Introduction......................................................................

1. Equine Virtues and Rights in Nineteenth-Century Children's Literature.............13

Locke, Rousseau, and the Conflation of Animals and Children in Literature for the Young................................... 15

From Animal Autobiography to Animal Rights..................................22

The Contrary Nature of Dick the Little Pony.......................................29

The Multiple Rhetorical Burdens of Black Beauty...................................

2. Human Values and the Wild Animal Body in Jack London's Canine Canon............45

The Historical Rhetoric of Wolves as Evil.......................................47

Imperialism and Animals - The Boys' Adventure Story ..........................50

Becoming Buck: Envisioning Posthumanity..................................58

California Dreaming: The Domestication of White Fang........................65

3. Carnophallogocentric Criticism in Charlotte's Web.............................72

A History of Hogs and Hog-farming........................................... 74

E.B. White, Self-professed Animal Murderer.................................. 85

The Western Carnophallogocentric Paradigm in Charlotte's Web....................89

4. Science, Species and Subjectivity in Mrs. Frisby and the Rats of NIMH

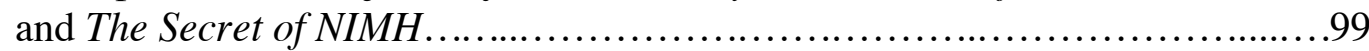

Experimental Uses of Animals..............................................101

Technologies of Pain, from Anti-Vivisectionism to NIMH...................... 105

Species and Subjectivity in Mrs. Frisby and the Rats of NIMH....................115

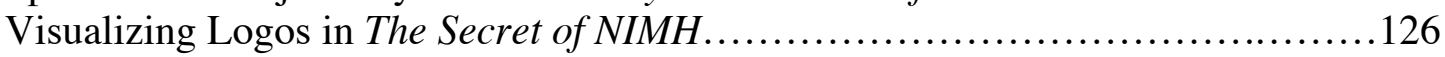

5. Performance and Personhood in Free Willy and Dolphin Tale ......................130

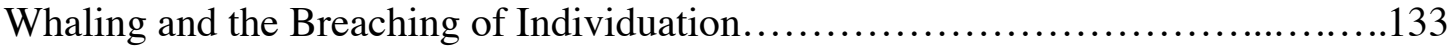

Beyond "Bare Life": The Cetacean Personhood Movement.........................141

Free Willy, Freeing Keiko................................................ 146

Interspecies Intimacy in Dolphin Tale .................................... 155

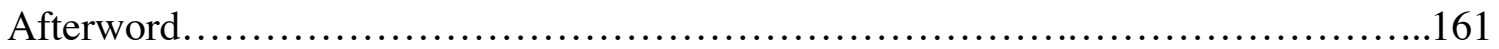

End Notes............................................................. 164

Works Cited................................................................. 178 


\section{Introduction}

The animal looks at us, and we are naked before it. Thinking perhaps begins there. (29)

Jacques Derrida, The Animal That Therefore I Am

Biologist Donna Haraway's work is guided by a central question, “whom do I touch when I touch my dog?” (When Species Meet 3, emphasis mine). She foregrounds her canine's individuality in order to propose a model of interaction that does not reinforce traditionally accepted boundaries between humans and other animals. This project has similarly been largely inspired and guided by a remarkable dog - Sam the husky, whose presence in my life has only ever served to enrich and enhance it. I didn't know, and could never have foreseen, the impact of embarking with Sam in what Haraway calls a "companion species" relationship (15), maintained by mutual respect and affection. Underwritten by love and interspersed with many long walks, my dissertation is, at its core, about my dog. And also about my daughter, Laila, who, at three years of age, has yet to notice any particular difference between herself and Sam. She considers him to be a sibling, often referring to him as her "big brother." Sam, for his part, seems to have always thought that he is people, and I have always been inclined to agree with him. Observing first-hand the easy fluidity of interspecies affection and identification in my own home made me keenly aware of how Western philosophy, historically, has worked to deny subjecthood to animals, to configure this relationship 
situated in love and mutual respect as delusional or wishful thinking. It is possible, however, that the act of anthropomorphizing an animal is not necessarily rooted in what we, as humans, wish to ascribe onto the animal to suit our own cultural or symbolic requirements, but instead expresses something we receive from the animal, when we are situated together in mutual understanding.

In this formulation, posthumanist scholarship works to de-prioritize the conception of an exclusively human subjectivity. Posthumanism, historically, has had more in common with cybernetics and systems theory, positing that the human brain functions not unlike a closed-loop feedback system. As such, the system itself can rewrite itself based on the information it receives from its environment. Scholars working in this field have reconceptualized the human brain as a type of biological computer, making people more akin to intelligent machines. Within this system, how the brain works is prioritized over what it might be thinking.

Working to undermine the concept of the liberal humanist subject, some developments in contemporary posthumanism have veered away from its previous technological focus to revisit the cultural assumptions underpinning our lived relationships with animals. Cary Wolfe in particular has recently worked to criticize liberal humanism and find ways to push cultural analysis beyond its inherent anthropocentrism in order to combat "the institution of speciesism" (Animal Rites 2), which continues to prioritize human beings, thereby excusing the exploitation or extermination of other species. To accomplish this goal, Wolfe gathers writings on animals found across different and often disparate disciplines in order to subvert the 
concept of a human/animal divide. According to Wolfe, however, the study of humananimal relationships can in fact continue to promote a worldview inconsistent with the larger goals of posthumanism. He contends, for example, that even if scholars study nonhuman animals "with the aim of exposing how they have been misunderstood and exploited, that does not mean we are not continuing to be humanist - and therefore, by definition anthropocentric" (What Is Posthumanism? 99). Wolfe questions whether calling attention to the plight of abused or oppressed animals is enough to challenge conventional boundaries between the human and the animal.

The assumption of human authority over other species dates back to antiquity, based on their lack of reason. Reason, however, had yet to be reconfigured into evidence of a specifically human subjectivity. This shift is historically situated in René Descartes's conceptualization of human thought and speech acts as tangible evidence of the cogito; for him, human thought proves human existence. As such, the cogito constitutes the dividing line between the human and the non-human animal. Speech - as concrete evidence of thought, reason and language - changes the way in which people perceive animals. Human identity, then, can be defined only when explicitly positioned against the animal body.

Since Descartes, Western philosophy has largely been invested in upholding this boundary. Jacques Derrida, however, has recently questioned not only the relevance of speech or speech acts in forming the division, but also whether or not people even have the right to demarcate and enforce it. According to Derrida, it is 
less a matter of asking whether one has the right to refuse the animal such and such a power (speech, reason, experience of death, mourning, culture, institution, technics, clothing, lie, pretense of pretense, covering of tracks, gift, laughter, tears, respect, and so on - the list is necessarily without limit, and the most powerful philosophical tradition within which we live has refused the "animal" all of those things) than of asking whether what calls itself human has the right to rigorously attribute to man, which means therefore to attribute to himself, what he refuses to the animal, and whether he can ever possess the pure, rigorous, indivisible concept, as such, of that attribution. (Therefore 137)

Although Derrida ultimately comes to reinforce a division between human and animal, he nevertheless undermines the centuries of cultural assumptions about animals that arose both prior to and after Descartes.

Derrida's queries are exemplary of posthumanist scholarship, which has proven a useful means by which to deprioritize the human as the yardstick against which all other life forms are measured. What has been notably overlooked in posthumanism's challenge to anthropocentric human liberalism, however, is how the human is encultured through literature geared specifically towards a child audience. By examining culturally significant and widely popular works of children's culture through a posthumanist, or animality studies lens, I will argue in my subsequent chapters that Western philosophy's objective to establish a notion of an exclusively human subjectivity is continually countered in the very texts that ostensibly work to configure human identity. Literature geared toward a child audience reflects and contributes to the cultural tensions created 
by the oscillation between upholding and undermining the divisions between the human and the animal. My dissertation focuses on the ways in which these works present the boundary between humans and animals as, at best, permeable and in a state of continual flux.

The configuration of childhood as separate from and subordinate to adulthood is, much like the distinctions between the human and the animal, predicated on maintaining the illusion of a clear boundary between two constructed states of being. According to Phillippe Ariès, childhood, as we contemporarily understand it, did not exist prior to the Middle Ages. At this early stage of its formation, it was seen as a brief period of developmental dependency that was passed through with little fanfare and considered to be of minimal importance. Infant mortality was high, contributing to a lack of sentimentality towards young people. Ariès contends that the first notions of children as special or different from adults were positioned in terms of innocence, or of infants being removed or protected from the cares and worries of the adult world. He observes that cultivating and maintaining this innocence "resulted in two kinds of attitudes and behavior towards childhood: firstly, safeguarding it against pollution by life [...] and secondly, strengthening it by developing character and reason" (119). This rhetorical stance presumes that children, like animals, stand outside society, and yet, unlike animals, will ultimately (when they become adults) be responsible for the continuance of that same society.

This notion of childhood innocence, as I argue in my first chapter, has its origins in the Romantic idealization of nature and reaction against the Enlightenment's 
valorization of reason, as well as the middle-class impetus for education and selfimprovement. As Andrew O'Malley observes, the emergence of the middle class corresponds with a conception of children as a separate literary audience (6). In this formulation, animals play "a critical role in the shaping of personal identity and social consciousness[...] in the passage to adulthood" (Shepard 3). In other words, this new literature written specifically for children makes use of anthropomorphized animal characters ostensibly to impart middle-class values to the young. As I will argue over the course of my dissertation, however, there are many slippages and ruptures when using animals in the formation of an exclusively human identity for the child, ones that in fact result in a popular form of literature that, often inadvertently, problematizes notions of species segregation.

The reliance on animals in children's literature over the past two centuries has become a key means by which the civilizing process that children go through has been mediated by the animal body. Children are asked both implicitly and explicitly to identify with animals, but then to position themselves as distinctly human through the mode of their interactions with both lived animals and those depicted in literature and film. This core question of identity formation - child/adult, animal/human - forms the foundation of my dissertation, which investigates the overlapping, double-sided rhetorics addressing children, childhood and animals. My dissertation is organized into five areas of interest that pose complementary questions regarding the way in which relationships between animals and children inform and underscore adults' lived relationships with both of them. 


\section{An Overview of the Chapters}

My first chapter will examine some of the surprisingly inter-related roots of the animal rights movement and the children's rights movement during the nineteenth century. Children's rights in fact arose as a development of animal rights and, as I argue, this co-reliance reflects the way in which the cultural conflation of children and nonhuman animals fulfilled certain demands that the industrializing adult placed on both. While the main focus of this chapter is on "equine" texts, an analysis of Sarah Trimmer's Fabulous Histories Designed for the Instruction of Children, respecting their Treatment of Animals (1786) provides crucial historical context. Trimmer is one of the earliest writers using anthropomorphized animals to impart moral instruction to children. As Tess Cosslett notes, "Trimmer uses the device partly in order to amuse her readers, but also as a way of educating them into sympathy with animal's-eye views" (5). Thus, children are encouraged to empathize with animals in order to reaffirm their humanity. This empathy is expanded upon in the anonymously written Memoirs of Dick the Little Pony, Supposed to be Written by Himself (1799) and Anna Sewell's Black Beauty (1877), both written from the equine's point of view. There are startling similarities between Dick the Little Pony and Black Beauty, with both central characters moving from their idyllic pastoral birthplaces to the confusion and cruelty of an urban setting. During this time period in Britain, an increasing number of livestock were no longer confined to farms, instead populating cities as both transportation and physical labour. Sewell especially is nostalgic for the countryside and agrarian lifestyle, writing at a time when industrial manufacturing was becoming increasingly important to British economic 
success. As these texts suggest, during the nineteenth century, horses became the body marking humans' own tension and unease with swift and monumental economic and industrial transition, resulting in the animals' placement at the forefront of the animal rights movement.

My second chapter addresses more specifically the way in which the animal body has been used to signify human values. One recognizes, for example, the nobility of horses, the loyalty of dogs, and the pacificity of cattle. This adaptation of the animal body became common and unquestioned in children's works, but the implications of such attributions for adult conceptions of species' relations has yet to be thoroughly addressed, especially when it comes to the wild animal. In this chapter, I build on my earlier discussion of the cultural conception of the domestic animal as a means by which the young were inducted into a culture of labour and suffering. Particularly important to understanding the politics behind these binary oppositions is London's own vision of interspecies friendship. In questioning the perceived boundaries between humans and animals, scholars such as Donna Haraway and Gilles Deleuze and Félix Guattari reconceptualize humans and animals as phenomena beyond ideology, presenting a challenge to the hegemonic structures of imperialism that had become central to humanist exploits of the nineteenth and twentieth centuries. By conducting an animality studies reading of Jack London's novels The Call of the Wild (1903) and White Fang (1905), I am able to focus on issues of wilderness and civilization, as London himself does, in order to demonstrate how assumptions regarding wild/civilized distinctions 
function not only to erase the agency of other species, but also to undermine the potential for cross-species identification.

Extrapolating on the identity politics arising from my consideration of humananimal relations in my previous chapters, my third chapter engages with conflicts arising from the rhetorically sympathetic fusion of children not only to other animals but also to the broader natural environment. I extend the notion of animal subjectivity and crossspecies identification through an examination of Charlotte's Web (1952) in the context of E.B. White's other writings on animals. As my study reveals, the author held a deeper ambivalence regarding the modern culture of animal consumption than is normally assumed. An analysis of the novel that accounts for Wilbur as an actual non-human animal - instead of as a representative of the concept of the human child, as has most often been done to date - calls into question the naturalization of what Derrida refers to as the "noncriminal putting to death" of the animal for human consumption ("Eating Well" 112). Moreover, my examination of Charlotte's Web accounts for the wider ethical implications of acknowledging the status of subject for an individual animal, but not for all animals. As I argue, although White promotes a vision of animal selfidentification that is at odds with what Derrida calls the "carnophallogocentric" (113) paradigm of meat consumption, he ultimately retreats from unraveling the false logic of the dominant paradigm, instead expressing regret that rhetoric around the death of the food animal is so obscured in Western culture.

In Chapter Four, I examine animal politics within the context of class and technology, as presented in Robert C. O'Brien's novel Mrs. Frisby and the Rats of 
NIMH (1971) and its filmic adaptation The Secret of NIMH (1982). Situating my analysis in the historical context of Victorian antivivisection debates, I reveal an ambivalence on the author's part regarding the centrality of technological progress in Western notions of value. As an extension of my argument in chapter three, this chapter builds on Derrida's carnophallogocentric paradigm to problematize the assumption that animals are lacking in logos, the divine speech act. Specifically, this chapter investigates the disturbances arising within the laboratory context, and how this experience is addressed in children's culture and O'Brien's novel in particular. In his formulation, the use of animals as experimental subjects brings forward the fact that the borders between human and animal are permeable and far from stable. In my analysis, I aim to push the boundaries of what "subjectivity" itself means in both the novel and the film, as well as in the framework of Western culture more generally. Emphasizing the notion of the collective in identity formation, the novel in particular can be seen as addressing the way in which texts from Dick the Little Pony to Charlotte's Web sacrifice the subjectivity of an entire species in their efforts to establish the individualism of a singular animal with which the young reader can identify.

In watching Laila and Sam interact, the notion of what constitutes family has frequently come to my mind, and this same topic can be seen to weave through my entire dissertation. I have therefore chosen to conclude my study with a chapter that brings the issue of familial affection and love to the foreground. My fifth chapter focuses on two films promoting legal personhood rights for whales. My analysis of Free Willy (1993) and Dolphin Tale (2011) focuses on the cetacean rights movement's proposal of a 
fundamental subjectivity and freedom from exploitation for all whales. The two films are predicated on the fresh assessment of child/marine mammal affections and identification. Each also, in different ways, addresses the issue of captivity in the context of cetacean identity formation in order to call attention to the need for legal acknowledgement of the personhood of whales. My previous chapter on the NIMH texts addresses animal subjectivity in the context of the aptitude for human language. This chapter builds on that argument, investigating more fully the centrality of language in self-identification, as well as Giorgio Agamben's use of zoe and bios as a site of conflict between constructs of nature and culture. Situating the topic of child/animal relations against the backdrop of family disruption, this chapter uses the overlaps between the films and the actual lives of their animal stars to argue for a conception of non-human identity that, rather than being defined as purely animal, must be recognized as existing outside such binary logic, a gesture that does not simply humanize animals but disturbs the notion of the human itself.

Children are influenced by the literature and cinema they consume and an outstanding proportion of this material relies on representations of non-human animals for its mediation of values and ethics. For the past two centuries, therefore, this material has done no less than establish the framework of understanding for the people behind the animal rights movement in the West. Moreover, it continues to do so. With my dissertation, I have worked to survey this set of ideological connections. Of particular importance to me has been the work of the advocates and scholars who have, over the 
years, demonstrated the validity of legal personhood for all animals, and who have challenged the notion of one species being superior, or having the right to steward, any other. 


\section{Chapter One:}

\section{Equine Virtues and Rights in Nineteenth-Century Children's Literature}

Generally, in the nineteenth century, if people were asked for the most obvious instance of cruelty to animals, then this spectacle of a beaten and exhausted horse would have answered. (63)

\section{Coral Lansbury, The Old Brown Dog}

During the nineteenth century, animal suffering was an appalling constant of both rural and urban landscapes, and one of the most visible forms of this suffering arose from the abuse visited upon the horses used for stagecoach or hansom cab transport. An integral part of the social and economic structure of human society at this time, equines had also become ubiquitous as symbols and metaphors. Sarah Wintle notes that, from the seventeenth century onward, horses were used to articulate "ideas and feelings about such central human concerns as status and class, sexuality, and the body" (4). In Romantic iconography, Robert Dingley observes, the horse is "at least as often the embodiment of untamed natural force as it is representative of subordination to human purpose" (245). During the nineteenth century, horses often simultaneously embodied such human values as status, wealth, nobility and military power, while also functioning in a far less glorified sense as necessary brute labourers in manufacturing and as familiar workers on crowded, polluted urban streets. 
The awkward fit of these two roles proved a major catalyst for the animal rights movement. Marian Scholtmeijer observes that the urban space and cruelty to animals were "strangely interlinked" (143). She contends that the conspicuousness of urban animals makes them significant in discussions of cruelty. She further posits that urban cruelty to animals "jars" with the ideals of civilization embraced by city dwellers (143). The high visibility of the animals, moreover, enhanced empathy for equines, so much so that, by the mid-Victorian period, Robert Louis Stevenson would find himself heavily criticized for portraying himself, in his generally lighthearted Travels with a Donkey in the Cévennes (1879), beating his stubborn travelling companion Modestine. ${ }^{1}$ While Stevenson's actions occurred within in a rural context, it was the urban space that offered the most public displays of animal abuse. This very visibility served as a catalyst for animal rights legislation such as the 1822 Martin's Act; targeted at the condition of horses and other domestic animals, the act stands as the first animal rights legislation in history. Because cities fostered greater communication among those sympathetic to animal suffering, they offered the necessary means of effectively voicing dissent. Postering, rallies and other events were easier to arrange. And because a smaller proportion of city-dwellers relied as heavily on livestock for their livelihood as people from the countryside, a larger audience of potential sympathizers was found in the cities and larger towns.

In this chapter, I explore the way in which horses became the site for capturing the hypocrisy behind the façade of civility and empathy maintained by a society driven economically by an unrelenting productivist ethos. Focusing on the anonymous Memoirs 
of Dick the Little Pony, Supposed to be Written by Himself (1799) and Anna Sewell's Black Beauty (1877), I will argue that the equine embodiment of this conflict was recognized as a means of educating the young into a culture of labour and suffering. As I will demonstrate, however, such works did not simply prepare children for the burdens of economic growth and the privileges of middle-class life, but encouraged the young to question the values of their parents.

\section{Locke, Rousseau, and the Conflation of Animals and Children in Literature for the Young}

According to Harvey Darton, literature designed specifically for the child audience did not become a "clear but subordinate branch of English literature until the middle of the eighteenth century" (1). Inspired by the writings of John Locke and Jean-Jacques Rousseau, publisher John Newbery began in 1744 printing illustrated books for children that were not only entertaining to read but, more importantly for middle-class purposes, provided instructions for living a life of virtue and financial success. Newbery revolutionized publishing first by conceiving of children as an audience separate from adults; and second by capitalizing on the middle class's disposable income, which they were more than willing to invest in shaping and securing their children's future.

Perhaps more than any other philosopher, Locke had an incredible (and stillenduring) impact on education and, by corollary, middle-class conceptions of childhood. His accessible prose and celebration of self-improvement led adult members of the emerging middle class to educate their children as a way of shaping not only their moral 
but also their financial values. Samuel Pickering characterizes Locke as "a popularizer," in that he synthesized prevailing ideas on children and education into a glorious tale of self-improvement (6). Of equal importance, Locke convincingly proposed that this potential for improvement was available to all citizens, not merely the sons of the aristocracy as had previously been the case. According to him, dutiful parents should instil in their children - along with abstract concepts of virtue - concrete and achievable "good habits," such as obedience, grace and politeness. Further, children are predisposed to such instruction, he postulates, because they are a "yet Empty Cabinet" (Essay 23), or "white paper, or wax, to be moulded and fashioned as one pleases" (Thoughts 179). The role of the parents becomes crucial then because, for their moral character, children rely wholly on observation, experience, sensation and proper instruction.

As Locke's ideas became increasingly influential on the eighteenth-century middle-class consciousness, it was the often explicit egalitarianism of his writing that particularly appealed to parents. As Andrew O’Malley notes, in Locke’s vision, starting from a position of equality, unhindered by obstacles to their development, and, by the same token, unaided by unfair hereditary privilege and hierarchy, the children who would naturally succeed would be those who had received the best education and who, by dint of industrious application, had acquired the most useful skills and knowledge. (5)

Proper education, it was believed, provides the key to transcending the place in the social hierarchy to which one happened to be born. 
Among the virtues and positive habits he espoused, Locke placed a notably heavy emphasis on kindness to animals. He observes that, if left otherwise uninstructed, children will "often torment and treat very roughly young birds, butterflies, and other poor animals which fall into their hands, and that with a seeming kind of pleasure" (Thoughts 91). In light of such inclinations, children need to be closely observed by their parents, who should seize every opportunity to instruct their offspring in kindness. Like Aristotle in Nicomachean Ethics, Locke contends that unchecked cruelty towards animals will lead to further cruelty towards fellow humans. Building on this observation, eighteenth-century writers who saw children as their audience often used animals as didactic tools for encouraging benevolence and sympathy (Pickering 12).

Among the first to use animal characters in explicitly pedagogical literature geared for the middle-class child, Sarah Trimmer's work serves as a clear early example of this transference of Lockean ethics to children's literature. ${ }^{2}$ Trimmer's Fabulous Histories Designed for the Instruction of Children, respecting their Treatment of Animals (1786) outlines how two families - one human, one avian - learn to live in harmony. The life lessons imparted by both species to their offspring are not surprisingly consistent with Locke's writings. Locke articulated a chain of warnings to parents "childish cruelty must not be tolerated, not to insects, not to birds, not to small animals, not to pets, not to each other" (Perkins 20) - and Trimmer's text offers a repeated affirmation of this chain.

The Bensons are an upper-class, though untitled, country family with a large estate, occupying a transitional niche between the middle class and the aristocracy. As 
landed gentry, the family is usefully suited to purvey virtues and values; above the middle class in station, they effectively depict a way of life to which middle-class readers could readily aspire. Their closest neighbours happen to be a family of robins nesting in the garden wall. Trimmer depicts both the human and avian parents encouraging their young to live virtuously and with moral rectitude, the bourgeois values gaining a naturalizing quality through their anthropomorphic displacement onto a nonhuman species.

Notably, despite the fact that members of the new middle-class generally saw themselves as transcending the working class, they tellingly retained a vested interest in maintaining a social hierarchy in which, they felt, the poor really ought to keep to their place. $^{3}$ In accord with this common perspective, the Benson family in Trimmer's Fabulous Histories emphasizes a respect for hierarchy and one's place in it, as well as the virtues of hard work and universal benevolence to all lesser creatures, including the human poor. In one chapter, after the Benson boy and girl have given the better part of their breakfast leftovers to the robins, their mother offers a lesson in the hierarchy of the needy. While she is "delighted by the children's [.. .] humane behaviour towards the animal creation, and wish[es] by all means to encourage it," she instructs them on "regulation":

let me therefore recommend to you, not to suffer it to gain upon you to such a degree as to make you unhappy, or forgetful of those who have a superior claim to your attention: - I mean poor people - always keep in mind the distresses 
which they endure; and on no account waste any kind of food nor give to inferior animals what is designed for mankind. (8)

In other words, it is a virtue to be kind to animals, but one's own species must maintain priority in one's interests. There is no such reciprocity with the robins, however. While they offer a grateful view of human kindness from the side of the recipient, teaching inter-species kindness is not a priority for the avian parents. Indeed, the robins emphasize a strict avian social hierarchy, in which each species is ranked and keeps to its own kind. Kindness is taught in a context of family relationships, as an extension of the performance of other virtues like industry and moral rectitude.

It is significant that the Benson children are raised with a sense of obligation to those in lower income brackets. Their acts of benevolence are not simply altruistic but function to reinforce the middle class's perceptions of its own moral superiority, a transposition of the noblesse oblige otherwise recognized as the exclusive privilege of the upper class. In Trimmer's text, human gestures of kindness to both animals and the poor afford the middle-class child with access to what Marian Scholtmeijer refers to as "that condescension which the wealthy could exercise in wider fields" (21). This dependency of the needy on the middle and upper classes for supplementary income, moreover, underscores the attitude that the lower classes are either content to be - or are destined to remain - poor; otherwise they would, as Locke explains, succeed in their middle-class aspirations. Trimmer's text thus stands as an early example of children's literature functioning as "one of the crucial mechanisms for disseminating and consolidating middle-class ideology" (O’Malley 11). Trimmer's intentions in this 
chapter as well as elsewhere in Fabulous Histories are exemplary of the pedagogical and ideological impetus implicit in the middle-class conception of education as primarily a means for advancing or consolidating one's social standing.

Rousseau's influence mitigated somewhat the explicitly didactic influence of writers such as Trimmer, who were content to let animals in children's literature serve as mere instructional devices. Where Locke focuses on kindness to animals as a performance of virtue, Rousseau postulates in Emile (1762) that children's kindness to animals stems from a natural sympathy for them. In Emile, Rousseau works to articulate an educational model that would allow the "natural" virtues of the human individual to persist despite the negative influence of modern civilization. According to Rousseau, the young are predisposed to recognize their similarity to nonhuman animals. He notes that, in order to develop pity and sensitivity, a child needs to become aware that "he has fellow-creatures who suffer as he has suffered, who feel the pains he has felt, and others which he can form some idea of being capable of feeling them himself" (254). "Indeed, how can we be stirred by pity," Rousseau goes on to argue, "unless we go beyond ourselves, and identify ourselves with the suffering animal, by leaving, so to speak, our own nature and taking his" (254). This demand for identification with the animal is an echo of other claims regarding animal rights and freedom from suffering, and gets revisited in literature of the era through the many animals' accounts of their interactions with humans. This technique proves especially common within children's literature depicting animals - and horses in particular - performing physical labour and other services for humans, questioning the arrogant assumption that animals are natural-born 
servants to humans. Trimmer herself characterizes horses as "formidable creatures" (127) who are fully capable of harming humans in the course of their labour-based interactions, but she adds that

God has wisely ordained that they should not [do] so; and having given mankind dominion over them, he has implemented in their nature an awe and dread of the human species, which occasion them to yield subjection to the lords of creation when they exert their authority in a proper manner. (127)

Thus for Trimmer, the subjugation of horses is a part of God's human-privileging design, a design that also sanctions some degree of animal abuse, or what Trimmer euphemistically describes as humans' "proper" exertion of authority. This model of species relations also hints at the author's awareness of the problems with bourgeois class distinctions that are somehow simultaneously essential and yet transcendable through a strong work ethic. Ostensibly unlike the human poor, horses can never move above their position in society, because they lack reason enough to perceive the inequity of their enforced servitude.

Musing on the same class/species correlations and distinctions, Rousseau remarked that we "only pity the wretched so far as we think they feel the need of pity" (257). As he goes on to observe, this is "one of the reasons why we are more callous to the sufferings of animals than of men, although a fellow-feeling ought to make us identify ourselves equally with either" (257). In eighteenth and nineteenth-century Britain, the emergent animal autobiography genre was pivotal in fostering this fellowfeeling with animals, as well as in challenging the normative notions of species 
hierarchy and the labour-based abuse these notions sanctioned. In England, this challenge proved to be the impetus for enacting many of the earliest laws against cruelty to animals.

\section{From Animal Autobiography to Animal Rights}

Early arguments for animal rights were largely the result of a major re-thinking of the relationship between humans and other animals. Indeed, the Romantic Movement arose in part in opposition to the Enlightenment's scientific rationalization of nature, thereby encouraging a reconception of the relationship of individual humans to their natural surroundings and the animals recognized as a part of those surroundings. ${ }^{5}$ William Blake's poem "The Fly" (1793) concisely captures the way in which the Romantics often problematized the concept of species segregation: "Am not I / A fly like thee?" the poem's speaker queries, “Or art not thou / A man like me?" (n. p.). In this brief passage, Blake has his narrator conflate his/her own identity with that of the insect in order to comment on the shared mortality of both humans and animals. On another level, within the context of suffering and death, the passage asserts the arbitrariness of perceived human superiority. It is the narrator's "thoughtless hand" - like that of some uncaring god - that crushes the life of the other. The oddly anthropomorphic assumption that the insect, until its untimely death, was occupied with "summer play" imbues not only the fly but also the speaker with a child-like naïveté that leaves the principal inquiry unresolved. Nor is this study of a fly a rare consideration for the Romantics. David Perkins recounts how poets such as Lord Byron, Samuel Taylor Coleridge and Percy 
Bysshe Shelley were emotionally distressed by the thought of cruelty to animals, insects and fish. As is well known, both Shelley and Byron espoused vegetarian diets, and Shelley went so far as to purchase crayfish at a market so that he could return them to the Thames. The Romantic celebration of nature as a sublime force beyond human understanding was coupled with a more clearly politicized problematization of humans' assumptions regarding their relation to other species.

As part of this spirit of the age, Jeremy Bentham in 1780 reintroduced and popularized philosophic debates around animal suffering. The critical issue, he proposes, "is not Can they reason? nor Can they talk? But, Can they suffer?" (Principles 311). Bentham circumvents the prevailing attention - in animal rights debates of the time - to questions around issues of language, reason and the soul without explicitly undermining the boundaries that Blake questions between humans and other animals. Bentham is not addressing children exclusively in this section of his Principles, but his argument nevertheless opens up a philosophic space within which one can begin questioning previous conceptions of the relation of young humans to animals as predicated on René Descartes's famous assertions in "Discourse on the Method" that animals are merely automata going through the motions of pain, without really experiencing it. ${ }^{6}$

Descartes's disavowal of animals' ability to experience pain creates a convenient means by which to excuse the abuse of animals in the context of labour. However, if animals can suffer, as Bentham argues, that suffering is morally relevant. As Sarah Wintle notes, Descartes's writings and the subsequent refutations of his postulations "prompted speculation about the nature of animals and how far they could be said to 
share or not share certain characteristics with humans" (5). Indeed, amateur naturalists began to create species categories established on how much the animal in question shared with the human. In other words, "nearness to man" became the basis of an animal hierarchy (Wintle 8). More often than not, in this hierarchy, horses were put on top because of their ubiquity, their centrality to travel, communication and commerce, and their physical proximity to human handlers and riders.

Animal rights activists of the time found that emphasizing the proximity of humans' and equines' lives proved especially effective for developing a culture of animal sympathy. Within literature, the animal's-eye view compels the reader into a close emotional bond with the animal as it relates the story of its difficult life. In light of this strategic development of emotional bonds between reader and animal character, Fabulous Histories, for example, reveals a more overtly compassionate purpose for giving animals speech than that of simply performing human virtue. In one scene, Mrs. Benson conjectures to a local farmer's wife that, prior to killing any animal, we should endeavour to change places with it, to imagine how the animal feels. The farmer's wife replies, "Indeed, madam... I have often wished that poor dumb creatures had somebody to speak for them; many an innocent life would then be saved which is now destroyed to no end" (117). By the time Trimmer was writing, the Cartesian assertion that animals cannot speak had become engrained as a cultural maxim, but this very inadequacy on the part of nonhuman species helped foster the powerful idea of animal advocacy. Animals' inability to speak back demanded that humans, as Trimmer suggests, take on the task on the other species' behalf, an ethical position aided by a literary form in which the reader 
is implicitly asked to trade places with the animal. This motivation for advocacy became instrumental during the nineteenth century, with the middle-class children educated by animal autobiographies becoming the adults behind the animal rights movement.

The middle class perceived both the upper and lower classes as particularly cruel to animals. Where upper-class recreation involved the organized ritual of fox hunting, the lower classes engaged in bull or bear-baiting, in which the larger animal was set upon by dogs trained to fight to the death. Spectators would place bets on whether or not the canines would succeed in killing the other species. This grisly spectacle was a popular recreational activity for the working class, and the earliest arguments against it were closely connected with social control of the poor, in terms of regulating work hours and restraining public drunkenness (Bailey 31). British Parliamentary debates of the late 1700s also questioned whether it was even possible to change such behaviour. It became the responsibility of the government to educate the lower classes and convert them into "rational" beings (31). The conclusion that the lower classes needed to be made rational implicitly allies them with the animals being protected, allowing the middle class to transpose the poorer members of society into a veritable subspecies. The only distinct difference between species being suggested here is an inherent humanity that supersedes any animality; there is an expectation that the lower classes can be tutored into being more rational - that is, more human.

On 2 April 1800, Sir William Pulteney, a Scottish lawyer and Member of Parliament, proposed the first legislation to outlaw bull-baiting. The intention behind the legislation was not a concern for animal welfare, but a sense of a need to eradicate public 
drunkenness and ensure labour productivity in the working classes. As Hilda Kean points out, however, participation in animal-fighting events cut across social strata, uniting the aristocracy with the lower classes in enjoying the spectacle or in owning and maintaining fighting animals. Many MPs that opposed Pulteney's legislation, moreover, were among those practising such "entertainment" (32); they had a vested financial interest in the continued legality of the sport. The bill was ultimately defeated.

Animal advocates needed to develop a new framework in which to generate support for their anti-cruelty cause. In 1809, Sir Thomas Erskine, a barrister, anti-slavery advocate, and former Lord Chancellor, proposed an anti-cruelty bill that focused on "routine cruelty" such as working horses to exhaustion or beating cattle as they are lead to market. This bill was also defeated, but the focus on visible and everyday abuse set the stage for further Parliamentary and public debates around cruelty to animals and animal rights, framed in both Rousseau and Bentham's language of shared suffering. In 1822, another Member of Parliament, Richard Martin, proposed the CruelTreatment of Cattle Bill, or "Martin's Act." This made it a punishable offence to wantonly and cruelly beat, abuse, or ill-treat any Horse, Mare, Gelding, Mule, Ass, Ox, Cow, Heifer, Steer, Sheep, or other Cattle, and Complaint on Oath thereof be made to any Justice of the Peace or other Magistrate within whose Jurisdiction such Offence shall be committed, it shall be lawful for such Justice of the Peace or other Magistrate to issue his Summons or Warrant, at his Discretion, to bring the party or parties so complained of before him. (n.p.) 
Offenders charged, tried and convicted under this new Act were subject to fines "not exceeding Five Pounds, not less than Ten Shillings to His Majesty, His Heirs and Successors" (n.p.). If they were not able to pay, or if the abuse was severe enough, the offender was to be "committed to the House of Correction or some other Prison within the Jurisdiction within which the Offence shall have been committed, there to be kept without Bail or Main prize for any Time not exceeding Three Months" (n.p.). The implementation of Martin's Act was a major achievement for animal rights advocates. It was, however, difficult to enforce because it relied mainly on animal abuse either being observed by law enforcement or being reported by members of the populace, many of whom were at best uninterested in reporting the abuse of livestock, or worse, abusers themselves.

To ensure that Martin's Act would be properly enforced, the Society for the Prevention of Cruelty to Animals (SPCA) was created. The SPCA attracted respectable citizens working on a number of other humanitarian causes - an urban, middle-class body defining itself against both the working class and the upper class, tormenting animals for sport. According to Kean, this entry of animal welfare into larger political debates, and the creation of societies dedicated to animal rights and protection, abetted the formation of political and moral perspectives that had not held strong currency in the past:

Changes in the law were invoked not just to defend property nor to regulate the behaviour of the rabble and seditious agitators; they also had the effect of giving protection to those unable to speak for themselves. The role of advocate and 
protector was being established to invoke the cause of those literally without human speech, dumb animals. (31)

It was now legally recognized that, while animals cannot make themselves understood in human words, they are still fully conscious beings, and thus humane treatment becomes a moral imperative. In fiction, an animal's ability to speak did not necessarily signify the view that it had a human mind; rather giving animals human speech simply allowed the reader access to a mind that British law now declared had rights to legal protection and, therefore, ethical value.

Children's literature proved a major vehicle for the naturalization of these legally acknowledged trans-species responsibilities. Among the many animal autobiographies of this period of animal rights development in England, Memoirs of Dick, the Little Pony (1799) and Black Beauty (1877) offer particularly astute conceptions of the ambiguities and difficulties surrounding eighteenth and nineteenth-century efforts to conceptualize the justification for non-human rights. Moreover, because they both do so through the equine body, these works bring attention to the nuanced divisions Western society placed among diverse species and their use-value to humans. As I will demonstrate, the creative leap to an animal's-eye view is key to understanding the way in which the rhetoric around not only class, but also race, sexuality and gender was played out in part against the backdrop of the anti-cruelty movement. 


\section{The Contrary Nature of Dick the Little Pony}

On the surface, Memoirs of Dick, the Little Pony appears to be a straightforward story about the life of a simple country pony intended to engender sympathy for the lot of a beast of burden. Dick grows up on Hounslow Heath, happy and carefree, until he is stolen by gypsies and introduced to the wider human world. Only at the end of the story, in his retirement years, does he return to an idyllic, pastoral setting - his forbearance with the vagaries of human cruelty finally rewarded. This prototypical animal autobiography is ostensibly intended to instill prudence, temperance and kindness towards animals in its child audience. But such a reading fails to make any account of Dick's inherent and often overt misanthropy.

The pony's sullen attitude and other unlikable qualities undermine the assumption that animals, and horses in particular, are designed for and content in human servitude. Dick's anger over his mutilations, as Samuel Pickering notes, stems more from a "sense of resentment than out of a desire to help children form habits of benevolence" (33). The animal's resentment distinguishes him from other fictional creatures such as Trimmer's robins, which are often depicted as inherently content with their lot. Dick rarely accepts his role as a servant to human whim, and only describes himself as truly happy when he is left in a field to his own devices. Dick struggles to achieve the kind of virtue and contentment of Trimmer's robins, and prides himself on a successful performance of virtue rather than actually being virtuous. When reflecting on the "eminence" to which he has risen, Dick finds it evident that "it was by merit alone: if I was esteemed, it was because I was useful" (34). In proposing his self-made status, 
Dick conveniently ignores the "noble" pedigree of which he had earlier spoken proudly; his sire "was of Cambrian origin, and tasted the sweets of liberty and independence on the lofty mountains of that romantic country" (2-3). His dam is beautiful and highspirited; she too is free-born and captured by a drover, "forced from her native haunts" (3). At one point in the capture, Dick tells us, his mother attempted escape and almost drowned before being saved by the drover. It is her beauty and nobility that make her worthy of saving. While Dick's pure blood and lineage suggest the creature's inherent equine nobility, they also function to explain the difficulties his human handlers encounter when training him. The resentment that Dick cultivates over the course of the text stems from his confusion over why he, being of such noble and spirited origins, should be so mistreated - gelded, tail docked, and forced to bear a rider. In his view, he has unquestionable rights to the freedom to live on the heath without any human contact.

His very first encounter with people establishes this lack of understanding. When a man robs a horse-drawn carriage but is caught after tripping over the sleeping Dick and his mother, the thief's pursuers fête the two horses with "thanks and praise" (9). While the humans compliment the horses for their service to the judiciary logic of their society, the horses remain utterly unclear of why their coincidental presence is complimented. The misunderstanding is exacerbated by Dick's sense of foreboding upon recognizing the horses pulling the carriage as members of his own species who have docilely acquiesced to their roles as laboring servants to humans. For Dick, passive obedience is simply not part of what it means to be a horse. 
The hero of the text actually perceives himself to be of the most docile nature, and this despite the fact that he consistently acts according to "the dictates of passion" (48). Dick's first master, a young boy, cruelly whips and spurs him to get him to behave. Though the pony has been trained by the gypsies to bear a rider, he has not been trained to understand specific commands, and he struggles under the lash to obey. Notably Dick defines his main impetus as pain, rather than any "desire to please" (45). Any pretense at pleasing his owner is forgotten when, startled by a passing carriage, he seizes the chance to throw off his rider and flee, "animated by resentment $[\ldots]$ and proudly triumphed in [his] liberty" (48). Dick's freedom is short-lived and the pain he experiences upon his subsequent training by the horse-breaker, Tom, leads him to reflect that he is "yet ignorant of the superiority of man, and the necessity of implicit submission to his will. The provocation I had received might have justified revenge, but it was certainly very impolitic to exercise it" (48). In this passage, the animal's-eye view allows the young reader - whom one imagines to be roughly the same age as Dick's cruel owner - to recognize that, rather than the cross-species affections assumed by so many equines' owners - the pony himself adopts his servitude solely to avoid the abuses sanctioned within human society as acceptable practices of training (46). The blur between animal training and animal abuse explored in this children's text echoes the language Bentham uses in his critique of slavery. The "evil inherent in the nature of slavery," Bentham writes, is situated in the "impossibility of subjecting the authority of the master over his slaves to legal restraint, and of preventing the abuse of his power, if he be disposed to abuse it" (344). For Bentham, not only does the structure of slavery fail to place any 
limitations on the abuses of the slave-owner, but the very nature of ownership itself exacerbates the abuse of power. In the children's story similarly, Tom would rather have Dick's complicity in the training process, but the horse-breaker readily demonstrates that he is able and willing to use both whip and spur if needed. As Dick astutely observes, the human "proceeds by gradual steps to show the malice of his power; first claims voluntary service, and afterwards demands it like a tyrant, frequently beyond strength, and generally beyond inclination" (62-63). What the equine has learnt then is not his due position in some ahistorical species hierarchy, but the duplicity of humans and the fact that their kindness is extended only as a means to gain or enhance another animal's usevalue. In Dick's case, his value is solely rooted in physical power, a mechanical benefit void of any consideration of pain or even sentience. By this logic, power over a living creature (human or otherwise) is tantamount to abuse of that creature. Animals and slaves were likened to one another in order for slave owners to justify the ownership and abuse of a human being. Thus, working to undermine the perceived superiority of the master over the slave becomes the cornerstone of both anti-slavery campaigns and the animal rights movement.

Members of the middle class constituted the majority of people engaged in the early animal-rights movement. The cause allowed them to highlight their restraint and virtue in comparison to the disregard of the upper and lower classes. While in Fabulous Histories, Trimmer foregrounds this bourgeois bias, the author of Dick the Little Pony leaves no particular class immune from Dick's criticism. Indeed, it is the lower-class farmer to which the hero shows greatest empathy, Dick describes the man as "a greater 
beast" than the pony himself (83) because he is a drunkard, but he does not loathe him, and the man does not beat the horse, only selling him because of a need for money. Though his own noble birth could predispose him to sympathy with the upper and middle classes, Dick actually suffers the most egregious abuse at their hands. Dick is subsequently abused by three youths - the sons of two country squires and a "young lady" of the nearby town. Thus in Dick the Little Pony, the main target of critique appears to be the middle and upper classes, but the key models of cruelty are children - a plot pattern that encourages the text's young readers to recognize that they should not blindly follow the guidance and examples of their adult educators.

The problems with adult relations to animals are apparent in the fact that the town itself serves as a concentration of the most corrupting influences of humanity. Dick spends an extensive period of time puzzling out the odd behaviours of its inhabitants (110-22). While Dick's mistress proves particularly destructive in her gossiping, the pony recognizes her as acting within the allowable strictures of the townsfolk. The pony recounts his surprise in seeing people

pass each other with an air of indifference, or ill-nature, without ever opening their lips, or moving the head. I have heard also, that the inhabitants of a fine house will not enter a mean one, and that it is a degradation to some to shew the attentions of civility to others beneath them, not in size or make, but in dress and purse, the grand distinction between man and man, and the riddle of all riddles, which those who are endowed with reason alone can explain. (116-17) 
The urban space provides a window through which Dick can discreetly observe humans' treatment of each other. The evidence only serves to heighten his contempt for and resentment of humanity, while reinforcing his view that equines ought not to be subject to their will. Notions of the "naturalness" of equine service are once again undermined.

Through such scenes as this, Dick repeatedly advocates sincere kindness to animals based on mutual respect between species. In the process, he implicitly raises the idea of animal equality and consent, while contesting the notion of natural service to humans. Donna Haraway proposes a model of human-animal relations that does not depend on the assumed superiority of the human and the forced subordination of the animal. She envisions a "companion species" model defined by human-animal interaction characterized by a sense of equality and interdependence (When Species Meet 16). The model works to undermine traditional Western notions of human exceptionalism, which views humanity as separate from the "spatial and temporal web of interspecies dependencies" (11). The author of Dick, the Little Pony explores just such a relation, drawing young readers into the relationship not only through the animal's-eye view and the youthfulness of Dick himself, but also through the sympathy demanded by the human in question being a consumptive young girl, Eliza. It is in his relationship with the gentleman's daughter that Dick, for the first time, is recognized not as livestock, but as a companion. He is allowed to exist not as an object of production but as a sentient being whose most valued quality is his emotional reciprocity. He is appreciated by both Eliza and her father for his ability to provide affection and to help ease her suffering. Dick's resentful attitude melts away in response to Eliza's kindness, which is 
freely given, rather than used to deceive Dick into providing more service. Fulfilling the function of a pet, Dick's service is now based on emotion rather than physical labour. However, as Dick insightfully confirms, he is still valued for service, observing that his gentle and kind mistress makes him feel more akin to "a servant, and not a slave" (95). But even the notion of servitude is more harsh than the pony's own valuation of the relationship suggests; it is more accurate to describe Dick and his mistress as bound together in what Haraway calls "significant otherness" (97), a relationship predicated on Dick's voluntary provision of companionship to Eliza. His willingness is key when differentiating "servant" from "slave." Such a relationship can only exist in a climate of consent, here predicated on affection. When Eliza dies, Dick's sorrow matches that of her human family members. He recalls that he had never been witness to such a melancholy scene as this. The father stood in mute agony; his sorrows were too big for utterance: the mother raved in distraction [....] This was the first time I had seen the debt of nature exacted from any of her children; and never could it be paid by one who had less reason to dread settling the account. $(96-97)$

The death of Eliza temporarily reverses the role of animal as pained victim, positioning Dick instead as witnessing subject. The inversion is enhanced by the fact that, while Dick articulates the death and its emotional impact, the humans lose their ability to communicate - one raving and the other unable to make an utterance.

This subjectivity is revisited in Dick's next encounter with a suffering child, as companion to a clergyman's consumptive son. The relationship between the pony and 
the boy echoes Dick's experience with Eliza, reinforcing the power of a companion bond based on affection and respect. Far from embittering Dick, Eliza's death had only enhanced the depth of his affection. While this second incidence of child suffering and death might seem redundant in the narrative, it serves to underscore the importance of Dick's choice in bestowing his affection a second time. It is immaterial whether a relationship based on a companion species model is permanent with any one human individual; it is the respect and consent that matters, as signalled by Dick's consenting a second time to enter into the role of significant otherness. Having gone through the death of one beloved companion, Dick is even more distressed when this second young consumptive passes away. "Could my life have ransomed that of this amiable boy," he laments, "gladly would I have sacrificed it for his sake" (168). In recognition of the pony's complete devotion to and love for the boy, the clergyman makes a gift of Dick to an especially virtuous country family. Dick helps their children and grandchildren learn to ride until, at age 18 , he is given "blissful emancipation" (178) and turned out into a meadow in the company of other good horses.

Dick's positive life experiences in fact result from his eventual docility, a docility arising from being treated with respect and affection. It is only when the pony gives up his rebellious spirit, that his life sustains a seemingly fulfilling trajectory. The image, however, is not utterly positive. Dick is bound to relations with these particular children, being given no choice of companion (an issue Haraway also fails to address). Moreover, his transferences from Eliza to the clergyman's boy and then to the final family are all acts of exchange that still define the sentient being as an object. Notably Martin's Act 
retained the notion of domestic animals as objects as well - a conception that has remained basically unaltered within legal discourse to the present day. ${ }^{7}$ While Dick enjoys his time with the country family, it nevertheless marks a state of enslavement characterized by forced labour. ${ }^{8}$

Dick's misanthropy distinguishes him from more common depictions such as Trimmer's of animals as inherently and happily subservient to human authority. The hero of Dick, The Little Pony eventually realizes that the vast majority of humans will simply refuse to recognize his overt demonstrations of contempt and resentment for what they are, preferring to perceive them as signals of stupidity and incompetence. To avoid physical punishment, the equine begins to conduct himself accordingly, at least most of the time. The docility, however, is a performance, with Dick simply suppressing his original nature and his opinions regarding his treatment. Having been given the fictional contrivance of human speech, the animal communicates directly with his young readers. The medium functions in part to teach children to treat animals with respect and kindness, but it also collapses the division between the young pony and the young readers, who both recognize the hypocrisy of adults, as well as their own position of subordination. The text thus serves to circumvent the conventional didactic function that the middle class had bestowed upon children's literature, just as Dick's misanthropy repeatedly challenges anthropocentric assumptions regarding the authority of any one species over another, a critique that implicitly extends to the essentialist hierarchies of class and race. 


\section{The Multiple Rhetorical Burdens of Black Beauty}

Black Beauty, perhaps the most famous animal autobiography, maintains an especially overt animal rights agenda. Building on the criticisms of anthropocentric assumptions in earlier texts such as Dick the Little Pony, Sewell actively campaigned to improve animal working conditions. The author, however, accomplished much more than this; Beauty's burdens problematize not only the animal-human divide, but also segregations of race and gender, with the novel ultimately offering a much more complicated and politically invested technology of oppression than, for example, Trimmer's portrayal of some birds as analogous to the working poor.

Judith Halberstam's notion of the architecture of monstrosity is particularly useful for analyzing Sewell's complex portrayal of the rhetorical relations among slaves, women and the equine, especially in literature intended primarily for a female child audience. ${ }^{9}$ In Skin Shows, Halberstam outlines how certain bodies are rendered monstrous, a process she calls the "technology of monstrosity" (6). Nineteenth-century gothic fiction, she argues, "made use of the body of the monster to produce race, class, gender and sexuality within narratives about the relation between subjectivities and certain bodies" (6). For example, the technology of Bram Stoker's novel Dracula (1897), "gothicizes certain bodies by making monstrosity an essential component of a race, a class, a gender or some hybrid of all of these" (105). The technology by which the Other is made monstrous includes the animalization of some humans. Dracula himself changes into a canine and demonstrates a frighteningly close kinship to wolves, 
bats, spiders and other species. But, as Anna Sewell's Black Beauty demonstrates, the adaptation of animality as part of a technology of monstrosity is not exclusively a gothic trope.

In Black Beauty, Sewell formulates what I call a technology of animality that foregrounds the imbricated relations of the identity categories of slaves, women and the equine. With regard to the human-animal divide, this technology can work in both directions. On the one hand, notions of race, class, gender and sexuality can function together to marginalize certain minority groups as animalistic, atavistic and subhuman. On the other, the representation of animals as inherently subordinate to humans buttresses the cultural marginalization of people characterized by nonhegemonic identity traits. This conflation of human inferiority and animality is key to the rendering of some human bodies as more animalistic than others.

Pointing out the significant similarities between Black Beauty and Uncle Tom's Cabin (1852), Robert Dingley notes that the rhetorical relationship between animal and slave has long been established, addressing the same ideological fissure between servant and slave explored in Dick the Little Pony. ${ }^{10}$ He likens Beauty to a perfect Victorian servant, "incapable of impertinence and even, by implication, safely emasculated" (241). As Dingley reminds us, however, the horse is not actually a servant because a servant by definition - must be able to negotiate the terms of that service, which is performed under the aegis of ownership. Instead, Beauty is "living merchandise" with the perceived capacity for limitless physical labour (242). To take the comparison to its logical conclusion, Beauty is in fact positioned by Sewell as analogous to a slave, with her novel 
bearing "more than a coincidental resemblance to the most celebrated of all narratives of human slavery, Harriet Beecher Stowe's Uncle Tom's Cabin" (242). Peter Stoneley likewise acknowledges Sewell's debt to the earlier text, noting that her novel was often subtitled "The Uncle Tom's Cabin of the horse" (65).

While there are strong parallels between Tom and Beauty (such as their idyllic agrarian origins, docile natures and inherent nobility), Dingley suggests that Sewell has presented an irresolvable comparison. If "the plight of horses under human domination is analogous to that of black slaves under white masters," he argues,

then, by extension, it is as wrong to deprive horses of liberty as it is to deny freedom to slaves. And indeed, for all the complacent assumption that horses are natural servants, Sewell's text is intermittently troubled by the unnaturalness of their servitude. (244, emphasis in original)

Dingley's parallel goes too far here, pushing for a full analogy that, in reconstituting the horses as part of a purely human history, can be said to work against the freedom of other species from human perspective. Since there is no reason why a Victorian author would feel compelled to avoid explicit discussion of slavery in her novel, it is unlikely Sewell is calling attention to the plight of slaves by coding the ethics of slavery into a novel about horses. Rather, the strong parallels and echoes that Dingely and Stonely both affirm suggest that Sewell is borrowing from Stowe's well-known novel to call attention to the plight of horses, as well as to emphasize the logical extension of the repeal of human slavery to the repeal of animal slavery. 
The pragmatism of Sewell's agenda is apparent from the fact that the subject of Black Beauty is not animal liberation but one piece of that venture, the abolition of the bearing-rein. A short strap connecting the bit to a ring on the back harness, the bearingrein was used to force a rigidly erect posture from the horse and with no other purpose aside from presenting the spectacle of a spirited horse under tight human control. Using the bearing-rein meant that "going uphill, the horse was unable to lower its head for greater purchase; going downhill, it suffered restricted vision and had difficulty in recovering from a false step" (Turner 156). Sewell questions the fairness of equine service (which is also foregrounded in Dick the Little Pony), but her implicit acknowledgement that English society is dependent on horses presents a quandary that she cannot easily resolve. Sewell's retreat from a full acknowledgement of the unnaturalness of equine service opens up another means by which the horse's body is used as a mechanism for exploring power imbalances in gender relations.

Gender is a key aspect of the technology of animality played out in Victorian fiction about equines. ${ }^{11}$ Positioning equine texts as a specifically female genre, Coral Lansbury notes that Black Beauty has, since its publication, been a "woman's book" with a particularly strong effect on adolescent girls (97). This gendered audience has arisen in part from the empathy women have been encouraged to feel toward the abused and needy. More than this, however, the text also creates a sympathetic image of womanly equines such as the chestnut mare Ginger, which gives Black Beauty much of its meaning for female readers. Lansbury relates further that she herself would repeatedly "turn to the passage where Ginger, proud, high-spirited Ginger, is dragged past in a cart" 
(97). As in Dick, the Little Pony, Ginger's proud nature and initial unwillingness to allow human domination can, as Lansbury posits, be read as a cautionary tale intended to reinforce the status quo of female submission. It is my contention, however, that the death of the female horse has a more nuanced and politicized function involving the exposure of a technology of animality that oppressed both women and animals.

Ginger instinctively knows that a better relationship can be forged between human and animal if there is kindness and respect involved. Like Dick, she rebels when she can, even though it invites further abuse. The heroine recounts an especially hostile engagement she has with her horse-breaker, during which she felt her "whole spirit set against him, and [she] began to kick, and plunge, and rear as [she] had never done before; we had a regular fight" (34-35). Afterwards, her owner comes and chastises the horse-breaker, tending to Ginger's bruises and wounds with his own hands, aware that respect functions only as an exchanged emotion. She tells Beauty that she "never had anyone that was kind to [her], or that [she] cared to please" (32), and knows the difference between that sort of kindness and merely being fed and sheltered. Ginger's story makes it clear that approaching horses with respect and kindness honours a bond of mutual dependence, as horses still played a pivotal part in providing labour and transport in Victorian England.

Ginger eventually dies after having toiled endlessly and without any kind treatment. That is the tragedy - that all of her owners extracted her labour by force, rather than attempting to work with her. Sewell implicitly suggests that there is a loss involved whenever the human part of the equation lacks respect, and even affection for 
his or her equine charge. ${ }^{12}$ Though it is Beauty's story, and he ultimately triumphs because of his saintly patience and virtue, Ginger's death is an injustice and an affront to all she has endured. Addressing the wrongs done to her in a context of female kinship in suffering drives a subtler form of animal rights reform, which acknowledges the interdependence of human and equine.

In Black Beauty, the equine body functions as a mechanism bearing multiple rhetorical burdens. The novel transposes not only issues of animal abuse, but also those of slavery and the oppression of women onto horses as a means of demonstrating the architecture of subordination that sustains a false hierarchy of privilege reinforcing the productivist ethos of the era. Moving beyond the dichotomous model of Dick the Little Pony, Black Beauty portrays a technology of animality aimed not only at bringing an end to the use of the bearing rein, but also to question the suppression of blacks, women and domestic animals. The cultural practice of symbolically conflating notions of human inferiority with animality suggests that some humans are more animalistic than others, and thus inferior. By this token, the reconceptualization of nonhuman species as worthy of respect and protection also has the potential of enhancing the rights of oppressed human subjects such as women and blacks.

If, as Haraway suggests, relationships with animals should be predicated on mutual respect, then there is as much a duty for the middle class to improve the lot of animals as there is to improve the lot of subordinated humans. As with animal rights legislation, however, much of Victorian children's literature - such as the equine texts I 
have discussed in this chapter - focus on evoking empathy for those species that had been trained to contribute to the economic production and imperialist ventures of the period. Notably less sympathy or respect was extended to animals of the wild. In my next chapter, I turn my attention to these creatures, with particular consideration of Jack London's unique efforts not to create animals with human minds and perception, but to enter into the subjectivity of the wild. 


\section{Chapter Two:}

\section{Human Values and the Wild Animal Body in Jack London's Canine Canon}

Becomings-animal are neither dreams nor phantasies. They are perfectly real. (238)

Gilles Deleuze and Félix Guattari, A Thousand Plateaus

Michael Lundblad has recently called for an "animality studies" reading of Jack London's Call of the Wild (1903), contending that this approach to the text would reveal "a more complex, unsettled and inconsistent engagement with the question of the animal and constructions of the human than we might otherwise assume" (498). Echoing the politics of stereotype endured by Black Beauty, the sled dog Buck in London's novel is burdened with not only western civilization's assumptions about his species, but also our assumptions about wolves as the embodiment of both wildness and wilderness. While Lundblad's examination focuses on the relationship of animality and sexuality in particular, it nevertheless correctly identifies a general oversight in critical analyses of London's canine canon. These works include The Call of the Wild, "Bâtard" (1904), White Fang (1905), and his often-overlooked nonfiction ode to sled dogs, "Husky - The Wolf Dog of the North" (1900).

One example of the type of scholarship that Lundblad challenges can be found in the work of scholar Jacqueline Tavernier-Courbin, who easily slots Buck into the role of a mythic hero or a representative of the Jungian collective unconscious. TavernierCourbin gives no consideration of the fact that Buck is also an animal, presenting the 
dog as thoroughly interchangeable with a human hero. There is therefore no need, in Tavernier-Courbin's view, to discuss why London casts a dog as the lead character of this "naturalistic romance" (Tavernier-Courbin 96). Earl Labor, in his analysis of London's dog stories, similarly focuses on the animal as representative of nothing but the human. Labor contends that London writes about dogs in order to provoke an interest "in the human situation, not the plight of the lower creatures" (115). According to Labor, Buck's animal body is reduced to a plot device for London to work through his contradictory espousal of both socialism and social Darwinism. A respect for London's canines as canines, however, brings forward a key conceptual shift in London's study not only of interspecies relations but the very humanist perspective that has placed blinders on scholars such as Tavernier-Courbin and Labor. As Donna Haraway argues, in accord with Lundblad, scholarship that ignores examining the animal for its own sake is marked by an overarching "scorn for all that is mundane and ordinary and the profound absence of curiosity about or respect for and with actual animals" (When Species Meet 27). Through an adaptation of Haraway's position, I wish to demonstrate that it is possible to acknowledge London's human-based social-justice interests while also examining his interest in the materiality of the animal body.

As I discussed in my previous chapter, the anthropomorphized animal body as a stand-in for the human had become a familiar, even expected trope. The domestic animal's body, for example, has often been used to signify human values; one recognizes, to cite two examples, the nobility of horses or the pacificity of cows and sheep. By the time London was writing his stories for children and young adults at the 
end of the nineteenth century, this adaptation of the animal body had become common in such works. This unquestioned and common appropriation of the animal body as a metaphor for the human makes it all the more important that the implications of such attributions for species' relations be acknowledged and more fully explored.

In this chapter I wish to build on my earlier discussion, in Chapter One, of the cultural conception of the domestic animal as a means by which the young were inducted into a culture of labour and suffering. In my consideration of London's work, I wish to focus on notions of wildness, with particular sensitivity to the politics behind the conceptual blur between the wild and the domestic as guises for the savage and the civilized. Through a posthumanist reading of the representation of wolves in The Call of the Wild and White Fang, I aim to demonstrate London's effective problematization of Western assumptions regarding human/animal, and civilized/wild distinctions. Of particular importance is London's vision of cross-species relations. It is my contention that the conformist politics underlying the apparent celebration of individuality and freedom in his representations of domestic and wild canines is undermined when he himself confronts it with the question of the animal.

\section{The Historical Rhetoric of Wolves as Evil}

The history of the wolf is also the history of its persecution. Once native to Britain, by the sixteenth century the wolf had been hunted to extinction. In Blood Sport: Hunting in Britain Since 1066, Emma Griffin attributes the species' demise to overzealous hunting, although she does not explain the cause of this zealotry. The expansion of the 
human population after the Norman Conquest of 1066 made it no longer practical economically for King William II and other noble landholders to maintain huge tracts of woodland. By 1078, the reduction of forests also fostered the loss of habitat for both deer and wolves, resulting in human hunters and wolves competing for the same prey. Already fearsomely depicted in the Old Norse mythology carried over from the Viking invasions of Normandy in the 700s, wolves were easily demonized. ${ }^{13}$

With this development, wolves were increasingly depicted, in European folklore, as monstrous devourers of innocents. Interpretations of a tale such as Little Red Riding Hood, for example, can benefit from an awareness of the medieval reality of living near forested areas, and actually encountering wolves. An early version of the story is included in Noel de Fail's Propos Rustiques (1547), a collection of oral tales told by peasants, in which he notes that the narrative had already been in circulation for hundreds of years (Darnton 17). ${ }^{14}$ In this cautionary tale aimed at instilling suspicion toward strangers, the wolf - increasingly involved in the lives of humans as the latter encroach on their territory - becomes the signifier of the foreign or unknown invader. As Claude Lévi-Strauss has observed, "animals are good to think" with (83); that is, they are considered, for whatever reason, uniquely suited to bear a particular kind of symbolism. Already burdened by uncomplimentary Norse imagery, the Big Bad Wolf was envisioned as outside of civilization, while its perceived ravenous appetite dictated that it could not be rehabilitated or tamed. Confined to untamed spaces, the wolf became the reified target of the anxieties arising not only from wilderness itself, but also from a full range of threats to human livelihood. In medieval England, "no other monster so 
embodied destruction" as the wolf (Crossley-Holland 193), a view that eventually lead in Britain to the eradication of the species. ${ }^{15}$

By the 1750s, hunters found themselves lacking challenging prey. To remedy this situation, they turned their eye on foxes. Country squire Hugo Meynell began breeding hounds for stamina and a keen nose for scent, capable of keeping up with foxes fleeing for their lives (Griffin 125). With his new canine creation, Meynell ensured that the fox provided as lively a chase as the red deer, and as much intellectual challenge as the wolf. Because the hunter was conceived as being only as noble as its quarry (Marvin 143), foxhunters rebranded their prey and the lowly fox - previously envisioned as no more than a thief of eggs and raider of refuse - was raised above its previous image as vermin. Beginning in the eighteenth century, the dearth of wolves in Britain led the landed gentry to construct the species of the fox as a glorified combatant in the sports arena. London's own analysis of the wolf, over a century later, is rooted in this peculiar cultural migration of human symbolism from one canine species to the other.

In North America, where London sets his own narratives, this image of the wolf as a dangerously sly embodiment of the wild met with a distinctly different anthropomorphism. North American aboriginal myth portrayed the wolf as a trickster but also a help to humankind. In many aboriginal tales involving wolves, the resolution to the trick often results in a positive learning experience for the human. Indeed, wolves and wolf-figures often played a significant role in the creation of the world. ${ }^{16}$ European writers' accounts of aboriginal myth and legend, however, were often coloured by their own conceptions of the wolf as a ravenous beast. John James Audubon describes a 
"universal feeling of hostility among men against the Wolf, whose strength, agility and cunning $[\ldots]$ render him an object of hatred" (497). As such, the wolf as teaching figure or trickster was simplified through a good-versus-evil paradigm that celebrated human victory as only possible at the expense of wolves (Robisch 169). North American settlers saw the wolf as an impediment to expansion and, while the Plains tribes had never complained of encroachment by wolves, white settlers defined the wolves as hostile and adversarial, characteristics that were also readily extended to the First Nations tribes inhabiting those same lands. The mass hunting and killing of aboriginal peoples in North America was justified in part by the established European conception of wolves as dangerous adversaries, as well as by the newer rhetoric of personal freedom integral to the founding of the United States of America (Lund 21).

\section{Imperialism and Animals - The Boys' Adventure Story}

Inspired by "manifest destiny," the belief that the westward expansion of the United States was both inevitable and divinely sanctioned, early-American writers also sought to break with European literary traditions and conquer new artistic territories. They borrowed from the Romantic view of nature as an embodiment of divinity and the sublime, but the harsh landscape and climate of the frontier also invited a discourse of domination and taming of the wilderness. For American writers and thinkers, Ralph Waldo Emerson best encapsulated this new transcendental wilderness spirituality. In Nature (1836), Emerson emphasizes not only the mind-altering potential of nature, but also its demand that it be approached in solitude and supplication. Only the individual 
with a clear and willing mind, he proposes, can grasp the mysteries of the natural world. The aim of his philosophic writings, he states, is to position a "connexion with nature" (73) as the means by which to transcend the banality of everyday concerns and distractions. In this, Emerson is aligned with Rousseau's celebration of the innate goodness of the pre-civilized human, contending that science and culture interfere in this perfect communion. ${ }^{17}$

The Victorian fascination with nature, linked to Emersonian Transcendentalism, was carried over from Romanticism. But the nineteenth-century advances in global exploration and scientific discovery lead both Romantic and Transcendental conceptions of nature to face new visions of nature itself. As Suzanne Rahn observes, this new intense interest in the natural world was characterized by a strong desire to control it (154). Jeffrey Richards likewise contends that imperialism was the dominant ideology from the mid-nineteenth to the mid-twentieth century and that, "linked to this was a definition of masculinity, which combined sportsmanship, chivalry and patriotism" (2). This imperialist rhetoric of conquest and ownership subsequently inspired a genre of children's literature devoted to furthering the goals of the empire in works privileging the "primacy of action" (3) over sentiment and feeling - the boys' adventure story. Texts such as Jules Verne's 20, 000 Leagues Under the Sea (1869), Robert Louis Stevenson's Treasure Island (1883) and Mark Twain's Huckleberry Finn (1885) were exemplary of this emergent genre.

By the late nineteenth century, a new form of juvenile literature arose that reflected the imperialist agenda of Britain, the United States and other nations - stories 
and novels that - within the conventions of the romance - idealized boys and male adolescents as adventurers and tamers of foreign, uncivilized territory. ${ }^{18}$ Part of this development in popular fiction saw boy culture appropriating travel and nature writing that had previously been intended for a general but still largely adult audience. Imperialist rhetoric transmuted the Romantic view from an Emersonian "connexion" (73) to a conception of the world "in which discovering, or seeing, the world is equivalent to controlling, or subduing it" (Rose 58). This subjugation of the natural world in adventure, shipwreck and hunting stories was highly popular with the young male audience. A boom in publications of adventure literature for boys generated multitudes of inexpensive, cheaply produced magazines such as Boy's Own (1879-1967) and Chums (1892-1941) in England, and Young Men's Magazine (1858) in America. These periodicals were considered appropriate reading because, it was felt, they would assist youths in developing into adults who would sustain the imperialist dream.

Though imperialist discourse is more popularly ascribed to Britain, the United States was not without its own vision of world domination. In 1892, Frederick Jackson Turner put forward his "Frontier Thesis." Turner's most notable contribution to American expansionism was to theorize and give historical weight to what could otherwise have been a haphazard progression of the population westward, organizing it into something more purposeful and meaningful in the nation's history. As Jacqueline Rose observes, in this way "history could be read directly off the land" (55); from geography comes the nation's history, at "the meeting point of savagery and civilization" (Turner n. p.). The Canadian author Ernest Thompson Seton problematized but ultimately 
upheld this line between the savage and the civilized in his popular Wild Animals I Have Known (1898). Seton purports that his stories were accounts of real-world animals, faithfully recorded for posterity, though perhaps not accurate in their finer historical detail. His hope, he declares, is that "some will herein find emphasized a moral as old as Scripture - we and the beasts are kin. Man has nothing that the animals have not at least a vestige of, the animals have nothing that man does not in some degree share" (n. p.). ${ }^{19}$ Seton's objective is to undermine conceptions of humans as distinct from and superior to animals.

In one of his more famous stories, "Lobo, King of Currumpaw," Seton recounts a battle with his nemesis, the wolf Lobo. The canine is guilty of having, for many years, preyed on cattle and more generally terrorized northwestern New Mexico. Lobo's uncanny ability to avoid traps, poison and other methods of extermination makes fools of the humans trying to protect their livestock. While Lobo incurs Seton's enmity and his respect, the bulk of the story focuses on how Seton tricks Lobo and traps him, each of his four great feet caught in a steel trap. After two days in the trap, Lobo is still dangerous and full of snapping fury. Out of respect, Seton cannot bring himself to shoot the animal and, instead, drags him home in chains, where he is kept until he finally dies. Though Seton claims kinship with animals, that relationship is easily disregarded and undermined if the animal itself becomes inconvenient to human encroachment on land and natural resources. While Seton pays lip-service to respecting Lobo, he ultimately reinforces tropes dating back to tales of the Big Bad Wolf.

Seton was instrumental in the literary transition from the sentimental and urban- 
based animal autobiographies to the subgenre of the wild animal tale to which London himself contributed. This new subgenre, an ostensibly masculine form that combined children's animal stories with the boys' adventure story, captured the attention of thenPresident Theodore Roosevelt, and sparked a major debate around the anthropomorphized animal body in literature. Roosevelt fancied himself somewhat of an expert on the wilderness in general and wolves in particular, and treasured his reputation as an outdoorsman. In 1893, he published The Wilderness Hunter, a memoir in which he cast himself as the hero of his very own boy's adventure. Roosevelt's book was as popular as anything written by Seton or London and, as S. K. Robisch posits, Roosevelt was "representative of the cultural context in which Jack London became the highestgrossing writer in the United States" (289). Roosevelt was also cashing in on the wildanimal adventure story. Disgusted with the new developments in nature writing, Roosevelt actively worked to discredit London and Seton, calling them both "naturefakers" in a 1907 article he wrote for Everybody's Magazine. Despite his own enthusiasm for Rudyard Kipling's anthropomorphized animal stories and adventure romances, Roosevelt nevertheless denounced these new stories: "I don't believe for a minute that some of these men who are writing nature stories and putting the word 'truth' prominently in their prefaces know the heart of wild things" (qtd in Carson 2). Roosevelt felt threatened by Seton's and London's problematizing of accepted boundaries between human and animal.

London was livid, and his published reply to the president - "The Other Animals" (1908) - provides insight into his engagement with the animal. London asserts 
that writing The Call of the Wild and White Fang was

a protest against the "humanizing" of animals, of which it seemed to me several "animal writers" had been profoundly guilty. Time and time again, and many times in my narratives, I wrote, speaking of my dog-heroes: "He did not think these things; he merely did them," etc. And I did this repeatedly, to the clogging of my narrative and in violation of my artistic canons; and I did it in order to hammer into the average human understanding that these dog-heroes of mine were not directed by abstract reasoning, but by instinct, and emotion, and by simple reasoning [...] and awoke one day, to find myself bundled neck and crop into the camp of the nature-fakers. (n. p.)

London is rightfully angry, particularly because, insofar as he was able, he wanted to engage in his writings with the animal for its own sake, as well as to use the animal body to articulate how his own perception of the animal differed from those presented in previous literary depictions. London continued his negation of Roosevelt's claims, contending that Roosevelt's opinion was rooted in a historical epoch that had long since passed. London refers to Roosevelt's stance as "distinctly mediaeval" (n.p.), in that Roosevelt persists in denying the capacity for reason to animals. In London's view, The Call of the Wild, conversely, was modern and "utterly different in treatment and subject from the rest of the animal stories which have been so successful” (qtd. in Labor 118), and forms the basis of his anger with Roosevelt's positioning him as a nature-faker. London situated his own works against previous animal stories such as Black Beauty (1877) and The Jungle Book (1894), which he perceived to be either overly 
sentimental or too anthropomorphizing (Labor 118). As a precursor to The Call of the Wild, London's essay “Husky - The Wolf Dog of the North” (1900) presents a straightforward and unanthropomorphized account of the aesthetics and behaviour of the wolf-dogs. For London, "wolf-dog” is nearly always synonymous with "husky," a species conflation that underscores both its wild and civilized ancestry. London makes this evident when he delineates their ancient domestication from wolves by the "savage autochthons of that forbidding region" (n. p.), then notes that part of the current process of breeding dogs for endurance involves the reintroduction of wolves into the immediate bloodline. Occupying a unique position between a fully domesticated draft-animal and a free-roaming wild hunter, the husky is comparable to Seton's Lobo in intelligence and capacity for mischief. Where Seton reinforces human superiority over the wild and its creatures, however, London's wolf-dog problematizes categories of wild and civilized. The husky benefits from its close proximity to humans to scavenge food, but retains from its wolf heritage a keen nose for scent and the stamina to run down prey when resources are scarce. As a hybrid of wild and civilized, the husky constitutes the ideal specimen to survive and even thrive in the harsh conditions.

Bolstered by his admiration of the wolf-dog of the North, London wrote The Call of the Wild largely as a response to Victorian animal stories in general, but also as a reaction to Kipling in particular. ${ }^{20}$ He brought Kipling's books and stories with him to the Yukon, and found it difficult to reconcile the civilized and hierarchical character of the "Law of the Jungle" portrayed by Kipling in The Jungle Book with the succinct brutality of what London called the "Law of Club and Fang" (London 17). Though the 
term "Law of the Jungle" is often conflated with Darwin's concept of "survival of the fittest, ${ }^{21}$ Kipling evokes it to describe a series of actual edicts governing wolf society, subverting the traditional depiction of wolves as the embodiment of unrestrained appetite and violence. The recounting of these laws concludes with an exhortation to "obey!" (215) for the greater good of the wolf pack, as well as jungle society in general. The Jungle Book is predicated on negotiating cultural alliances in what was becoming an increasingly global imperialist context (Hagiioannu 113). In the face of shifting societal boundaries, Kipling uses an ostensibly innocuous children's tale to reinforce societal caste systems. The wolves in The Jungle Book are arbiters of social order; however, when the wolves rescue the young boy - or "man-cub" - Mowgli from becoming the dinner of Shere Khan the tiger, they upset the balance of this order. Ultimately, they are compelled to redress this shift of power over the course of the text by indoctrinating Mowgli into adhering to the jungle's moral codes. The neologism "man-cub" itself hints at the difficulties underlying such efforts at species transmogrification. Mowgli's species remains foregrounded, with the animalism remaining more a performance than a replacement.

By contrast, there is something uniquely North American about London's "Law of Club and Fang," insofar as its inherent violence is tied to basic survival and is far removed from Kipling's "Jungle Eden" (Harrison 77) of temperate climate and plentiful resources. While Kipling's wolves obey their laws in the best interest of their pack relations and society at large, Buck and the other sled dogs in The Call of the Wild are brutalized by their human handlers and forced to compete with one another for scraps of 
food. The Law of Club and Fang is comprised of only one rule - do whatever is needed to survive, whether it is steal, fight or kill. Buck observes that it was

all well enough in the Southland, under the law of love and fellowship, to respect private property and personal feelings; under the Law of Club and Fang, who so took such things into account was a fool, and in so far as he observed them he would fail to prosper. (28)

London conceives of a social reality defined by values other than those monopolized by human visions of civility and human relations. His critique of the logic of the "Southland" invites, instead, a conception of kinship that crosses species and, in so doing, offers solutions to the early twentieth-century animal writers' efforts to work outside of anthropocentric literary conventions.

\section{Becoming Buck: Envisioning Posthumanity}

In questioning the perceived boundaries between human and non-human animals, scholars such as Lundblad aim to undermine the humanist privileging of human over the animal. Donna Haraway similarly reconceptualizes humans and animals as phenomena beyond ideology, challenging the hegemonic structures of empire that had become central to humanist exploits of the nineteenth and twentieth centuries. She pinpoints "an oversight in traditional liberal ideology that reinforces the deep divide between nature and culture, which in turn continues to reinforce structures of hierarchy and dominance in the natural sciences" (Cyborgs 10). Haraway's ongoing objective is to link the life sciences to philosophical questions of the animal and, in doing so, collapse traditional 
boundaries between nature and culture. For example, in her most recent works on companion species relationships, she does not view nature and culture as mutually exclusive or inherently combative, and works instead to collapse their constructed boundaries, calling the resultant merger a "natureculture" (Companion Species Manifesto 8). When Haraway invokes this term, she is discussing the intersections and overlaps between the established binary of nature and culture to demonstrate that engaging with the non-human animal itself presents a new means by which to explore human/animal relations in a way that no longer privileges the human. And by collapsing the boundary between nature and culture, other boundaries also falter. As I hope to demonstrate, London has his wolves and dogs function as a similar form of natureculture, one through which London hopes to enter into a deeper relation with canines.

The Call of the Wild is the story of Buck, a dog stolen from his owner's estate in California and sold as a sled-dog in the Yukon Territory. Shortly after arriving in "the Northland" (1), Buck is confronted with a harsh climate and harsher realities. The Law of Club and Fang dictates that, to survive, he must put aside civilized behaviours. The wolf-dogs of the North work hard, fight hard, and pilfer food from the mushers to survive. Buck is put into harness, clashes with the other dogs, gets beaten by the mushers and, within the span of a couple of months, has taken to Northland living as though he were born to it. He then challenges the vicious lead-dog Spitz to a violent fight to the death, which he wins. Outlining Buck's arctic education in a chapter titled "The Dominant Primordial Beast," London repeatedly uses descriptors such as "further 
decay," "primitive code" (27), "decivilization," "retrogression" (28) and "primeval" (29). London's atavistic terminology signifies a transformation that, for most London scholars, is predicated on the divide between nature and culture. Earle Labor, for example, interprets this as a rite of passage that an exemplary individual must undergo in order to demonstrate his inherent leadership over those less well-equipped to adapt and survive (120). Despite London's stated attempts to engage with the animal itself, Labor's structural and psychoanalytic analysis deliberately erases the canine presence in the novel, proposing instead that Buck is a mere stand-in for the human. ${ }^{22}$

London's efforts to capture cross-species engagement is supported by two episodes in the text most often discussed as the author's coded attempts to reconcile the contradictory elements of social Darwinism and socialism, predicated on the firm boundaries between individuality and conformity, wild and domestic, and nature and culture. ${ }^{23}$ Both of these scenes deal with Buck dreaming of a time out of time, in which he is a canine companion to an earlier, ape-like man. In these dreams he envisions a man who is

shorter of leg and longer of arm, with muscles that were stringy and knotty rather than rounded and swelling. The hair of this man was long and matted, and his head slanted back under it from the eyes. He uttered strange sounds, and seemed very much afraid of the darkness, into which he peered continually, clutching in his hand, which hung midway between knee and foot, a stick with a heavy stone made fast to the end[....] About his body there was a peculiar springiness, or resiliency, almost catlike, and a quick alertness as of one who lived in perpetual 
fear of things seen and unseen. (60)

Robisch notes that London references the "campfire myth" (295) of wolf domestication, in which wolves, attracted by warmth and the promise of leftover food, invited themselves to dinner and never went home (38). It is curious, however, that Buck dreams not of wolves, but of a relationship with early humans. Buck envisions not only the primitive, but the primitive-domestic, in that his ancestral self is already domesticated. It is not a wolf's dream, but a dog's dream, undermining straightforward interpretations of Buck's subsequent joining of the wolf pack as a triumph of nature over civilization.

Buck's first dream instead enacts what Gilles Deleuze and Félix Guattari would call a "becoming." In A Thousand Plateaus, Deleuze and Guattari describe "becoming animal" as the way in which an entity "changes elements" (27). This change is not a true physical transformation, nor is it merely an imitation. One becomes animal "only if, by whatever means or elements, you emit corpuscles that enter a relation of movement and rest of the animal particles, or what amounts to the same thing, that enter the zoene of proximity of the animal molecule" (275). Becoming animal is relational, predicated on closeness and immediacy. This is consistent with Haraway's theories of "contact zoenes" (Species 4), where the lives and bodies of various humans and animals brush against one another and, in the process, are altered. Haraway's argument foregrounds those sites of interchange and alteration, but Deleuze and Guattari go further in proposing that, in fact, there are no predetermined entities that engage in change. For them, the act of change - what they call "becoming" - is the principal state of existence, rather than a transition between two fixed states (such as that of being dog and being 
wolf). Adapting Deleuze and Guatarri's claims, Haraway describes this transition to domestication not as a becoming, but as a "becoming with" (Species 16), highlighting the contact zoene itself as the site of the perpetual state of change and fluidity. This model of humans and canines arising through the process of becoming in tandem foregrounds a mutual reliance that is central to London's representation of the wild dog.

London's version of becoming is highlighted by Buck's strong, passionate affection for John Thornton, who rescues him from egregious abuse and overwork at the hands of ignorant greenhorns. Under Thornton's care, Buck finds new purpose in his love for Thornton, and this reshapes his life. After Buck's physical recovery, the two search the wilderness together for a lost gold mine. On this journey, Buck's visions increase in vividness and frequency, with Buck dreaming of days spent traveling with the "short-legged hairy man" (112). For Buck, London tells us, the "salient thing of this other world seemed fear" (112), but in the context of Buck's "passionate" affection for Thornton (90), it seems that these memories of mutual interdependence are underwritten by love. While Buck "remembers" fear, it is not his own fear, but that of his human companion. The notion of love is reinforced by the fact that the non-human animal can conceivably leave his human at any time, but chooses to spend his nights in "vigil" (113), on guard while his human sleeps. It is neither need nor fear, but the becoming with of affection that keeps him with his early human.

Jeffrey Moussaieff Masson postulates that, historically, humans have domesticated many species of animal, but "only the dog has domesticated us" (Dogs 
Never Lie 15). Further, he positions this as the dog's choice, "not because it is confused about our identity, not because dogs think we are the marvel of creation, but merely because dogs love us." Though he does not use Haraway’s term, Masson is proposing a becoming with, a model of interspecies engagement based on mutual respect and affection. ${ }^{24}$ In proportion to Buck's adoration for Thornton, however, remain equally strong yearnings for the wilderness. After his second dream, Buck spends a significant portion of his leisure time running free in the forest, hunting and exploring, but always returning to Thornton in "a frenzy of affection" (117). While Buck's vacillation between Thornton and the "call still sounding in the depths of the forest" (113) could be interpreted as a rejection of becoming with, this very inconstancy actually effectively underscores the fluid nature of becoming itself.

When Thornton and his human companions are killed by another group of humans, Buck's state of becoming with is also inevitably damaged. As he sniffs Thornton's dead body, Buck hears from far away a faint yelp, followed by similar sharp yelps[.... He walked to the centre of the open space and listened. It was the call, the many-noted call, sounding more luringly and compellingly than ever before. And as never before, he was ready to obey. John Thornton was dead. (129)

As Buck realizes that he is no longer becoming with Thornton, the wolves emerge from the forest "in a silvery flood" (130) to investigate and invite Buck to join them. The fluid nature of the pack constitutes what Deleuze and Guattari call a "threshold of intensity" (31), the moment at which the anomalous individual is absorbed into the pack or 
multiplicity to become-wolf. They contend further that a becoming "always involves a pack, a band, a population [...] in short a multiplicity" (239). In becoming-wolf, then, "the important thing is the position of the mass, and above all the position of the subject in relation to the pack or wolf-multiplicity: how the subject joins or does not join the pack, how far away it stays, how it does or does not hold the multiplicity" (29). In other words, the state of becoming depends on the degree to which the subject commits to giving itself up to it. Buck's earlier vacillation between Thornton and the pack does not signify that Buck is bound by his relationship with Thornton, but that he is at an intersection of two equally strong modes of becoming. In the shift between companion and not-companion, between wild and domestic, Buck enters into a state of becominganimal, defined by his transitional position between dog and wolf.

Though Buck's life is now with the wolf pack, he continues to become with the human. Buck returns every summer to the valley in which Thornton died, and "muses for a time, howling once, long and mournfully, ere he departs" (133). In remaking the contact zoene, in which he is once again a companion species, he carries simultaneous burdens of civilization and wilderness, which he conveys to his own progeny along with the "splashes of brown on the head and muzzle, and a rift of white centring down the chest" (133). More than that, just as Thornton has contaminated Buck, Buck has contaminated the wolf pack. These acts of transmutation are what sustain the continual process of becoming. While the ending can be read as the logical and exhilarating conclusion to the imperialist narrative - in which Buck faces down the wilderness and then joins it, marking it with his own biological stamp - such an interpretation is in fact 
undermined by Buck's continual transition between fully inhabiting one space or the other.

\section{California Dreaming: The Domestication of White Fang}

In a 1905 letter to his wife, London outlined his ideas for another novel featuring a canine protagonist, "a companion to 'The Call of the Wild.' Beginning at the very opposite end - evolution instead of devolution; civilization instead of decivilization. It is distinctly NOT to be a sequel. Merely same length, dog-story and companion story" (C. London 12). Though London aimed to write a story in the same vein as The Call of the Wild, his vision of a "companion" story foreshadows Haraway's concepts of companion species and significant otherness. For Haraway, significant otherness is the result of a companion species relationship; it is what happens when one becomes with the animal. Haraway contends that she and her own dog are companion species, making "each other up, in the flesh. Significantly other to each other, in specific difference, we signify in the flesh a nasty developmental infection called love. This love is a historical aberration and a naturcultural legacy" (16). The cross-species contact zoene is forged and maintained by mutual affection, resulting in a state of significant otherness. While London himself postulates that White Fang is a bookend or a reversal of the themes and issues raised in The Call of the Wild, it is in fact an extension of the ambiguity inherent to Buck's continual transitions and becomings. As such, London contends that a relationship based on mutual respect and affection is transformative and ultimately desirable. In White Fang, he proposes that the need for love and affection is an inherent part of the 
eponymous hero's nature, no matter how poorly he is treated by his human handlers. If The Call of the Wild is read as a tragedy of loss and regret, then White Fang is a reverse journey to reunion and reconciliation. The confirmation of a companion species model, in which significant otherness is predicated on love, transcends the artificial divides between wild and domestic.

White Fang chronicles the life of a wolf-dog hybrid born into the wild. By deceitful means, he is betrayed into the hands of a man named Beauty Smith, who brutalizes him and forces him to fight other dogs until he is worn down and nearly killed. White Fang's life changes significantly when Weedon Scott appears out of nowhere to stop the fight and remove White Fang from Smith's custody. While Scott has no apparent motive at the time for rescuing the dog, London informs us that Scott "had set himself the task of redeeming White Fang - or rather, of redeeming mankind from the wrong it had done White Fang" (241). This commitment is a tacit acknowledgement of human-canine interdependence, which in the novel has been corrupted by violence.

White Fang's longing for a relationship based on affection underwrites the novel. His earliest memories are of his mother, who possesses "a gentle, caressing tongue that soothed him when it passed over his soft little body, and that impelled him to snuggle close against her and to doze off to sleep" (72). This peaceful domestic scene establishes that White Fang's inherent nature is affectionate, and that his later "redemption" by Scott is a revival of the canine's ability to feel and demonstrate love and to be with as a companion species. The physicality of his affectionate relationship with his mother, moreover, positions love as being communicated through and with the body. In outlining 
the many similarities between human and wolf, Masson contends that our mutual sociability as "pack animals" stems from common bodily traits and habits (Dogs Never Lie 147). He notes that "even a wolf's facial expressions are similar to ours and not difficult to read: the alert and happy face, the friendly grin, the closed eyes as a sign of pure pleasure" (147). Human and animal recognize the physical grounds for a companion species relationship. If as Masson posits, love is the "master emotion" of dogs (39), and that "humans and dogs seem to be the only two species that are capable of great love that crosses the species barrier" (42), then this capacity for mutual affection has driven the process of domestication.

Affection, demonstrated by physical contact, is crucial in companion species interactions, which is what Haraway means when she links flesh and love as the bases for that interaction. Though initially leery of the humans and their intentions, as a puppy White Fang yields to "an unaccountable sensation of pleasure" (London 111) when first caressed by human hands. This betokens "the fearless relationship with man that was ultimately to be his" (111). Ultimately though, White Fang receives shelter, food and fire from his human masters, but never love. It is an erroneous human assumption that his wolf heritage precludes his ability to develop into a companion species that facilitates the violence perpetrated against him, and also the violence he is forced to commit. ${ }^{25}$

In calling attention to how Scott goes about redressing the wrongs done to White Fang, London is more critical of the violence inherent to the Law of Club and Fang than he is in The Call of the Wild. Repeated instances of receiving corrective blows from Grey Beaver or his hunters and fighting with the other dogs reforms White Fang's 
character from one that expresses curiosity, joy and affection without reservation to a more reserved and suspicious one (London 166). London continually attributes White Fang's solitary and aggressive behaviour to a culture that interprets kindness as not the overt expression of affection, but the withholding of a blow (155). London posits further that

it might have been otherwise, and he would then have been otherwise [...] Had Grey Beaver possessed the plummet of affection and love, he might have sounded the deeps of White Fang's nature and brought up to the surface all manner of kindly qualities. But these things had not been so. (188)

In this fashion, London maintains that White Fang is still capable of becoming with Scott after his rescue.

Scott gradually brings the dog back not only to the state of trust that he had experienced with his mother, but to a state of "wild, keen-thrilling satisfaction" (242) arising specifically from his bond with a human. As their relationship develops over time,

like had been replaced by love. And love was the plummet dropped down into the deeps of him where like had never gone. And responsive out of his deeps had come the new thing - love. That which was given unto him did he return. This was a god indeed, a love-god, a warm and radiant god, in whose light White Fang's nature expanded as a flower expands under the sun. (243) Framed in a way that highlights its pleasure, the consummation of their physical relationship - with White Fang allowing Scott to touch and pet him - in turn becomes an 
issue of mutual dependence. Deleuze and Guattari highlight the importance of love as a form of becoming when they posit that to love someone is always to seize that person in a mass, extract him or her from a group $[\ldots]$ then to find that person's own packs, the multiplicities he or she encloses within himself or herself which may be of an entirely different nature. To join them to mine, to make them penetrate mine, and for me to penetrate the other person's. Heavenly nuptials, multiplicities of multiplicities. (35)

If, as they posit further, "becoming and multiplicity are the same thing" (249), then love itself forms an infinite loop of becoming. When Scott attempts to return to California and leave White Fang in the Klondike, he dishonours their becoming with. Unlike Buck, White Fang cannot regress back to a wild creature without losing the self that Scott has recognized and "redeemed." Scott cannot deny his responsibility in forging that bond, and brings White Fang home to California.

In his analysis, Robisch reinforces the wild/domestic, wilderness/civilization binary, in which he sees the erasure of White Fang's wolf-self as in line with imperialist discourse and, as such, ultimately tragic. For Robisch, this tragedy results from White Fang surrendering his wild nature in order to be merely a dog in Scott's civilized household. There are ambiguities, however, that problematize this pat conclusion. An obvious interpretation of the novel is that White Fang has earned his reward through suffering, much as Black Beauty had, albeit at the cost of his wolf-self. When the novel is positioned against The Call of the Wild, however, the character of White Fang is more readily recognized as redressing Buck's own loss and regret. Buck, while becoming- 
animal with the wolves, can only partially become with the human in the place where Thornton died. Though the fluid nature of becoming is such that no subject's identity as one thing or another is ever fixed (Deleuze and Guattari 239), the corporeality and physical nature of affection that London highlights in White Fang presents a model of becoming that accounts for the reciprocal physical pleasure inherent to an affectionbased companion species relationship. London saw human-canine bonding as an issue that the Law of Club and Fang elides. Taken together, the two novels present a spectrum of choice within the context of becoming-with.

Because London's canine canon concludes on a note of reconciliation and reintegration, White Fang's wolf body still operates as a window onto that world. As such, it collapses the nature/culture divide. In an imperialist reading, White Fang can be seen as a trophy brought back to the more civilized California. However, Scott's initial unwillingness to remove the animal from his natural habitat reconstitutes the move south as White Fang's sacrifice for his companion. The final image of White Fang, drowsing in the sun in the company of his beloved human and his companions, reinforces a reading of the text as not a struggle between the wild and the domestic but a portrait of the natureculture that houses companion species.

While London's early twentieth-century texts reflect a set of values and concerns not identical to those of the present day, London invites even recent readers to look closer at their relationships with non-human animals, allowing us "to see how shifting constructions of the animal are linked with new constructions $[\ldots]$ at this historical 
moment" (Lundblad 498). Scholars are not wrong in calling attention to London's use of the wolf-dog body as a metaphor for human issues and values, but this approach tells us more about the human than the animal. More importantly, it countermands London's own efforts to meet and represent the animals on their own terms. The author himself invites an animality studies reading in which the canine is seen not as a fixed species but as a process of becoming whereby the subject loses itself within diverse forms of collectivity, shifting through diverse states of wildness, domesticity, and categorical hybridities. While a companion species relationship often prioritizes canines over other animals with whom we may not live so closely, there remains the possibility to become with all animals. In my next chapter, I turn my attention to the farm animal, with particular consideration of E.B. White's espousal of a model of subjecthood inconsistent with the paradigm of meat consumption in Western culture. 


\section{Chapter Three:}

\section{Carnophallogocentric Criticism in Charlotte's Web}

Dying in season evokes no terrors. (115)

John Griffith, "Charlotte’s Web: A Lonely Fantasy of Love”

E.B. White's Charlotte's Web (1952) has long been considered by scholars and educators to be a classic of children's literature. Most analyses of the text retain the practice of seeing the animal body as a stand-in for human values, emotions and experiences. Early scholarship on Charlotte's Web focuses on its structural elements, including White's proficiency with poetic language. Peter Neumeyer, for example, attends to the "mythopoetic dimension" (66) of the novel, clearly positioning it within the pastoral tradition. Perry Nodelman similarly examines the narrativity of the novel in the larger framework of folklore studies. Karen Coats, meanwhile, has recently approached the novel through a psychoanalytic lens, contending that "reading Charlotte's Web through Lacan's theory of subjectivity [...] enables us to come to an understanding of just how complicated the Other (as other people, as our own unconscious, as language itself) is in the formation of our identities" (105). Coats is correct in envisioning the Other as a means by which identity is formed, but her analysis remains focused on the creation of human identity, unproblematically using Wilbur as a stand-in for the human child. Ashraf Rushdy similarly prioritizes the human experience, positioning Charlotte's Web as "a representation of individual and communal desires" 
(36), by which he is referring to human desires. Rushdy further characterizes Wilbur as becoming, by the end of the novel, "integrated into the human community" (37), despite the fact that the pig remains in the barn with Charlotte's descendants for company. In reality, Wilbur has not actually been integrated into human society, but merely granted a reprieve from the fate of most livestock.

Examining the politics of animal subjectivity in Charlotte's Web as part of the larger context of White's other writings on animals, however, reveals a deeper ambivalence on the author's part regarding the West's culture of animal consumption. Through an animality studies reading of Charlotte's Web, I aim in this chapter to push the boundaries of what "subjectivity" and "community" mean in both the novel and in the larger framework of Western culture. An analysis that accounts for Wilbur as an actual non-human animal instead of as a representative of the concept of the human child calls into question the naturalization of what Jacques Derrida refers to as the "noncriminal putting to death" ("Eating Well" 112) of the animal for human consumption.

In my analysis of White's writing, I wish to build on my discussion in the previous chapter, which highlights the importance of animal subjectivity in a companion-species relationship. My examination of Charlotte's Web will account for the wider implications of granting subjectivity to a singular animal and not to all animals. More specifically, this chapter delves into the crucially important area of the relationship of ethics to edibility. Expanding on Donna Haraway's conception of companion species, I explore White's rhetorically sympathetic fusion of children and 
animals, as well as the possibility of interspecies friendship. Charlotte's Web promotes a vision of subjectivity for the individual animal at odds with the West's "carnophallogocentric" (Derrida "Eating Well" 113) paradigm of meat consumption.

\section{A History of Hogs and Hog-farming}

Sanders Spencer, founder of the British Pig Association, characterized the pig in 1919 as "a machine for the conversion of farm produce into meat" (132), a straightforward and utilitarian view of the animal consistent with Descartes's conception of the animal as an unfeeling beast-machine for the human to put to use as seen fit. As journalist William Hedgepeth posits, however, the development of human civilization advanced "hand-in-hoof [...] in a symbiotic sort of equilibrium" (43) with the domestication of the wild pig. Naturalist Roger Caras believes that, historically, this symbiosis facilitated the shift towards stable agriculturally based societies across Europe and Asia (118). The human domestication of animals in general had, between eight and ten thousand years ago, already encompassed other livestock, as well as dogs, but the stubborn swine's refusal to be herded made it difficult to assimilate the species into a nomadic lifestyle. The animals' destructive foraging habits made confinement an attractive idea because this ensured no direct competition between swine and humans for the same resources. Possessed of a lively natural curiosity, the pig's inclination to roam was circumscribed by farmyard fences (Malcolmson and Mastoris 19).

Reliance on confinement had significant repercussions for the pig, changing its previous behaviours. As a wild beast, the pig would seek shade from the heat of the sun 
or root for food in the ground; after domestication it was restricted to wallowing in mud to keep cool, and became dependent on its keeper for its meals. Human perceptions of the pig changed accordingly, and the pig became aligned with filth and indolence. In this vein, Robert Malcolmson and Stephane Mastoris observe that, historically, the pig has "fared poorly" in comparison to the human treatment of other livestock such as cattle and horses (33). Where horses in particular became an "embodiment of untamed natural force" (Dingley 245) and a figure around which the early animal rights movement coalesced, the pig became representative of all that was "disagreeable or uncouth, or even revolting or beyond the pale" (Malcolmson and Mastoris 2). Author and lexicographer Samuel Johnson, for example, defined the swine in his 1755 dictionary as a creature "remarkable for stupidity and nastiness" (906). Prevailing opinions historically held pigs to be filthy creatures, lacking in intelligence and sociability.

Despite the important role the domesticated swine played in establishing human civilization, this development did not lead to the same kind of affection and mutual respect that has characterized human relationships with, for example, dogs. ${ }^{26}$ And yet, according to Jeffrey Mousaieff Masson, pigs have more in common with humans than canines:

Like us, pigs dream and can see colors. Also like us, and like dogs and wolves, pigs are sociable[....] The females form stable families led by a matriarch with her children and female relatives. Piglets are particularly fond of play, just as human children are, and chase one another, play-fight, play-love, tumble down 
hills, and generally engage in a wide variety of enjoyable activities. (Pig Who Sang 19-20)

Despite humans having more in common with porcines than canines, the absence of the kind of companion relationship experienced by dogs stems primarily from the pig's primary status as "a critically important, highly productive, low-cost maintenance meat animal" (Caras 111). ${ }^{27}$ For Masson, the crucial difference between companion and edible animals stems from the way they are treated (Pig Who Sang 18). Dogs sleep on our beds and are often fed from our tables as companions. Hogs are comestibles, confined to barns and farmyards.

In When Species Meet, Donna Haraway foregrounds the intersections between food and friendship, but differentiates between the "companion animal" and "companion species" (16). What Haraway envisions is a table at which humans and animals sit together in mutual subjectivity, not a table at which the animal body is eaten by the human as the meal. What Haraway calls "becoming with" is rooted in this mutual subjectivity, making it impossible to become with the meat animal because its transformation into dinner is predicated on the disavowal of animal subjectivity.

Vegan activist Carol Adams similarly argues that meat constitutes an "absent referent" (51); that is, animals

in name and body are made absent as animals for meat to exist. Animals' lives precede and enable the existence of meat. If animals are alive, they cannot be meat. Thus a dead body replaces the live animal. Without animals, there would 
be no meat-eating, yet they are absent from the act of eating meat because they have been transformed into food. (51)

In accord with Masson, Adams posits that the denial of the animal's subjectivity prior to its death is manifested in part by the conditions in which it is kept and how it is treated. More specifically, humans generally segregate meat animals by keeping them out of the domestic space and confining them to farmyards, a move that ensures they are treated not as integral members of the community but as a distinct entity with which there is no need to interact in any extensive or meaningful way.

The conditions of animal-keeping were not always ideal for maintaining the separation of human and animal. In nineteenth-century Britain, smaller or lower-income households without the space or financial means to build an outdoor paddock at a distance from the home often shared close quarters with their family pig, keeping it indoors at night and in inclement weather. This co-habitation created a deep ambivalence regarding the killing and eating of what, up until harvest time, was considered a treasured family pet. This unease is reflected in the increase of porcine advocacy. By the 1880 s, those who worked closely with pigs began to write admiringly of their unique personalities (Malcolmson and Mastoris 20). These authors promoted acknowledging the subjectivity of the animals, respecting their chosen family structures, and even naming them in order to build feelings of trust and "good fellowship" between a farmer and his hogs (Morrison 209).

However fond a family grew of its pig, affection was not enough to offset the desire for its meat. Householders solved their ethical dilemma not by sparing their 
animals, but by hiring what was called a "pig-killer" to kill and butcher on their behalf (Malcolmson and Mastoris 95). This individual would take the animal from its sty and bring it either to a work shed behind the house or to another nearby area where it could be killed and bled without contaminating the local water supply. Not only was this activity emotionally draining, it was also physically demanding, requiring a certain level of skill.

In his 1895 novel Jude the Obscure, Thomas Hardy provided a harrowing account of the unfortunate experience of an unskilled butcher. In this scene, the eponymous hero is being bullied by his new wife, Arabella, into killing an animal for which Jude feels a notable degree of empathy:

"Upon my soul I would sooner have gone without the pig than have had this to do!" said Jude. "A creature I have fed with my own hands."

“Don't be such a tender-hearted fool! There's the sticking knife - the one with the point. Now whatever you do, don't stick un too deep."

"I'll stick him effectually, so as to make short work of it. That's the chief thing."

"You must not!" she cried. "The meat must be well bled, and he must die slow[....] Just touch the vein, that's all. I was brought up to it, and I know. Every good butcher keeps un bleeding long. He ought to be eight or ten minutes dying, at least."

"He shall not be half a minute if I can help it, however the meat may look," said Jude determinedly. Scraping the bristles from the pig's upturned 
throat, as he had seen butchers do, he slit the fat; then plunged in the knife with all his might.

“Od damn it all!” she cried, “that ever I should say it! You’ve overstuck un! And I telling you all the time -"

"Do be quiet, Arabella, and have a little pity on the creature!" [...]

However unworkmanlike the deed, it had been mercifully done. The blood flowed out in a torrent instead of the trickling stream she had desired. The dying animal's cry assumed its third and final tone, the shriek of agony; his glaring eyes riveting themselves on Arabella with the eloquently keen reproach of a creature recognizing at last the treachery of those who had seemed his only friends. (54-55)

Arabella takes a matter-of-fact approach to the killing of the pig, potentially recognizing that it feels pain but ignoring this as unimportant because of the creature's inferiority to humans. Jude, conversely, does recognize the animal's subjectivity, although even he fails to extend that recognition to a problematization of the androcentric quality of his ethics. Hardy himself suggests a more complex view of the problem, with the novel's main thrust actually focusing on the hero's own slow bleed, metaphorically speaking, due to his subordinate class status.

Hardy's novel does not overtly advocate animal rights, but this passage in particular encapsulates the qualms and anxieties surrounding home butchering that White revisits in his own work 60 years later. As an architectural reminder of animal suffering and death, the private slaughterhouse scenario described by Hardy became a 
key site around which animal rights activists and health reformers from the latenineteenth century onward gathered to lobby for increased regulation (Otter 89). This was due not only to the moral and aesthetic distastefulness of backyard butchery, but also to a larger societal shift towards greater sanitation and mechanization.

As outlined in my first chapter, humanitarian efforts on behalf of animals were often framed in a way that benefited the human as well as the animal. Social reformers in the nineteenth century believed that continual exposure to animal distress "infect[ed] and barbariz[ed] those around them, mysteriously stimulating drinking, fighting and prostitution" (Otter 91). As part of a rhetorical stance that held that cruelty towards animals led to cruelty to other humans, the move to replace the private slaughterhouse functioned as an extension of Member of Parliament William Pulteny's arguments in the early part of the nineteenth century against bear-baiting as a social control of the poor. This regulation was "advantageous in many respects, notably as regards cleanliness, space and supervision" ("Metropolitan” 425).

Stephen Thierman links this call for regulation to Michel Foucault's concept of docile bodies and disciplinary power. Foucault posits that the century saw the start of a new kind of bodily control, "a machinery of power that explores it, breaks it down and rearranges it" (138). Adapted from military and monastery practices, discipline is differentiated from violence and force, creating a new kind of obedience predicated on perpetual conditioning and training. Thierman contends that Foucault's writings on prison are also applicable to the new public abattoir, which replaced countless work sheds and alleyways with a singular site of death and dismemberment. According to 
Theirman, the slaughterhouse can be seen as "a site of disciplinary power (and domination) where a multitude of bodies are rendered docile" (103). In his formulation, the public abattoir is dependent on harnessing the power of mechanization to further remove subjectivity from the docile animal.

By the early 1900s, the new system became fully automated and the phases of disarticulation were divided amongst several workers; no longer was a single human alone responsible for an animal's death. Animals were now mass-transported by train to the reconfigured abattoir on the outskirts of the city, then prodded along into the main area to be stunned, hooked and further transported to the killing area with as little physical contact as possible between animals and humans. ${ }^{28}$ Given that repeated exposure to animal suffering and death was considered a contributing factor to an increase in criminal and other socially unacceptable behaviours, mediating humananimal contact with machines was deemed an ideal means for controlling the amount of exposure the working class would have to the dead or dying animal.

What reformers could not foresee, however, were the negative long-term effects of replacing the "traditional culture of craftsmanship" practiced by small-scale butchers (Lee 3). The artisan was viewed as exacerbating both human and animal suffering by performing their grave task in close proximity to urban residents, most notably children (Otter 91). Late nineteenth century and early twentieth century public discourse around mechanized slaughterhouses was framed in a way that highlighted both the alleviation of animal suffering and human emotional disturbance, as well as the "rhetoric of technological progress," in terms of faster processing and improved hygiene (Lee 7). 
The significant increase in the amount of animals killed for meat ironically exposed the human workers to a previously unparalleled amount of death and dismemberment, to which the abattoir employees became increasingly desensitized. This elision of sympathy for the animal is directly linked not only to the volume of animals killed at the slaughterhouse, but also to the mechanical conditions that facilitated it. As Thierman puts it, "the living, breathing animals who ate, slept and interacted [...] literally disappear. In the slaughterhouse, their individuality is elided as they become inert commodities for human consumption" (107). In other words, minimizing the amount of human-animal contact did not improve the lot of the edible animal; transported and largely handled by machines alone, the animals conceptually became part of the machine and, as such, were even less likely to be considered as subjects. ${ }^{29}$ As the animals were often already stunned or dead when they reach the workers, the only task that remained for the human was disarticulation, to be accomplished as swiftly as possible. The enforced pace of the dismemberment process meant that the human worker had no time for the intimate scenario Hardy described, in which Jude conflates his own subjectivity with that of the animal.

The speed at which the mechanized slaughterhouse was able to turn out dead animals drove an increased demand for meat. Chris Otter notes that British meat consumption "rose from around 80 [pounds] per person in the 1840 s to around 132 pounds per person by the early twentieth century" (89). Roger Horowitz similarly points out that, as incomes rose over the nineteenth and early twentieth centuries, "so did the demand for beef and poultry" (11), with pork rounding out the top three preferred meats. 
This acceleration necessitated major changes in the scale of livestock management. The slaughterhouse had already normalized the use of technology in food production, and the same principles of scale and speed were applied to the raising of farm animals. This resulted in the institutionalizing of the "industrial compartmentalization" of the edible animal, radically shifting human-animal relations (Lee 2). The kind of backyard pigsty that Hardy described, or even the family hobby farm that E.B. White purchased as a retreat from the bustle of New York, was, by the time Charlotte's Web was published in 1952, being phased out and replaced by massive industrial farmsteads called

Concentrated Animal Feeding Operations (CAFOs). Inside these animal factories, the entire life of the animal from birth to slaughter was mechanized to maximize meat production. ${ }^{30}$

The successful CAFO is built on the backs of smaller, quick-maturing animals like pigs, who produce multiple offspring. These offspring can in turn be raised quickly and packed together in large numbers in smaller spaces. Jeffrey Moussaieff Masson observes that, at many factory farms,

pigs are routinely sedated and kept in dark or semidark giant sheds so all they can do is eat and sleep for twenty-three out of twenty-four hours. All the joie de vivre is driven out of the pig. Fattened to immobility, tails cut, teeth removed, their natural instinct to investigate frustrated by the cold concrete floor, their desire for order destroyed by being forced to exist in a small pen, their sense of cleanliness ruined by being forced to urinate and defecate in their sleeping place, something no pig would ever do in nature [....] Piglets are taken from their mothers and put 
into "nursery" pens - where of course, no nursing takes place - with metal bars and concrete floors. They move to "growers" and "finishers," and at about six months, when they attain their "slaughter weight" of 250 pounds, they are killed. (Pig Who Sang 38-39).

Such close quarters breed crippling disease and neurosis, sentencing the factory-farmed hog to unbelievable mental torment and pain for the duration of its short life. ${ }^{31}$

As an animal advocate working to reform the meat industry, Temple Grandin regrets that the human diet includes meat. She prefers that "humans would have evolved to be plant eaters, so we wouldn't have to kill animals for food. But we didn't, and I don't see the human race converting to vegetarianism anytime soon” (179). Grandin's objective, like Jeremy Bentham's, is to minimize suffering. ${ }^{32}$ Because the animal has no foreknowledge of its death, it cannot experience any tormented anticipation. All the human owes to the animal is a swift, painless death, ensuring that the animal does not suffer overmuch in the act of killing. In accord with Bentham, Grandin contends that the animal "should feel as little pain as possible, and he should die as quick as possible" (180). While Grandin aligns herself with animal subjectivity, she is unwilling to challenge the paradigms of mass meat consumption in the Western world.

Masson takes exception, however, to visions like Grandin's of a “kind death" for animals (Pig Who Sang 41). He views the concept as remaining complicit in a systemic disavowal of subjectivity to all animals on the grounds that we are "supposed" to eat them. Masson observes that "it is in our own self-interest not to know them; it is easier to disconnect from whom we are eating if we know nothing at all about them" (Pig Who 
Sang 283). There is thus a critical ethical conflict between acknowledging individual animals as unique subjects while not allowing for an overarching notion of subjectivity for all animals. This crisis is echoed by White throughout his writing career.

\section{E.B. White, Self-professed Animal Murderer}

Michael Sims contends that White situated Charlotte's Web in the animal world because "throughout his long life animals were White's favorite acquaintances" (3). Lynn Overholt Wake likewise characterizes White as a nature-writer, positing that his witty, urbane columns for The New Yorker and Harper's Magazine and his "animal fables" for children "should not be divided into two separate provinces; his accomplishment was more holistic than it was fragmented" (103). Both Sims and Wake propose a nuanced vision of White and his literary works, which encompass the city and the countryside, as well as the creatures - both human and non-human - found there. White often makes no clear distinctions between nature and culture, finding each in the other. In his piece "Art of the Essay," for example, he contends that the city is part of the country. When I had an apartment on the East Forty-eighth Street, my backyard during the migratory season yielded more birds than I ever saw in Maine. I could step out on my porch, spring or fall, and there was the hermit thrush, picking around in McEvoy's yard. Or the white-throated sparrow, the brown thrasher, the jay, the kinglet. John Kieran has recorded the immense variety of flora and fauna within the limits of Greater New York. But it is not just a question of birds and animals. The urban scene is a spectacle that fascinates 
me. People are animals, and the city is full of people in strange plumage, defending their territorial rights, digging for their supper.” (n.p.)

White's writing career is characterized by the unexpected entwining, or even subversion, of the accepted opposition of nature and culture, stemming from his childhood association with animals and the outdoors.

Born in Mount Vernon, New York, White experienced a childhood that was a mixture of time spent in the city as well as on holiday in the Maine countryside. He spent many hours developing a kinship with the horses and assorted stray dogs sheltered in the family's stable. White "found the dark and pungent stable intoxicatingly rich in romantic associations of life and death and adventure" (Sims 11). Similarly, as a young reader, White was a fan of wild animal adventure stories, such as those of Canadian author Ernest Thompson Seton. He appreciated the blending of scientific observation with fantastic tales of animal daring (43). Seton in particular emphasized kinship with animals, prefacing Wild Animals I Have Known (1898) by boldly stating, "we and the beasts are kin. Man has nothing that the animals have not at least a vestige of, the animals have nothing that man does not in some degree share" (n. p.). This sentiment resonated with White, who even as a child sought to develop the kind of companionspecies relationship Haraway describes as situated in mutual subjectivity.

Never a robust child, White was often confined to bed with complications from his allergies. During one such confinement, he made friends with a particularly friendly and curious mouse. With little else to do during his enforced rest, he devoted his efforts to gaining the mouse's trust. White spent long hours observing the mouse going about its 
business (Agosta 6), observations he would later put to good use in Stuart Little (1945). White's earliest published piece is in fact a poem dedicated to that mouse, and it won him a prize from The Woman's Home Companion in 1909 (Elledge 30). White was only nine years old, but this preliminary publication helped set the tone of his adult career.

As a young adult, White was influenced by Henry David Thoreau's Walden (1845). In a letter to a friend, White describes Walden as "the only book he 'owned,' that the others merely lived with him" (Sims 141). White saw himself as following in Thoreau's footsteps, even, in 1939, visiting Thoreau's cabin and addressing a letter to "Henry" (One Man's Meat 80). In this piece, he juxtaposes modern conveyances and appliances with the peace of the woods around Thoreau's cabin, though he ruefully notes that some young fun-seekers have left beer bottles and the remains of a campfire in the centre of the structure. White's merging of the setting of Thoreau's treatise on solitude and communing with nature undermines boundaries between nature and culture, which White himself points out, describing the landscape around Concord, Massachusetts as "not quite suburban, not quite rural" (82), capturing a feeling of a modern nation encompassing both past and present, rural and urban.

White's affinity for nature is carried over into his novels for children. The author delighted in keeping animals as pets and, when he bought his farm in 1933, he immediately stocked it with sheep, cattle, geese and of course pigs (Griffith Salvation 55). White re-creates his daily farm routines and the structures of rural life in Charlotte's $W e b$, and this attention to detail and distinct tethering to the real world make it impossible to dismiss the novel as mere fantasy. ${ }^{33}$ White's inspiration for Charlotte's 
Web stems from an incident in his second career as a gentleman farmer, and his ambivalence toward his own role as butcher. In his famous essay "Death of a Pig" (1948), he recounts how he fought to save the life of his pig, stricken ill with erysipelas. White notes with his characteristic gentle irony that he felt baffled by a situation in which he would feel so badly for the premature death of an animal he would have killed anyway. In the course of raising his pig, the author merged his own state of well-being with that of the animal, an identity conflation that Haraway explains as a form of "natureculture" (Companion Species Manifesto 8). She posits that engaging with the non-human animal itself presents a new means by which to explore human/animal relations in a way that no longer privileges the human. White similarly observes that, from "the lustiness of a healthy pig a man derives a feeling of personal lustiness [...] and when this suddenly comes to an end and food lies stale and untouched, souring in the sun, the pig's imbalance becomes the man's, vicariously, and life seems insecure, displaced, transitory" (Essays 20). Foregrounding his affinity with animals, White's alignment of human and animal health and wellbeing in this essay forms a counter argument against the enforced segregation of human and animal, and as such, becomes an implicit endorsement of animal rights. ${ }^{34}$

White directly addresses the hypocrisy inherent to raising an animal for its meat in the essay "Pigs and Spiders" (1953). The author writes that a farm is "a peculiar problem" for anybody who actually likes animals: "the fate of most livestock is that they are murdered by their benefactors. The creatures may live serenely but they end violently, and the odor of doom hangs about them always" (49). Noting his keen efforts 
in raising his pigs over the years, White confesses: "The relationship bothered me. Day by day I became better acquainted with my pig, and he with me, and the fact that the whole adventure pointed toward an eventual piece of double-dealing on my part lent an eerie quality to the thing" (49). White's thorough account of his conflation with the animal in "Death of a Pig" and his desire in "Pigs and Spiders" to redress the wrong he feels he is doing to a trusting fellow creature provides a direct impetus for creating Wilbur. Here he has given himself a pig that he gets to save by granting him a unique subjectivity, thus removing Wilbur from what Derrida calls the "carnophallogocentric" paradigm of Western meat consumption (“Eating Well” 113). Like Haraway, White foregrounds issues of edibility, seeking to invite the animal to the table as a guest, not the dinner.

\section{The Western Carnophallogocentric Paradigm in Charlotte's Web}

Derrida describes the "ideal" subject as a human, male, meat-eating individual, actively "possessing" nature and accepting the sacrifice inherent to eating flesh ("Eating Well" 114). Rooted in the Judeo-Christian myth of God's granting dominion to man over animals, this authority becomes inherent to the act of consuming flesh by the adult male subject. According to Derrida, carnophallogocentric cultures construct their social structures and morality around this schema, the noncriminal putting to death of the animal in order to evade the ethical consequences of what White himself characterizes as "murder" in both "Death of a Pig" (14) and Charlotte's Web (49). According to John Desmond, Derrida deconstructs "the prevailing assumption inherent in logocentrism, 
which presumed speech to be more pure than writing. He later appended the phallus, or signifier of male power, to logocentrism, in questioning the presumed superiority of the male. In his final articulation of 'carno' to phallogocentrism, he calls into question the bases of the assumption that humans have the legal right to kill animals" (240). For Derrida, then, the authority of the phallogocentric subject is granted to "the man (homo and vir) rather than to the woman, and to the woman rather than to the animal. And of course to the adult male rather than to the child. The virile strength of the adult male, the father, the husband, or brother [...] belongs to the schema that dominates the concept of the subject" ("Eating Well" 114). White's desire to "save" a pig is far more than a wish to help or rescue it, rooted instead in the wish to develop an undeniable subjectivity for the fictional Wilbur in a context that sees human dominion over animals as divinely granted. ${ }^{35}$ White's framing of killing his pig at harvest time as "double dealing" and "betrayal" (49) reveals what Derrrida calls the "sacrificial structure" of the Western paradigm of meat consumption and the discourses surrounding edibility ("Eating Well" 112). What both Derrida and White wish to problematize is the tradition of not extending the biblical prohibition "Thou shalt not kill" to animals as well as humans. Through an adaptation of Derrida's position, I will demonstrate White's own ambivalence toward the Western culture of meat-eating, which encourages the young to question the ethics of animal consumption, but only insofar as nonhuman animals ultimately remain a potential resource.

Charlotte's Web is the story of the young pig Wilbur and his friendship with Charlotte, a spider. Charlotte develops an ingenious plan to prevent Wilbur from being 
killed as part of the fall harvest, aiming to make the human community complicit in the recognition of Wilbur as an individual. As the spider knows, if the humans recognize the pig's subjectivity, he will not be killed at harvest time. As Charlotte calls attention to Wilbur's subjectivity, so too does the reader become implicated in Wilbur's removal from the carnophallogocentric framework.

The act of putting to death is central to White's novel. The text in fact opens with murderous intent. Young Fern Arable, hearing that her father John is about to kill the runt of a litter of pigs, is deeply distressed and intervenes. Karen Coats asserts that Fern does not necessarily care about this particular pig, but instead wishes to challenge her father's authority in general, grabbing his axe in order to threaten the symbolic male power structure (108). Such a reading, however, ignores the natural sympathy that children are seen as having towards animals. Fern's tactic, like White's, is to align herself rhetorically with the animal in order to force her father to acknowledge the artificial separation between animal and human. "The pig couldn't help being born small, could it?" she argues. "If $I$ had been very small at birth, would you have killed $m e$ ?" (3). John maintains the boundary between human and animal, replying that "this is different. A little girl is one thing, a runty pig another" (3). Fern reiterates that there is no appreciable difference and her father, who clearly does not relish the task anyway, gives in to Fern and brings the runt into the home. According to Ashraf Rushdy, what Fern offers her father is "a new way of determining the bonds and boundaries of community" (53), one that can encompass the meat animal. This exchange between father and 
daughter lays out White's objective for the novel, which continually undermines the established structures that alienates and disempowers the meat animal.

Though John is ostensibly merciful, White's immediate description of the kitchen smelling of, among other things, bacon, implies that the little pig has only been granted a temporary reprieve (3). The evocation of food terminology, however, further underscores the nature of our relationships with food animals. Echoing White's juxtaposition of the saved runt and the scent of bacon, Haraway acknowledges there are "necessary, hard, ethical and political questions" inherent to the act of eating animals (When Species Meet 295). There is, she contends, no way to eat and not to kill, no way to eat and not become with other mortal beings to whom we are accountable [....] Because eating and killing cannot be hygienically separated does not mean that just any way of eating and killing is fine, merely a matter of taste and culture. (295) White's inclusion of bacon in an opening scene in which a live animal has been brought symbolically into the home deftly implies that there is a culturally marked difference between the living animal and its function as food. As Carol Adams observes, moreover, the act of transforming a live pig into breakfast is not only enacted by the death and dismemberment of the animal, but by the re-naming of the inert parts. Live animals are, she argues, "the absent referents in the concept of meat[....] When we eat animals, we change the way we talk about them, for instance, we no longer talk about baby animals, but veal or lamb" (51-53). In accord with Adams's insight, White's reference to the scent of bacon permeating the novel's opening scene establishes an ethical conundrum 
between meat and animal subjectivity that the remainder of the novel attempts to unravel.

Fern's treatment of Wilbur as a human baby does not effectively challenge her father's view of the pig's destiny. As Wilbur thrives in Fern's care and grows large enough to sustain himself, John becomes adamant that the pig must be sold, as it is costing too much in food and upkeep. His wife negotiates a compromise, suggesting that "Uncle Homer" Zuckerman might take Wilbur and allow Fern to visit him in the barn (12). Once sold and relegated to the barn, however, Wilbur no longer benefits from his status as a beloved pet. White compensates for this by moving the narrative from Fern's point of view to Wilbur's. Though Lucien Agosta positions the Zuckerman barn as idyllic and life-affirming $(81,85)$, the mundane loneliness of Wilbur's existence actually underscores the differences in the human treatment of companion-species animals and food animals. Masson notes that "pigs were rarely seen as companions," even on small, family-owned farms (Pig Who Sang 32). In the novel, Fern can visit Wilbur under his new identity as livestock, but she is no longer allowed to relate to it as a friend or a human baby. This forced separation is the cultural means of ensuring her acceptance of Wilbur's status as a meat animal. In the original edition of the novel, Garth Williams's illustration of Fern watching Wilbur in the barn reinforces the segregation of the meat animal from not only the human, but also other livestock (White 14-15). Peering over a fence at her old friend, Fern is flanked by a sheep on her right and a goose on her left, suggesting a cross-species community. Indeed, as per Williams's design, the girl is separated from Wilbur not only by a wooden division, but also by the very gutter of the 
page. Williams would have been well aware that his illustration had to work around the intrusion of the gutter. What he does is effectively isolate the pig on one page, while allowing all the other living beings to stand as a community on the other, contributing to the subjectivist politics of White's own narrative.

Fern resists her indoctrination as a meat eater, frequently visiting the barn to observe the animals, gaining their trust and becoming privy their conversations and subjectivity. One discussion that Fern does not overhear is Wilbur's introduction to Charlotte the spider. At the end of what Wilbur considers the worst day of his life thus far, a small voice from "out of the darkness" (31) offers the kind of friendship and comfort he previously experienced as Fern's pet. White undermines the false idealism of this happy interlude, however, by setting Wilbur up as already entangled in the web of ideological structures pertaining to the eating of animals. Wilbur is aghast that Charlotte kills and eats flies, but fails to realize, as the goose contemptuously thinks to herself, that "Mr. Zuckerman and Lurvy are plotting to kill him" around Christmastime, so that Wilbur's dead body will provide meat over the winter (40). As Levinas points out, eating is not necessarily reducible to "the chemistry of alimentation" (128); but rather, "the act of eating involves above all $[\ldots]$ the way the I, the absolute commencement, is suspended on the non-I" (128-9). In other words, the consumption of flesh positions the eater as a subject, and the consumed as a "thing." Because Charlotte kills and eats her own flies, she is a consuming subject and, as such, has the ontological authority to stand in for White in order to save Wilbur. 
Charlotte's authority is reinforced in the episode in which the old sheep lets Wilbur know of his impending murder. The pig and the spider have been friends long enough for Wilbur no longer to be bothered by the deaths of unsuspecting flies; in fact, he finds Charlotte's insect pain management admirable (48). By normalizing the killing and eating of insects, White increases Wilbur's shock at finding out that he himself is to be killed and eaten. The old sheep tells Wilbur that his destiny is to be "smoked bacon and ham [...] Almost all the young pigs get murdered by the farmer as soon as the real cold weather sets in" (49). Fern, in the barn visiting, is attuned to Wilbur's anguish and becomes tense and upset because, as Griffith notes, "creatures who speak the same language as the author and his readers have souls; that is to say, their deaths are just as significant as the death of a human being" (45). For Fern, Wilbur's impending doom is especially upsetting, as she had naïvely assumed that, by rescuing Wilbur from her father's axe, he would be safe forever. Williams's illustration for this conversation between the pig and the sheep depicts Wilbur's distressed reaction, with the informant looking on in a disapproving fashion at the pig's display of emotion (White 50). Williams captures the sheep's sense of superiority and self-righteous distancing from the meat animal, while maintaining the visual distinction between Wilbur and the rest of the animal community by depicting the sheep on the opposite side of the fence.

In Charlotte's view (as in White's own), the secrecy around the animal's scheduled death is a form of unethical betrayal. Charlotte's challenge, then, is to make Wilbur's subjectivity manifest to the Zuckermans and the larger human community through the appropriation of human language. As Adams notes, the carnophallogocentric 
power structure is maintained by the double distanciation of the living animal through language. Just as the dead animal becomes meat; the living animal is further denied subjectivity through objectifying pronouns such as "it." In Adams's formulation, "the generic 'it' erases the living, breathing nature of the animals and reifies their object status" (75). ${ }^{36}$ Both living and dead animals in this worldview are continually denied subjectivity in order to enact the noncriminal aspect of the death of the animal for human consumption. Similarly arguing for the transformative power of language, Agosta posits that words "operate as true miracles in our world. They call things into being that did not exist before. They transform and create. Language is the creator of reality and is responsible for the formation of a self" (99). Just as words can deny subjectivity to the meat animal, Wilbur's subjectivity can be made legible to the novel's human characters by Charlotte through the power of language. Griffith argues, however, that, if Charlotte's efforts on his behalf revealed

that Wilbur is a person (which would presumably lead to the greater revelation that all animals are people), and therefore that to kill him would be murder, presumably her web-words would be very different: something like "Wilbur has a soul!" or "Meat is murder!" But she proposes to leave people in their misconception that animals are mere things, and to save Wilbur by convincing them that he is a wonderful thing, a thing worth saving. (Salvation 48) What Griffith overlooks is that White himself has already characterized the act of killing an animal as murder, in both the text itself and the essays surrounding its conception. Becoming a writer in her own right, Charlotte functions as a voice for White himself, 
using language to highlight the plight of a single animal by startling the humans out of their complacent thoughts about animals.

Despite the subtlety of his exploration into carnophallogocentrism, White ultimately gets trapped in the web of discourse politics. Toward the end of the novel, the author reinforces entrenched human attitudes toward animals when he contrasts a "radiant" (114) Wilbur with the common vulgarity of "Uncle," the pig against whom Wilbur is to compete for the blue ribbon at the fair. Though of the same age and anthropomorphized in the same fashion as Wilbur, Uncle is depicted by Williams as much larger and more grotesque, even more adult. Uncle is covered in coarse, shaggy hair and the downward slope of his eyes makes him appear dull and stupid (White 135).

Although his name implies that Uncle is the member of a human family or community, it distances him as well since, unlike "Wilbur," it is not an actual name, but instead a descriptive signifier, signalling a degree of separation from the nuclear family. At the same time, the name adds a further element of adultness that counters any potential sympathy that the young reader - meant to identify with the perpetually childlike Wilbur - might develop for the second pig. Charlotte's conversation with Uncle similarly renders him an unsympathetic character. According to the spider, he is "too familiar, too noisy, and he cracks weak jokes. Also, he's not anywhere near as clean as you are, nor as pleasant. I took quite a dislike to him in our brief interview" (135). By contrast, Wilbur is an exceptional individual, worthy of Charlotte's (and the reader's) efforts on his behalf. White thus undermines his arguments for an inclusive notion of animal subjectivity by presenting a second individual pig that reinforces negative 
porcine stereotypes of filth, stupidity and indolence. In short, White sacrifices all the others of the porcine species in order to ensure the safety of his hero.

In Charlotte's Web, White can be seen as ultimately reinforcing the carnophallogocentrism of which he was so critical both in this novel and his other writings. He rhetorically encourages his readers to animal husbandry and stewardship, but only insofar as the nonhuman animal remains a potential resource. Despite his acknowledgement that meat entails murder, the author is not actually out to unravel the false logic of the dominant paradigm so much as to express regret that Western rhetoric around the death of the food animal works so hard to disguise itself. Charlotte's web, in this sense, is the web in which White finds himself entangled - that of a discourse already engrained in his humanist sense of self and thus already structured to counter-act any individual's attempt to speak outside of its essentialist façade of human privilege. In my next chapter, I turn my attention to an animal collective, with a particular emphasis on Robert C. O'Brien's efforts to account for animals as species, not as individual subjects, in order to move beyond White's ultimately circumscribed presentation of subjectivity as benefiting only a singular, exceptional animal. 


\section{Chapter Four:}

\section{Science, Species and Subjectivity}

\section{in Mrs Frisby and the Rats of NIMH and The Secret of NIMH}

To speak of "enhancement" already espouses a particular value judgment as to the role of science and technology $[\ldots]$ and uncritically enrols a transhumanist promise of technological inevitability. (49)

Richard Twine, Animals as Biotechnology

Despite its continued popularity as both a novel and a film, Robert C. O'Brien's Mrs. Frisby and the Rats of NIMH (1971) has received limited scholarly response. To date, the analyses that have appeared focus primarily on the novel's pedagogical applications in a classroom context. Richard Seiter, for example, posits that O'Brien's "animal fantasy extols the importance of reading" for children ("Hollywood" 51). Paula T. Connolly similarly examines the novel as a "sophisticated presentation of moral issues and characters in children's literature" (73). Some scholars, however, have foregrounded the work's relevance to animal-related issues. Robin Murray and Joseph Heumann have recently approached it in the context of ecocriticism, contending that the filmic adaptation, The Secret of NIMH (1982), paved the way for more recent animated features with environmentalist themes (77). Murray and Heumann are correct in pointing out that "animals deserve rights because they so resemble us" (77), but their analysis deprioritizes the ethical concerns raised by the novel's and film's explorations of the 
creation of genetically enhanced rodents, creatures that would not otherwise exist outside of human intervention.

Not only do O'Brien's rats gain the ability to read and understand human language; they also adapt human tools and technology to assist in creating their own civilization. The author frames their nascent civilization as a utopia, where manual labour and communal efforts for survival will provide them with a meaningful existence as something other than vermin or parasites. While O'Brien's emphasis on the perceived virtue of hard work and stewardship of the land is laudable, his representation of the benefits of science and the uses of technology is far more ambiguous. Examining the politics of class, subjectivity and technology in Mrs. Frisby and the Rats of NIMH in the historical context of antivivisection politics reveals an ambivalence on the author's part regarding the centrality of rhetorics of evolution and technological progress in Western culture. Through an animality studies reading of Mrs. Frisby and the Rats of NIMH and its filmic adaptation, The Secret of NIMH, I question the limits of what subjectivity means in the texts and in the larger framework of Western culture. An analysis that accounts for the rats as a species, as I will demonstrate, this query problematizes enforced linguistic threshold between human and animal.

In my analysis of the NIMH texts, I build on my discussion in the previous chapter on Charlotte's Web, which addresses animal subjectivity in the context of edibility. More specifically, this chapter delves more fully into the "logos" component of Jacques Derrida's concept of carnophallogocentrism. Building on Derrida's argument, this chapter investigates the disturbances arising within the laboratory context, and how 
this experience is addressed in children's culture, and O'Brien's novel in particular. What Derrida and O'Brien both wish to problematize is the unquestioned assumption that, as part of a carnophallogocentric paradigm, animals are lacking in logos, the divine speech act. In O'Brien's formulation, the borders between human and animal are permeable and, moreover, are in continual flux, as we continue to use animals as experimental subjects. In my posthumanist reading of the text, I will demonstrate O'Brien's critique of the anthropocentrism inherent to traditional conceptions of the liberal humanist subject.

\section{Experimental Uses of Animals}

Animal experimentation in the name of scientific inquiry dates back to antiquity. As most ancient societies had strict prohibitions against the post-mortem mutilation of human bodies, animals became a natural alternative. Aristotle (384-322 BCE) in particular found it logical and expedient to enumerate overlapping physiological characteristics between humans and other species. He noted that many of the same attributes are present in many different kinds of animals, e.g. sleep, respiration, growth, deterioration, death, and in addition any remaining affections and dispositions such as these[....] It is apparent that, especially when speaking one by one, we shall repeatedly say the same things about many kinds; for instance, each of the attributes just mentioned belong to horses, dogs, and human beings. So if one speaks of their attributes one by one, it will be necessary 
to speak repeatedly about the same things - whenever, that is, the same things are present in different forms of animal, yet themselves have no difference. (2) Despite such recognition of the characteristics shared between the human and the animal, the prohibitions against dissection were not extended to the latter. Rather, they were considered to be lacking a rational soul, a lack recognized as grounds on which to deny them the same privileges proffered to humans.

Physician and anatomist Galen of Pergamon (130-201 CE), who was also forbidden by Roman law to work with human cadavers, extended Aristotle's work on dissecting dead animals to the act of dissecting living animals, or vivisection, to observe their systems in action. Galen's work is particularly notable for its detailed observations on the circulatory systems of many different species, and for its Stoic indifference to the pain and suffering of his vivisected subjects (Maehle and Tröhler 15). Galen's ideas dominated the emerging practice of Western medicine, with his masterwork $O n$ Anatomical Procedures (written in the second century) continuing to be copied through the Middle Ages, albeit with limited distribution. When it was finally translated from Greek into Latin in the 1530s, it re-popularized anatomical studies and vivisection as a means by which to further the profession of medicine.

However popular Galen's methods became, it was not until Andreas Vesalius took up his visiting professorship at the University of Pisa in 1544 that existing anatomical doctrine was challenged. Dawn McCance characterizes Vesalius as a modernizing force, dismissive of the traditional anatomy lesson as a demonstration of the classical authority of the text (70). Prior to Vesalius, dissection was not performed by 
the anatomist himself; a sector, or barber, performed the dismemberment as instructed by the lector, who read the instructional textbook aloud from a podium situated at a distance away from the cadaver (McCance 68-69). This ritualized activity was performed not to produce new knowledge, but in order to illustrate and reinforce the authority of ancient texts. Vesalius's push to work on human corpses and living animals with his own hands was a challenge to the traditionally accepted superiority of the text to actual anatomical practice.

The most groundbreaking work in Renaissance physiology was performed by William Harvey, who, like Vesalius, originally studied anatomy at the University of Padua. In 1628, Harvey published a refutation of Galen's claims that the blood only moved back and forth in the blood vessels, replaced by fluids from the liver. By vivisecting his own animals, Harvey proved conclusively that the blood circulates throughout the body, with the directional flow controlled by the blood vessels. Though Harvey, like Aristotle, took a holistic approach to the body and believed that life could not be reduced to its mechanics (Guerrini 33), his most significant legacy was proving conclusively that the heart was responsible for pushing the blood through the circulatory system. Harvey's work reconfigured the heart as not the seat of intelligence, sensation and the soul, as had been generally believed, but as a mere mechanical pump. His argument was seized upon by the emergent mechanical philosophers to prove that all life was, in fact, a technology. One such scholar was René Descartes.

Influenced by the natural world and the early field of engineering, Descartes used the machine as a model to demonstrate "how all animal life, and a good deal of human 
life, are strictly a matter of engineering, and potentially, trompe l'oeil'' (Senior 62). Enamoured of the popular novelty automata tableaux constructed on French country estates, Descartes asserts that, if there existed machines that possessed the organs and outward form of a monkey or some other animal without reason, we should not have any means of ascertaining that they were not of the same nature as those animals. On the other hand, if there were machines which bore a resemblance to our body and initiated our actions $[, \ldots]$ we should always have two very certain tests by which to recognise that, for all that, they were not real men. The first is, that they could never use speech or other signs as we do when placing our thoughts on record for the benefit of others[.... And the second difference is, that although machines can perform certain things as well as or perhaps better than any of us can do, they infallibly fall short in others, by which means we may discover that they did not act in knowledge, but only from the disposition of their organs. (115-16)

Descartes's philosophy explicitly aligns animals with machines, reorganizing the natural world into a series of mechanical parts that could only be understood by human reason. Speech acts, including thought and writing, are of crucial importance to Descartes as the exclusive purveyors of the cogito - the philosophic notion that one's existence is proven by the fact that one thinks. As such, speech acts became the means by which to divide the exclusively human from the animal, radically changing how animals would be perceived in relation to humans for centuries. The ancients had, of course, denied reason to animals, but reason itself had not yet been conceptualized as the cogito. Human 
mastery over the natural world, then, was achieved through the explicit subjugation of animals by denying them speech and subjectivity. McCance positions the opposition to granting "real speech" to animals as reconfiguring and determining the boundaries between human and nonhuman to the present day (74), something that O'Brien subverts in Mrs. Frisby and the Rats of NIMH in order to problematize discourses on human language as serving as evidence of a fundamental form of subjectivity.

\section{Technologies of Pain, from Anti-Vivisectionism to NIMH}

As I outline in my first chapter, the denial of speech as a means by which to subjugate the animal was circumvented by Jeremy Bentham in the late-eighteenth century. By asking, "can they suffer?" (311), he changed the foundational premise on which species distinctions had been formulated. By foregrounding the moral importance of animal suffering, Bentham played a crucial role in the early animal rights movement, and particularly in debates around vivisection. The practice was so common that it rapidly became synonymous with experimental uses of animals in general, thus making it a touchstone for the full spectrum of animal rights issues being put forward.

Manifesting a heightened awareness to pain, opponents of vivisection presented "an alternative model of social progress in which the evolution of emotional sensitivity to suffering is central" (Mayer 411). This was based largely on sympathetic observations of humans' emotional kinship to domestic pets. The educator and children's author Anna Barbauld even easily extended this sympathetic paradigm to non-domestic animals, drafting a poem about a mouse captured by her friend, the natural philosopher Joseph 
Priestly. The mouse was intended for use in an experiment, but Barbauld's poem inspired Priestly to free the rodent. "The Mouse's Petition" (1773) was quickly claimed by the emerging antivivisection movement to be a scathing indictment of animal experimentation (Bellanca 48). The piece presents the point of view of the "pensive prisoner," who pleads not only for his own freedom, but an overarching compassion for animals in general. The mouse warns, "Beware, lest in the worm you crush / A brother's soul you find / And tremble lest they luckless hand / Dislodge a kindred mind" (28). While the poem makes reference to compassion several times, the reference to a "kindred mind" recalls and subverts Descartes's concept of the cogito, implying that animals are, in fact, thinking subjects. As such, the image of the caged animal awaiting the vivisector evokes a complex cultural move to explore sympathy with and kinship to animals outside of a Cartesian worldview.

Despite advocating against cruelty to animals in her educational literature for children, Barbauld was not an overt agitator for animal rights. She was, however, instrumental in presenting topics in natural history to a juvenile audience. As an instructor at the Palgrave School, she instructed her students in geography, history of government, manners and the natural history of animals (Ferguson 120). With her work specifically geared to a juvenile audience, Barbauld was contributing to the new genre of "natural history." Paradoxically, the field of study, and Barbauld's contribution to it, ultimately reinforced the subordinate status of animals, as well as any humans aligned with them. As Gilles Deleuze and Félix Guattari have noted, natural history has remained "concerned primarily with the sum and value of differences" (234). As Harriet 
Ritvo frames the discipline's agenda, natural history construed the "animal kingdom, with man in his divinely ordained position at its apex, offer[ing] a compelling metaphor for the hierarchical social order, in which the animals represented subordinate human groups" (81). Ultimately, despite its investment in enhancing human understanding of other species, the field of natural history provided a scientific rhetoric that further entrenched the inferior status of animals, a distinction rooted in denying them reason and language.

In Frankenstein (1818), Mary Shelley undermines the discourses that maintained that animals were subordinate to humans, notably those discourses that upheld the scientist or natural historian's right to use animals as experimental tools. Shelley's novel is often portrayed as taking an anti-science stance, but positioning the text as explicitly against science ignores how the author negotiates between the differing views on science, technology and progress. As Christa Knellwolf and Jane Goodall posit, the eponymous hero is "torn between two kinds of vision" (8), on the one hand benefiting from the advancements of technological innovations such as the electric current, while on the other aligning himself with the more ancient discipline of metaphysics. This tension is reflected in the hybrid nature of Frankenstein's creation. Neither fully human nor fully animal, the creature is comprised of a mixture of human and animal parts that Frankenstein gathers in "charnel-houses," "slaughterhouses" and the "unhallowed damps of the grave" (53). Frankenstein's creature, like O'Brien's augmented rats, is a life form that, if not for human intervention, would not exist in nature. Unlike the rats of NIMH, however, the creature turns out to be (in Frankenstein's horrified opinion), a 
"demoniacal corpse" (57), lacking in any semblance to humanity. Tellingly, it is the creature's "inarticulate sounds" (57) that drive the scientist to flee in terror. Like Descartes's automaton, the creature possesses the capacity for speech, but cannot articulate its thoughts in a manner Frankenstein can comprehend. The being's acquisition of language over the course of the novel evokes the civilizing process human children also undergo, engendering reader sympathy for this human/animal creation. Indeed, in a letter to Henry More, Descartes describes pre-language infants as essentially human, because of their potential to gain language and reason as they grow and develop (qtd. in Wilson 498). They are given honorary human status here not because of their promise of developmental cogito, but because other humans recognize them as suggesting promise through their physical similarity. In the Romantic period, Shelley's sympathetic portrayal of an unjustly abused "creature" with signs of promise contributed to a growing resistance to the Cartesian view of animal subjectivity.

As part of this resistance, animal advocate and founding member of the Society for Prevention of Cruelty to Animals (SPCA) Lewis Gompertz lamented that scientists espoused the Cartesian view of animals as beast-machines to excuse the pain inflicted during experiments. In his opinion, natural philosophers

frequently forget themselves on this subject, and relate, with the greatest indifference, the numerous barbarous and merciless experiments they have performed on the suffering and innocent brutes, even those which show affection for them; and then coldly make their observations and calculations on every different form in which the agony produced by them manifests itself. (29) 
According to Gompertz, while cruelty to animals was not unique to the lower classes alone, the educated classes should certainly have known better. The subjugation of animals, however, functions to reinforce their life of privilege.

Gompertz, moreover, offers parallel arguments regarding the treatment of both women and the poor. He contends, for example, that men enforce the subordinate status of women, but then "despise them for the want of that knowledge [education] and that honour of which they have deprived them; and even prevent their having any share in the formation of the laws of society" (62); the result is an adversarial relationship that places women at a distinct disadvantage. He similarly contends that the poor are not to be seen as defective or lacking in character, but instead are to be recognized as exploited by the rich. Gompertz goes on to liken the "difference in rank" between rich and poor to the differences between human and animal, opining that "there arises a great degree of evil to all classes of men, which in justice to man must not be overlooked in the comparison between him and brutes" (58-59). Thus in espousing rights for animals, Gompertz is careful to note that women and the poor must not be overlooked. ${ }^{37}$ Of equal importance, his rhetoric envisions the abuse of animals not as a unique issue, but as a situation operating within a much larger technology of oppression.

The antivivisection debates are thus reflective of equally fraught debates about class in Victorian society. As a working knowledge of anatomy and natural philosophy was considered a "badge of genteel culture" (Fara 8), proponents of vivisection opened themselves up to accusations of class advancement on the backs of defenceless animals. Medical men in particular were keen to improve the standing of their profession, which 
was dogged by allegations of butchery and quackery, lagging behind mathematics and natural history or philosophy as a legitimate pursuit. As I argue in my first chapter, the middle class had a vested interest in maintaining a social hierarchy in which the poor and others that they saw as undesirable were kept in their place. The middle class was guarding itself from infiltration from those who were using vivisection as a shortcut to the trappings of gentility. ${ }^{38}$

The anti-vivisection movement was bolstered further by the work of Charles Darwin and the discussions arising from his claims. Evolutionary theory emphasized the animal origins of human beings, calling into question long-held beliefs of human superiority. Darwin's theory of "expression," an espousal of the validity of communicative forms exhibited by animals (such as body language), further destabilized boundaries between animal and human, making "the human more animal, and the animal more human" (Morse and Danahay 2). Jed Mayer contends that this destabilization provided a "biological foundation for the era's culture of compassion" (402), bringing humans both biologically and philosophically closer to the animal than ever before. According to Darwin, as long as man and all other animals are viewed as independent creations, an effectual stop is put to our natural desire to investigate as far as possible the causes of expression. By this doctrine, anything and everything can be equally well explained; and it has proved as pernicious with respect to expression, as to every other branch of natural history. (19) 
Darwin's objective to reconcile the universality of emotional expression across species and races suggests that animals have communicative modes that are as valid as human verbal language. Antivivisectionists felt that Darwin's theories added scientific authority to their presentation of animal suffering as ethically relevant, undermining provivisection assertions that an emotional response and connection to animal suffering was lacking in merit. ${ }^{39}$

Sustaining Barbauld's positioning of animal rights within youth culture, Darwin's theories of expression and evolution also found a home in children's literature of the period. Perhaps most notably, Charles Kingsley’s The Water Babies (1863) effectively incorporates Darwin's espousal of a fluid human-animal continuum into a narrative of a child's self-realization. In the story, Tom, a young chimney-sweep, falls into a river and is transformed into a water baby, or a sort of human-tadpole hybrid species. As such, Tom is neither fully human, nor fully animal. Anne Chassagnol contends that Kingsley translates Darwin's challenge to human superiority by "transposing the vertical hierarchy of the great chain of being along a horizoental stream" (n.p.), with the protagonist encountering not only other animals but also strange and fantastical creatures that utterly undermine any effort at a clear structural model of species categorization. At the same time, other Victorianists were chipping away at the legal discourse that had been so cleanly separating humans from other species in an effort to sanction their lack of a sense of responsibility to them.

In 1876, the Royal Society for the Prevention of Cruelty to Animals (RSPCA) successfully lobbied for legislation that would extend the prohibitions against animal 
cruelty to livestock established in Martin's Act (1822) to domestic animals intended for use in scientific experiments. This did not ban the practice of vivisection, but at least restricted how and under what circumstances it could be performed. The AntiVivisection Act made it illegal to experiment on animals for public exhibition. Moreover, experiments could now legally only be performed by a licensed practitioner. Further, the use of anaesthetic was mandatory, and an experiment had to be halted immediately if the effects of anaesthesia wore off before the event's conclusion ("Cruelty" n.p.). The measures were only a partial victory, as the Act was often difficult to enforce. Experimental activity was often conducted behind closed doors, unlike, for example, the very public activity of driving livestock to market that inspired Martin's Act decades earlier. To maintain this level of secrecy, those interested in conducting animal experiments found it most efficacious to work on small, easily obtainable mammals, preferably those that other humans would not miss. Rodents were found to be ideal for such purposes.

Though humans and rats have cohabitated for millennia, the rat - unlike the horse, dog or pig - has never been seen by humans as providing a use and never been domesticated to any notable degree. Nor has it managed to garner any general positive sentiments. Seen as subsisting primarily on garbage and carrion, rodents seem to have always been considered unclean, despite the value of the waste disposal services they performed. Historically characterized as "hateful and rapacious" (Barnett 5), by the Middle Ages rats were further degraded in public opinion as "portents of evil" aligned with malignant supernatural forces, most likely stemming from the supposition that they 
were carriers of the plague (6). ${ }^{40}$ Like rodents, the plague thrived in an urban setting, where poor sanitation, overcrowding and extreme poverty constituted an ideal breeding ground for mass contagion. This cemented the rat's association with filth, violence and squalor. Living on the fringes of human society, neither fully wild nor fully domesticated, the rat became emblematic of all the problems associated with the city. Even rural rodents have been similarly characterized as an unpleasant species. In Charlotte's Web, for example, Templeton the rat is portrayed as belligerent and selfcentred. Though ultimately Templeton is crucial in saving both Wilbur's life and Charlotte's egg sac, he is only persuaded to help by appealing to his enormous appetite, and is depicted in one of the novel's last illustrations as having grown quite corpulent on the choicest morsels of Wilbur's feed.

As Samuel Anthony Barnett contends, rats are undeserving of their negative reputation. Intelligent and readily adaptable to their surroundings, they develop highly sophisticated social structures and kinship units, not unlike humans. These qualities, along with their rapid reproductive cycles, made them attractive to scientists and researchers who, due to enormous public outcry, found it increasingly difficult to defend their experiments on other common mammals such as cats and dogs. In 1895, at Clark University in Massachusetts, the first domesticated white Norway rats were brought into the laboratory as "models for the study of human physiology" (Barnett 21). Unlike companion animals, rodents had few advocates to speak against their inclusion in laboratories, and their small size and easily facilitated breeding made them ideal laboratory denizens (Birke et al 25). 
As a researcher with the psychology laboratory at the National Institute of Mental Health (NIMH) in the mid-twentieth century, John B. Calhoun was well aware of the cultural burdens carried by rats; in fact, it drove his rationale for choosing rats as his experimental subjects. In 1947, Calhoun built a rat enclosure on his neighbour's property to explore what he determined would be the detrimental effects of large populations confined to a small, restricted space over time. His paper, "Population Density and Social Pathology" (1962) achieved iconic status, largely by reaffirming popular conceptions of the overcrowded urban slum as a hotbed of deviance and pathology. Over the course of many rodent generations, Calhoun observed long-traumatized rats congregating in clusters of violence and squalor, which he characterized as behavioural sinks (Ramsden and Adams 763). The term "sink" had been used since the sixteenth century to refer to a uniquely urban concentration of poverty, filth and brutality. By forcing his rats into ever-increasing forms of pathological behaviour, including gang violence, social withdrawal, indifferent parenting and atypical sexual activities, Calhoun's experiments served to force his rats to model the breakdown of modern society. By using the "culturally tainted" rodent as his experimental subject (Ramsden and Adams 768), Calhoun magnified the impact of his research on the popular imagination, and his ideas were then oversimplified and sensationalized further by the journalistic community. The counterculture artists and writers of the 1960s and 70s, such as Anthony Burgess and Robert Silverberg, seized on the concept of the behavioural sink in particular. The exaggeration of the dystopian conclusions eclipsed Calhoun's later 
work, which posited that some rats, led by marginalized or subordinated groups, exhibited previously unseen levels of creative and adaptive behaviours and tool usage. Though Calhoun's reputation through the 1970s was more often than not associated with science fiction than actual science, the scientist still had one remaining fan. Robert C. O'Brien, under his real name Robert Leslie Conly, toured Calhoun's lab at NIMH in the late 1960s in his capacity as an editor for National Geographic magazine. ${ }^{41}$ With such an interest in NIMH, O'Brien clearly would have been aware of the impact of Calhoun's work. Playing on existing assumptions about rats, O'Brien offers an extension of the issues explored roughly a century earlier by Darwin and Kingsley.

\section{Species and Subjectivity in Mrs. Frisby and the Rats of NIMH}

In The Animal That Therefore I Am, Derrida questions language as the site of demarcation between the human and the non-human animal, as posited by philosophers from Descartes to Martin Heidegger. Descartes is particularly clear in his assertions that the animal is akin to an automaton, capable of reacting to stimuli, but not capable of responding with a speech act, as a human would do. Derrida, however, questions whether we as humans can define or even understand what "respond" means, and how response can be fully distinguished from reaction (8). According to Akira Mizuta Lippit, Derrida seeks to "uncover the traces of animality that are embedded in language, arguing that the animal that Descartes vehemently censured as irrational machines or speechless 'automata' nonetheless remain inextricably linked to discourse on human language" 
(15). Derrida questions post-Cartesian thought that positions human mastery over the animal as stemming from the denial of reason and language to the animal. What Derrida challenges is the assumption that, as part of a carnophallogocentric paradigm, animals are lacking in logos, the divine speech act. As O'Brien effectively demonstrates, the borders between human and animal are permeable and, moreover, are in continual flux, as we continue to use animals as experimental subjects.

By following O’Brien's lead in how an animal civilization would manifest itself, I am able to articulate his espousal of a model of animal subjectivity aligned with current posthumanist scholarship, a model that contradicts anthropocentric analyses of the novel and film to date. An animality studies approach to the NIMH texts incorporates "a historical lineage of ideas that have served to decentre the human, which, as Derrida points out, include the Copernican revolution, the Darwinian recapture of the human to the animal kingdom and the Freudian questioning of a human subject in control of itself" (Twine 12). Expanding on Derrida's paradigm of carnophallogocentrism examined in my third chapter, I aim to address the innovations of O'Brien's original text and the limitations of Don Bluth's filmic adaptation, The Secret of NIMH. The novel promotes a notion of animal subjectivity at odds with Bluth's vision in the film, which reformulates the story as part of the overarching Western conception of animals lacking speech and reason.

According to Derrida, subjectivity, historically situated by Descartes in language, or logos, is granted to the virile adult male over women, children and animals ("Eating Well" 114). Derrida works to explicitly and specifically undermine the presumption of 
"uniquely human access to the symbolic realm of language" (Desmond 241) in order to call attention to the arbitrary nature of the criteria that humans espouse in order to divide themselves from the animal. Derrida's questioning of the right of humans to construct a model of subjectivity built specifically on the animal's perceived lack of language assails every Western philosopher since Descartes, who assumed human superiority over animals is both situated in language and divinely granted.

The same set of assumptions and declarations of authority are played out quite differently in O'Brien's novel. Mrs. Frisby and the Rats of NIMH encompasses two separate but interconnected narratives. The reader is first introduced to Mrs. Frisby, a widowed field mouse, and her family. Her young son Timothy is gravely ill with pneumonia, and must be confined indoors until his lungs are healed. Compounding Frisby's dilemma is the early arrival of spring weather, meaning that their cinderblock home is in immediate danger of being destroyed by Farmer Fitzgibbon's plough. Mrs. Frisby is advised by the wise owl in the woods to seek out the rats who live under the Fitzgibbon rosebush for assistance in moving her residence to safety near a large boulder. The rats, meanwhile, have been keeping a secret from their farmyard neighbours. As Nicodemus, the ostensible leader of the rats, reveals to Mrs. Frisby after she approaches them for help, the rats, as well as her deceased husband, are escapees from the laboratories of NIMH. In the lab, the rats and mice were injected with "new DNA" (118) and taught to read human written texts. ${ }^{42}$ Their enhanced abilities also include engineering and tool use. As Mrs. Frisby learns more about their background, 
the reader becomes increasingly implicated in "The Plan of the Rats of NIMH" (82) to establish their own civilization in an isolated valley, away from human interference.

O’Brien's interwoven narrative presents a unique model of interspecies interdependence. Unlike, for example, Jack London's wolf-dogs, or Wilbur the pig, the rats in the novel remain distanced from the human world, rejecting a companion-species relationship with the few humans they encounter in the course of their travels. Indeed, the rats specifically and deliberately work to discourage the individuality that such a relationship would require; instead, they minimize distinctions such as rank or even political power. In their egalitarian society, the rats vote on important issues, with no one rat's voice carrying any more weight than another. As such, they constitute what Deleuze and Guattari call a "multiplicity" (32); a nonhierarchical aggregate, or a means by which to engage in subjectivity without individual subjects. In the novel, the rats as a species serve a more important function than any one rat. As Nicodemus tells Mrs. Frisby when they first meet, though each rat has a job to perform, they deliberately dispense with titles (89). By presenting his rats as a unified collective, O'Brien avoids falling into the same rhetorical traps as does, for instance, E.B. White, who exceptionalizes a single individual at the potential cost of an entire species. As I argue in the previous chapters, the enforced conflation of the reader with the fictional animal does not result in an overarching acknowledgement for the fundamental subjectivity of all animals.

Alethea Helbig considers the emphasis on species and collective as a failing on O'Brien's part as a writer. She contends that, due to this focus on collectivity, the 
characters are "flat and static," and the multiple narratives constitute "a serious flaw" (205). What Helbig elides in her criticism of the novel is the centrality of the collective to O'Brien. She overlooks his overt emphasis on altruism and cooperation as a means of species survival, as well as how the author undermines the traditional means by which young readers are encouraged to conflate their own identities and experiences with any one exceptional animal character. While Helbig would prefer that the novel excise Mrs. Frisby altogether to focus solely on the rats' tale of capture and escape, such a drastic revision would result in the narrative itself breaking down entirely. However unlikely it may seem, the widowed mouse proves to be the pivot on which the narrative turns. Her activities motivate the web of interdependence around which the novel is structured. An initial act of kindness - setting free a crow caught in some string tangled in fence wire results in a reciprocal act of kindness on the crow's part. It is Jeremy the crow who, after hearing Mrs. Frisby's dilemma, recommends she visit the wise owl in the woods and flies her on his back to the owl's tree. The owl himself only agrees to help the mouse after he hears that she assisted Jeremy, and also reveals to her that, because of her husband, the rats in the rosebush may agree to help her (56). The rats indeed help the widow in honour of her husband's memory, as it was he who helped them through their last obstacle in their escape from the lab. Mrs. Frisby returns the favour by helping the rats drug the Fitzgibbon's cat (an activity that claimed the life of Mr. Frisby the preceding summer), so that they can safely move her home. Caught in the act and caged by young Billy Fitzgibbon, Mrs. Frisby overhears Farmer Fitzgibbon making 
arrangements to bulldoze the rosebush and exterminate the rats, and is thus able to warn them to hasten their move to Thorn Valley.

The circularity of the narrative reinforces the importance of reciprocity and communal efforts for survival, but it also serves to offer a conceptual trans-species model of the rodents' own social structure. No one species in the narrative is more important than any other. As with Kingsley's Water Babies, O'Brien's novel undermines the hierarchy of species, in this case specifically by downplaying the role of the humans in the text. Minimizing the presence of human characters allows O'Brien to sidestep an adversarial relationship between the humans and animals, which would only serve to reinforce species distinctions. The anthropomorphism of the characters, meanwhile, does implicitly acknowledge the presence of the reader, but it would be an assumption that goes against the logic of the narrative itself to assume that the novel's intended readers are humans and only humans. In fact, the communication of empathy across species disturbs the notion of any reader being exclusively human.

On the issue of the human/animal divide, Heidegger stands out for the vehemence with which he maintains the boundary between the two. He negatively characterizes the animal as poor in world (weltarm), compared to the human. It is "not a question of whether or how the animal takes what is given to it in a different way," he contends, "but rather of whether the animal can apprehend something as something, something as a being, at all" (383-84). For Heidegger, animals are, but do not exist; that is, they do not conceive of their existence in the world or indeed have any conception of the world at all. Animals demonstrate a fundamental lack of awareness of identity, of 
being-in-the-world (Dasein), a condition he explicitly links to human subjectivity. What Heidegger elides in his discrete conception of human and animal subjectivity is the "embodied nature of human existence, that Homo sapiens is a creature of the same biological origin as the plethora of species we label 'animal"” (Vint 8). In other words, Heidegger finds it convenient to reify human and animal boundaries to escape the full rethinking of their relations that an acknowledgement of animal subjectivity would require.

O'Brien addresses what can be seen as a Heideggerian reification of human/animal boundaries. In an episode just prior to the rats' escape from the laboratory, Nicodemus and Jenner discuss their future plans. The latter knows that they cannot go back to their original home, even if they could find it again:

"Do you want to go back to living in a sewer-pipe? And eating other people's garbage? Because that's what rats do. But the fact is, we aren't rats anymore. We're something Dr. Schultz has made. Something new[....] We're probably as intelligent as he is - maybe more. We can read, and with a little patience, we'll be able to write, too. I mean to do both. I think we can learn to do anything we want. But where do we do it? Where does a group of civilized rats fit in?" (137)

Both Jenner and Nicodemus intuit that, as rats, they are trapped within the dominant Western discourse on animals, which makes no allowances for animal subjectivity. At the same time, in this formulation, the rats of NIMH become the inheritors of a Victorian notion of progress stemming from and contributing to technological advancement. By 
virtue of their enhanced abilities, they are freed from the confines of a Cartesian view of animals as unthinking, unfeeling machines. Jenner believes that his community of rats has evolved, and that their enhanced intelligence and linguistic ability now make them superior to humans. With this perspective, however, he remains just as deeply invested in a notion of species hierarchy, albeit one that inverts a notion of human superiority.

The discord between species that Jenner wishes to reinforce for his own benefit can be usefully situated in what Giorgio Agamben terms zoe and bios. In Agamben's formulation, zoe, or "bare life" (4), is the biological state of being alive, the embodied condition of existence. Bios, meanwhile, refers to the laws and other cultural structures developed by humans in order to enact subjectivity and to establish tangible evidence of civilization. These laws are then used to demarcate the boundary between zoe and bios, or between animal and human (1). According to Agamben, Western politics and philosophy work to simultaneously include and exclude the concept of zoe from bios (5). That is, the bare life of animals is acknowledged in human law and philosophy, but only so that it can be explicitly excluded from a specifically human conception of subjectivity. In accord with Agamben, O'Brien presents a model of animal subjectivity that does not preclude the ability to form civilizations. In this context, Jenner's contention that the rats could easily become the dominant species highlights the limitations of a hierarchical model of species relations, a concept that Nicodemus and the other rats explicitly reject. After their escape from the laboratory, the rats spend their winter on a vacant estate reading books, practicing writing and eating stolen food. Even at this early stage in their newfound freedom, Nicodemus has grave misgivings 
regarding the ethics of their clandestine activities. He wonders why, "whatever we ate, whatever we needed, must always be stolen. Rats had always lived that way. And yetwhy?" (144). In order "to live without stealing," the rodents formulate the Plan of the Rats of NIMH (157).

Nicodemus's worries that the rats' continued theft in the service of their survival could be dismissed as a by-product of the genetic augmentation, if not for the opposing opinion put forward by Jenner. The latter does not believe that relying on stolen goods automatically makes their existence meaningless and empty. Despite Nicodemus's passionate espousal of a future in which the rats are completely self-reliant, Jenner remains unconvinced that they are ethically obligated to engage in generative or creative activities to forward their own civilization. He asks Nicodemus,

“But why? Why move? We've got a better place to live right now. We've got all the food we want. We've got electricity, and lights, and running water. I can't understand why everybody talks about changing things."

"Because everything we have is stolen."

“That's silly. Is it stealing when farmers take milk from cows, or eggs from chickens? They're just smarter than the cows and chickens, that's all. Well, people are our cows. If we're smart enough, why shouldn't we get food from them? [...] You've got this idea stuck in your head. We've got to start from nothing and build a rat civilization. I say, why start from nothing if you can start with everything? We've already got a civilization.” (175) 
In this dialogue, Jenner explicitly espouses the Western paradigm of subjectivity predicated on intelligence, reason and a facility with human language. By equating humans to livestock, moreover, he elides the humans' subjectivity and proposes that they become tools for the rats to use. Nicodemus and Jenner's disagreement is not merely a difference of opinion, but in fact exemplifies the distance between zoe, the embodied existence Nicomedus emulates, and bios, the culturally constructed notion of civilization which Jenner recognizes as superior (albeit based on a comparison to humans' sense of privilege).

In this formulation, it would be easy to follow Helbig in dismissing Mrs. Frisby's contribution to a notion of animal subjectivity. Possessing human language and the ability to create and use human tools, the rats have already undermined the logocentric conception of subjectivity represented in the novel. But by making Mrs. Frisby the central character around which the narrative revolves, O'Brien effectively displaces a phallogocentric model of subjectivity; instead he foregrounds Mrs. Frisby's animality and femininity consistent with the historical notion noted by Gompertz of the alignment of animals with both women and the poor within a larger technology of subjugation. O'Brien is notably careful in his opening chapter not to anthropomorphize his heroine overtly, instead emphasizing the Frisby home as a normal rodent burrow, lined with "bits of leaves, grass, cloth, cotton fluff and other sorts of things" collected by the female and her children (4). Unlike each of her children, moreover, Mrs. Frisby has no first name to individualize her; her identity is subsumed into that of her husband. It is entirely possible that she in fact does not actually have a name. As an animal, "deprived of language, one 
loses the power to name, to name oneself, indeed to answer [répondre] for one's name" (Derrida Therefore 19). According to Derrida, the act of naming is another means by which subjectivity can be enacted. O'Brien, by referring to his main character only by her married title, underscores her broader lack of subjectivity and agency. For O'Brien, however, this absence is not a site of subjugation but a signification of non-subjectivity that defines the female as the de-individuated nucleus of a trans-species collective. In this way, O'Brien (in an episode that has been overlooked in analyses of the novel to date) employs traditional gender and species expectations to extend a posthumanist model of subjectivity to all animals.

Using his heroine in this fashion allows O'Brien to problematize the value of literacy as a marker of human intelligence. After gaining entry to the rats' home, Mrs. Frisby must wait for them to finish a meeting in which they are strategizing their move to Thorn Valley. Looking for something to occupy her wait, the rat who ushers her in asks if she reads much:

"Only a little," said Mrs. Frisby. "My husband taught me. And the children..." She started to tell him how. Laboriously scratching letters in the earth with a stick - it seemed so long ago. (81)

Though not as proficient as her children, who have inherited their father's abilities, Mrs. Frisby is nonetheless able to read. Literacy and the capacity for human language thus become an issue of class and education, not the limits of biology. In O'Brien's formulation, not only are language and subjectivity not an exclusively human trait; they 
are not the sole province of the exceptional rats either, calling attention to the arbitrary nature of language as a means by which to deny subjectivity to the animal.

\section{Visualizing Logos in The Secret of NIMH}

In the film The Secret of NIMH, the conflation of animal with image undermines the centrality of reading and written texts that O'Brien foregrounds in his novel, thereby contributing instead to the conception of animals as lacking speech and reason. The filmic adaptation retains O’Brien's original narrative structure, albeit with a few disconcerting additions in the form of supernatural talismans. Don Bluth's Nicodemus is transformed from a pragmatic and engaged leader into a spiritual figure, spectrally divorced from the quotidian aspects of the rats' routine as they prepare for their move to Thorn Valley. Retaining a trace of the importance of literacy and human language, he keeps a magic self-writing journal. The text functions as a means by which to access the past, suggesting more a link to a historical civilization than a particularly innovative tool. Indeed, even this time-travelling capability is overshadowed by a large gyroscope through which Nicodemus can view events from past to present. He also possesses an amulet that shows him current events. In contrast to the rats in the novel, those in the film are aligned with futuristic technology, electricity and spiritualism, as well as the visual.

Bluth's shift from O’Brien's emphasis on the significance of human written language to a focus instead on the visual image utterly de-rails the de-individuating strategies of the novel. The disparate positions of O'Brien and Bluth are readily apparent 
in the works' depictions of Mrs. Frisby's first meeting with Nicodemus. In the novel, Nicodemus is anthropomorphized but he is illustrated as an average rat at home in his study (98). The room is cozy and well appointed, "elegantly furnished" (98) with comfortable chairs. The furniture replicates the Victorian upper-class study of the estate where the rats initially stayed after their escape from the laboratory. The table pedestal is ornately carved, as are the feet on Mrs. Frisby's chair. The books and other decorative objects represent both knowledge and wealth, but they are not ostentatious. The open book on the table has no function in the scene other than serving as a visual reminder of the centrality of the written text for O'Brien. Though Mrs. Frisby is depicted as smaller in stature, it is only insofar as a mouse would be smaller than a rat in real life, and not to imply any sense of inequality between the two rodents. The two appear as mutually appreciative colleagues, if not friends, echoing images from such earlier works as Kenneth Grahame's Wind in the Willows (1908) and A.A. Milne's Winnie-the-Pooh (1926).

The film offers a distinctly different sense of relationship and context. In Bluth's text, Nicodemus now sits on a throne in an uninviting, gothic space that seems to be nobody’s home. Mrs. Frisby (now called Mrs. Brisby) approaches the rat as a supplicant, referring to him as "Your Majesty" and performing a curtsey before he beckons her to approach. The curtsey calls attention to the ragged edges of her cloak, which is then contrasted with the heavy opulence of Nicodemus's robes as he partially stands to motion her closer. The strange cage-like structure around Nicodemus's throne visually reinforces his isolation. It is this very alienated space, moreover, that Bluth's version of 
Jenner takes advantage of in order to seize control of the rat parliament (yet another hierarchical structure that the film introduces into O'Brien's narrative). The film's underworldly aesthetic serves to underscores the source of Nicodemus's authority as both spiritual and disembodied, bypassing language altogether. After this introductory scene, Nicodemus allows Mrs. Frisby to read of her husband's death from his magical journal, then immediately afterwards calls up a vision with the gyroscope of how the rats and mice escaped from NIMH. The film's emphasis on the visual here and elsewhere can initially be read as suggesting Bluth's wish to demote the logos that Descartes and others relied on in their anthropocentrism. However, the film does not pursue this creative line of exploration any further. Meanwhile, O’Brien's subtle questioning of language as a point of demarcation between human and animal is simply erased.

The film departs in a second key way from O'Brien's original narrative. In the novel, the rupture in the collective - that is, the disagreement between Nicodemus and Jenner - leads to a separation but not a destructive conflict. In the filmic adaptation, however, their difference of opinion gives rise to an epic struggle for control of the magical objects, and the amulet in particular. Paula Connolly contends that the "problem of magic" (79) in Bluth's narrative dilutes O'Brien's core message of interdependence and an overarching subjectivity for all species. She rightly points out that this change comes "at the cost of transforming the central focus from community to independence, and even those depictions of independence become problematic" (81), particularly because the film proposes that power (and by extension, subjectivity) must be embodied by an object external to the rodent collective. By situating power in external objects such 
as the amulet, Bluth makes it possible for that power to be seized and held by a single individual, rather than shared among animals or species. The magical objects thus become a locus of contention between Jenner's worldview, in which hierarchy and his own authority must be maintained at all costs, and the collective view that espouses an egalitarian approach to species distinction.

In transforming the novel's depiction of interdependent communities into a struggle for political power embodied in a magical amulet, Bluth takes the ontological complexities that O'Brien interweaves in his novel to support his vision of an overarching subjectivity for all species, reducing it to a banal morality play about virtue triumphing over ambition. As such, the film disavows an expanded notion of subjectivity, without directly undermining the traditional humanist vision of subjectivity as situated in language. Avoiding O'Brien's difficult material, the film ultimately reinforces a traditional Western conception of the animal as lacking in subjectivity. O'Brien, however, emphasizes the collective aspects of subjectivity, thereby inviting an animality studies reading of his novel. In this way, the novel can be seen as addressing the failure of texts from Dick the Little Pony to Charlotte's Web, which sacrifice the subjectivity of an entire species in establishing the individualism of a singular animal with which the young reader can identify. In my final chapter, I wish to consider the impact of contemporary, mainstream representations of animal individualism when it is the animals - in this case, whales and dolphins - that are constructed as the very texts of entertainment themselves. 


\section{Chapter Five:}

\section{Performance and Personhood in Free Willy and Dolphin Tale}

Can whales "return the gaze"? To do so, they would have to possess a subjectivity capable of understanding themselves as both watcher and watched. This might be

going too far, but the question of the animals' subjectivity, which is heightened in so many ways throughout the park [Marine World Africa] and in a great deal of the popularization of the research on marine mammal intelligence, is interestingly brought to the fore. Do we grant them a subjectivity but not a consciousness, or a self-consciousness? (212-13)

Jane Desmond, Staging Tourism

Despite being enormously popular with filmgoers, neither Free Willy (1993) nor Dolphin Tale (2011) has received any scholarly analysis. To date, discussions of Free Willy have focused primarily on the real-life efforts to repatriate Keiko the killer whale ("Willy") to Iceland, an endeavour that cost millions of dollars and took the better part of a decade. As a film that promotes freedom for the captive performing animal, Free Willy foregrounds how entertainment facilities like Marineland and Sea World work to erase the history of whales and whaling, as well as disguise the fact that the animal is being held against its will and forced to perform. Dolphin Tale similarly makes use of the politics of animal performance to emphasize the slippages between subjectivity and captivity. As live animals that play fictionalized versions of themselves, Keiko and 
Winter the dolphin are caught up in discourses about the ethics of captivity and performance as the latest chapter in a long history of the exploitation of whales as a natural resource. Only in the last forty years have these marine mammals been culturally reconfigured from an exploitable resource into a special species from whom humans have so much to learn. To accomplish this reconfiguration, environmentalists called attention to the drastically low populations of certain species due to centuries of hunting. As part of their tactics, they encouraged children in particular to conflate their own identities with those of cetaceans, as representatives of the mysteries of the deep, a fusion that also drew the young to re-imagine whales and dolphins as subjects with a unique subjectivity worth saving from extinction.

An examination of the politics of animal performance in the context of historical changes in the whaling industry reveals an ambivalence about cetacean subjectivity in Western culture. Venues such as Marineland or Sea World make use of the uniqueness of whales in order to attract audiences who may not be able to observe them in the wild. Susan Davis and Jane Desmond have both recently examined marine parks in the context of cultural tourism, situating them in the history of zoos as a commodification of nature. Desmond in particular identifies Sea World's presentation of the orca body as simultaneously transgressing and upholding species boundaries; according to Desmond, Sea World does so by alternately foregrounding both their differences from and similarities to humans in the script of the animal show. In order to encourage audience identification, for example, whales are presented as independent subjects. That subjectivity, however, is undermined by the animal's performance of tricks on 
command. Due to the environmentalist movement, cetacean captivity has become unpalatable to contemporary audiences. Therefore, within the context of the show, the wild animals must be made to appear as though they are natural performers who love their job, thereby minimizing the negative aspects of their containment. By framing their trained behaviour as voluntary, Marineland, Sea World and other marine parks elide the ethical ramifications of the captives' lack of agency.

Through an animality studies reading of Free Willy and Dolphin Tale, I aim to consider the cetacean rights movement's proposal of a fundamental subjectivity and freedom from exploitation for all whales. The two films are predicated on the conflation of child and marine mammal identity, and each in different ways addresses the issue of captivity in the context of cetacean subjectivity in order to call attention to the need for legal acknowledgement of the personhood of these particular species. My previous chapter on the NIMH texts addresses animal subjectivity in the context of the aptitude for human language. This chapter builds on that argument, addressing more fully Giorgio Agamben's use of zoe and bios as a site of conflict between constructs of nature and culture. Building on Agamben's argument, this chapter will focus on the overlaps between the films and the actual lives of their cetacean stars, as well as how those overlaps are addressed in children's culture. It is my claim that these similarities champion not only the notion of legal personhood for the species in question, but the fundamental importance of extending that personhood to all animals. 


\section{Whaling and the Breaching of Individuation}

Though the Inuit and the Faroe Islanders have engaged in subsistence whaling for thousands of years, there is no evidence of large-scale or commercial whaling prior to the Basques leaving the Bay of Biscay in the early-fifteenth century. As the right whales they hunted migrated steadily north over the century, the whalers followed them past Scotland to Iceland and, by 1540, reached the eastern coast of Canada. With a monopoly on the industry, the Basques made an enormous profit purveying whale products on the European market. Flexible baleen, the bristle-like dentition growing from the upper jaw of several whale species, was used for women's foundational garments such as corsets and the hoops of underskirts. Whale oil, meanwhile, provided a lamp light that was superior to that provided by animal tallow. According to Eric Jay Dolin, the Basques were producing up to 500,000 gallons of whale oil annually (23). The enterprising whalers, however, could not hold their economic advantage. In 1611, the English were tipped off by explorer Henry Hudson to the presence of thousands of bowhead whales in the Arctic circle. Larger than the right whale, the bowhead not only produced more oil per foot, it also had the longest baleen of all the whales. Considered an "ocean-going cash cow" (Armstrong 23), the bowhead was hunted to near-extinction by the English and Dutch over the next 200 years.

While England and the Netherlands were fighting each other for control of the Arctic, New England whalers were making their first forays into the mid-Atlantic. Having made good use of dead whales washed up on the shoreline, colonists grew to depend on the oil they rendered from the corpses. As part of a worldview that held that 
the great whales were designed by God as a resource intended for human use (Scoresby 135), the colonists began to feel entitled to exploit the whale in increasing numbers. To this end, they took to small boats along the shoreline in the hope of catching live whales. The gains from this pursuit were negligible, and the colonists spent their efforts instead on designing a means by which to hunt right whales and sperm whales from the open sea, finally killing their first sperm whale in 1712 . By the early 1800 s, whaling was well on its way to becoming the dominant industry for the New England states (RobertsonLorant 93).

The golden age of American whaling is forever immortalized in Herman Melville's Moby-Dick (1851). The novel is based both on Melville's own employment on a whaling vessel, and Mocha Dick, a notoriously vicious bull sperm whale who sank numerous boats of all sizes in allegedly unprovoked attacks off the coast of Chile, near the island of Mocha (Faiella 32). Mocha Dick was particularly renowned for the speed and ferocity of his attacks, and the genius with which he escaped from pursuit by whalers (Dolin 81). Given his notable intelligence, it is entirely possible that Mocha Dick, like his fictional namesake Moby Dick, would find it expedient to strike preemptively against whaling vessels. Melville himself forwards this theory, characterizing the sperm whale as "sufficiently powerful, knowing, and judiciously malicious, as with direct aforethought to stave in, utterly destroy, and sink a large ship; and what is more, the sperm whale has done it" (172). Melville's novel chronicles Captain Ahab's need to avenge his lost leg, consumed by Moby Dick in one such assault during a previous voyage. 
Injuries of this nature were all too common, even without risk of attack. Whaling was a brutal, visceral and physically demanding activity. Harpooning a whale was not actually intended to kill it, merely provide a means by which a smaller boat full of whalemen could attach themselves to the animal and hang on until it was exhausted. The whale would then be dispatched with a long lance designed to pierce into the lungs or the brain, a slow, insensitive process that Melville captures accurately:

When reaching far over the bow, Stubb slowly churned his long sharp lance into the fish, and kept it there, carefully churning and churning[....] And now it is struck; for, starting from his trance into that unspeakable thing called his "flurry," the monster horribly wallowed in his own blood, overwrapped himself in impenetrable, mad, boiling spray, so that the imperilled craft, instantly dropping astern, had much ado blindly to struggle out from that phrensied twilight into the clear air of the day.

And now abating in his fury, the whale once more rolled out into view; surging from side to side; spasmodically dilating and contracting his spout-hole, with sharp, cracking, agonised respirations. At last, gush after gush of clotted red gore, as if it had been the purple lees of red wine, shot into the frightened air; and falling back again, ran dripping down his motionless flanks into the sea. His heart had burst! (239)

According to Kyla Schuller, "the intimacy of the hunt" (4), lengthy voyage and close confines of the ship fostered a sense of affinity between the whalers and the subject of their pursuit. ${ }^{43}$ To catch a whale, particularly the intelligent and wily sperm whale, the 
men needed to be familiar with and appreciate their habits. After a successful expedition, the "cutting in" process (Melville 252) and subsequent crawling through of the entrails enacts a bodily intimacy that Schuller posits is a means by which Melville can position whales as "thinking, feeling subjects with the capacity for affective relations with each other and their hunters" (5). Not unlike the kill itself, the bloody, visceral and claustrophobic rendering process put the whaler inside the whale's body, providing a unique perspective on the physical similarities between humans and cetaceans, despite their differences in size.

Melville's comparison of the two, moreover, benefited the whales. In a chapter describing the excavation of a whale cranium, Ishmael observes that, when viewing the dismembered head from behind, "you will be struck by its resemblance to the human skull, beheld in the same situation, and from the same point of view" (289). It is telling that the passage is addressing the similarities of the brains, bringing to mind the dictum "I think, therefore I am," that Descartes articulated as a cornerstone of humanism itself. By foregrounding the rational and emotional similarities between human and animal, Melville calls into question the ethics of commercial whaling by implicitly interrogating the whale's obligation to accept its status as a natural resource. ${ }^{44}$ In this configuration, Moby Dick is less a "malevolent" (152) force of nature than a furious whale rightfully angry that he and his kindred are being stalked and murdered by humans. The destruction of the Pequod and Ahab's death at the end of the novel can be considered an act of resistance to a worldview of the whale as an exploitable resource and not a subject in its own right. 
Despite Melville's attempt to put forward a model of cetacean subjectivity, whaling persisted in the Arctic and the Atlantic. American companies retained their stranglehold on the mid-Atlantic, hunting hundreds of thousands of sperm and right whales, until the industry began to decline in the early-twentieth century due to a significant decrease in whale populations and subsequent profits. This decline prompted the need for regulation and conservation. To this end, in 1927, the Whaling Committee of the International Council for the Exploration of the Sea recommended that no new whaling companies should be formed and existing whaling companies should be licensed and regulated (Nagtzaam 392-93). This initial effort, however, did not include any protections for vulnerable populations, including the North Atlantic right whales. The oversight was addressed by the establishment of the Convention for the Regulation of Whaling in 1931. The Convention recommended prohibitions against the killing of calves and nursing female whales in general, and that North Atlantic right whales in particular should not be hunted at all, with the expectation that the prohibition would eventually be lifted once the population had reestablished itself. ${ }^{45}$

Despite the Convention's counsel, whaling continued unabated, and even expanded into the Antarctic. It would not be until 1948 that the Convention's objective changed from conservation to preservation. To this end, the International Whaling Commission (IWC) was established as a body that could set and, more importantly, enforce the proposed whaling quotas. David Day likens the early commission, however, to a "big game shooting club" that met annually to discuss the "good old days" prior to dwindling populations and profits (27). According to Day, the IWC's annual quota 
bargaining sessions constituted a "gentleman's agreement" that none of the nations actually kept. At the time, the commission had no means by which to monitor their members, nor any real authority to punish those nations breaking the agreement. Despite their espousal of a rhetorical stance arguing for cetacean protection, the IWC was more interested in protecting the long-term profitability of the whaling industry. It would not be until 1958 that the question of the humaneness of whale killing would be addressed at the Geneva Conference on the Law of the Sea, but only insofar as new killing methods would spare marine mammals unnecessary pain and suffering (D'Amato and Chopra 36). Industrial whaling quotas remained too high to sustain global whale populations, with additional significant decline in the Antarctic.

It was in the 1960s that cetacean awareness was moved to the forefront of the environmental movement. According to Mette Bryld and Nina Lykke, very little research had been done on cetaceans. Not until that year [1960] did the echo-locating or sonar abilities become an established scientific fact[....] Because of their extra-terrestrial environment, these sea mammals were incredibly difficult to study, and of the Marinelands or oceanaria that became so widespread later on there were at that time only a couple in the USA. (186) Within a few years, whales and dolphins became popular subjects of a "New Age" sensibility (183) that traded on the similarities between human and marine mammals that Melville had suggested a hundred years earlier.

The popularity of sentimental accounts of dolphin-human friendships in particular, including the case of Opo the dolphin (who voluntarily frolicked with adults 
and children off the coast of New Zealand in the 1950s), were exemplary of a radical shift in ideology, in which humans' sense of mastery over nature was undermined by the environmental and animal advocacy movements. The 1963 film Flipper helped fix the dolphins in the popular imagination as lively, friendly, and, most notably, intelligent human helpers. In the film, young Sandy Ricks rescues an injured dolphin, whom he names "Flipper." Sandy struggles with his father, Porter, to keep the dolphin as a pet. Porter views Flipper as a pest who will eat up the fish he needs to catch in order to ensure his family's economic survival. Although the adult releases the animal against his son's wishes, at the film's climax the intrepid dolphin returns to save Sandy from a shark attack, prompting a change of heart on Porter's part. Reminiscent of the father/child conflict in E.B. White's Charlotte's Web, the demonstrable affection between dolphin and child overrides the adult's inclination to prioritize the human family's economic future, proposing that emotional bonds supersede financial gain but also species distinctions.

By emphasizing not only the emotional but also the rational overlap between human and marine mammal, the environmental movement has worked towards making whales the face of conservation efforts. Just as, 200 years ago, hunters reconfigured the fox from the status of vermin to that of a wily beast worthy of upper-class pursuit (as I discuss in Chapter Two), animal rights activists re-scripted whales from the category of a homogenous natural resource to be harvested into that of a species deserving rights and protections due to distinctive qualities, such as the ability to think and act both as community members and as heroic individuals prepared to assist humans in their own 
struggles. In this sense, western society re-conceptualized the species of the whale as - if not human - at least honorary members of Team Human, so to speak.

According to Norwegian anthropologist Arne Kalland, environmentalists accomplished this new vision for the mammal by rhetorically synthesizing all whale species into a single "super-whale" (4). In Kalland's formulation, this über-species stands out because it

is the largest mammal on earth (this applies to the blue whale); $[\ldots]$ has the largest brain on earth (the sperm whale); [...]has a large brain-to-body-weight ratio (the bottlenose dolphin); [...]sings nicely (the humpback whale); [...]has nurseries (some dolphins); $[\ldots]$ is friendly (the gray whale); $[\ldots]$ is endangered (the blue and right whales) and so on. (4)

By focusing on the most vulnerable, caring or humanlike qualities of any species of all the whales, this cetacean conflation situates them as a metaphor for the deeper connection to nature that modern humanity has allegedly lost. But at the same time, it places expectations on the actual mammals that none of them individually is able to fulfill. The contemporary popular notion of the whale is, like Melville's wise monster, an anthropomorphic fiction; the difference is that now the fiction is intended to shift the ethical focus not onto one species, such as the horse, or onto a single practice, such as factory farming, but onto humanity's over-arching attitude toward all other animals in general. 


\section{Beyond "Bare Life": The Cetacean Personhood Movement}

In light of the changing perceptions of cetaceans in the popular imagination, the United Nations found it expedient to capitalize on this new awareness of the importance of whales, and passed a resolution at the 1972 Stockholm Conference on the Human Environment, asking the IWC to institute a ten-year moratorium on whaling so that the populations could recover. This recommendation incensed nations such as Iceland, Japan, Norway, and Russia, who believed that their national economies depended on the profits from hunting whales. Their objections sparked a war between the whaling and non-whaling members of the IWC. Environmentalist groups such as Greenpeace allied themselves with those countries which favoured the moratorium, often engendering public sympathy by going to extreme measures to call attention to the activities of the whaling nations. ${ }^{46}$ Despite the best efforts of the pro-whaling countries, the IWC finally voted in 1982 for a ten-year global moratorium on whaling, which was upheld again in the early 1990s, to be maintained for the foreseeable future. The moratorium, however, did provide a number of loopholes for exploitation. Whales could be killed for research purposes and subsistence whaling was permitted for aboriginal communities in the Arctic. Moreover, the measures only protected the largest species of whales, with no provisions to prevent the killing of smaller cetaceans such as orcas or dolphins, who could also be captured with impunity and sold to entertainment facilities such as Marineland or Sea World. For cetacean rights activists, a simple ban on whaling was not enough - whales needed to be guaranteed legal protection and a right to life by virtue of their unique subjectivity. 
Most of the scientific work on cetaceans since the 1960s has been done to establish an unequivocal subjectivity for cetaceans of all sizes. The "super-whale" that Kalland describes is not necessarily just wishful thinking on the part of conservationists and environmentalists; the similarities between humans and whale species are now in fact well-documented. Neurophysiologist John Lilly pioneered the field of cetacean communication research, focusing primarily on dolphins. As part of a generation of "countercultural scientists" (Dudzinski and Frohoff 119), Lilly espoused unconventional research techniques, including placing a lone dolphin in a partially-submerged house with a woman, who then attempted to live with the animal as though she were a fellow dolphin (119). In another experiment, Lilly administered LSD to six dolphins and himself in an attempt to communicate telepathically (Burnett 616). Despite his unorthodox techniques, over his lengthy career Lilly was able to conclude decisively that dolphins were at least as intelligent as humans, if not more so, and extended his findings to include the greater whales (Nash 185). Similarly, the recent "The Declaration of Rights of Cetaceans" argues that whales and dolphins are deserving of legal personhood. In addition to Lilly's conception of a "cetacean nation" of subjects deserving rights, he also influenced other researchers and activists, including science journalist Scott McVay and legal scholars Anthony D'Amato and Sudhir Chopra. With biologist Roger Payne, McVay recorded and analyzed the phonetic structure of the songs of the humpback whales, establishing that the songs constituted a mode of communication akin to human language (Burnett 628). D'Amato and Chopra, meanwhile, have proposed that whales should be entitled, under international law, to a right to life by virtue of their sentience, 
intelligence, and capacity for interspecies communication (22). D'Amato and Chopra's efforts, moreover, have inspired others to argue for legally protected rights for whales. In her espousal of cetacean subjectivity, Italian philosopher and animal rights advocate Paola Cavalieri likens industrial whaling practices to "genocide" (n.p.), arguing that whales can be mass-murdered with impunity because they legally constitute no more than what Agamben calls "bare life," or zoe (4) - the biological state of being alive, or the embodied condition of existence. They are seen to lack the quality of bios the laws and other cultural structures developed by humans in order to enact subjectivity and to establish tangible evidence of civilization. As I outline in my previous chapter, humans have used these laws to demarcate the boundary between the human and nothuman to such a degree as to deny the zoe of humans entirely. According to Agamben, "man is the living being who, in language, separates and opposes himself to his own bare life and, at the same time, maintains himself in relation to that bare life in an inclusive exclusion" (8). In accord with Agamben, Cavalieri contends that, while humans can be reduced to a state of bare life (via denaturalization, deportation or degradation), animals are trapped within a

juridical apparatus which includes their exclusion by ratifying the harms that can be inflicted upon them. This holds in a particularly distinct way for the current situations for cetaceans. Differently from what was the case when, being definitely seen as fair game, they were the objects of genocidal practices, in fact, their present deprivation of rights does not stem from a total exclusion from the juridical order, but is rather inserted in an international legal system which 
frames and countenances it[....] All considered, what one confronts in whales and dolphins is the instantiation of a life that as such remains exposed to violence "precisely in the most profane and banal ways" - that is to say, bare life. (n.p.)

The bare life of animals is acknowledged, or included, in human law or philosophy, but only so that it may be excluded from a specifically human conception of subjectivity. To this end, D'Amato and Chopra argue that the notion of legally granted and protected rights has, historically, continued to expand to include those to whom personhood has been granted, including women, racial minorities and the mentally disabled. Legal personhood rights, moreover, have also been extended to what are commonly recognized to be nonhuman entities such as corporations, trusts, municipalities and joint ventures. In this context, they contend, there is nothing strange about recognizing the rights of whales - creatures that are more animate than corporations, more communicative than infants and mentally enfeebled persons, more communal than the society of nations, and perhaps more intelligent than the smartest human beings. (51)

By foregrounding their communicative abilities, D'Amato and Chopra circumvent language as a traditionally accepted boundary between animal and human. In so doing, they open up a space in which cetaceans are, like the rats of NIMH, able to escape the confines of bare life, as well as the restrictive view of subjectivity as exclusively human.

If whales and dolphins constitute subjects deserving of legal protections and rights, as Cavalieri and D'Amato and Chopra have established, then marine parks such as Marineland and Sea World represent a threat to their objectives by promoting 
cetacean slavery as entertainment, a concern that Free Willy overtly addresses. For marketing reasons, these venues have found it necessary to disguise the ethical ramifications of the whales' and dolphins' captivity and forced performance. In order to accomplish this, the animals are anthropomorphized as "willing partners" in presenting a spectacle of their physical prowess (Desmond 235), despite the fact that all trained behaviours are "based on captive operant conditioning, not volition" (Davis 178). In Marineland and Sea World's programming, slavery must be reconfigured into voluntary servitude in order to de-emphasize the reduction of the cetacean to a state of bare life. This rhetorical manoeuvre engenders a tension between the presentation of the individual whale, for example, as a subject with whom the audience is encouraged to identify, and the conditions of its "employment" at the marine park. Paradoxically, the thematic emphasis on partnership and family in the scripts devised by these entertainment venues elides the fact that the whale has been abducted from its family pods and forced to make new bonds with human trainers.

While the rapport between trainer and orca or dolphin can be envisioned as what Donna Haraway calls "significant otherness" (97), she notes that a companion species relationship can only exist with consent on the animal's part. While the bonds between human trainer and animal performer can become close, cetacean consent can arguably never be granted, since the animals are being held against their will. By following Desmond and Davis's leads in examining the politics of captivity and forced performance, I argue in my next section that Free Willy, as an overt cetacean rights text, makes use of the themes and ideas disseminated in Marineland's and Sea World's 
theatrical programming to argue for an unequivocal freedom for all captive animal performers. ${ }^{47}$

\section{Free Willy, Freeing Keiko}

Free Willy is a story of interspecies friendship between Jesse (Jason James Richter), a preteen juvenile delinquent being shuffled through the foster care system, and Willy (Keiko), a live-captured killer whale who demonstrates a similarly bad attitude towards his trainers. As Jesse learns over the course of his time spent cleaning up his acts of vandalism at the Northwest Adventure Park, Willy refuses to perform tricks in front of the crowd and is rapidly becoming a financial liability for the park's owners. As such, the owner, Dial (Michael Ironside), develops a plan to kill Willy, who is insured for $\$ 1$ million. Upon learning of the plot against his friend's life, Jesse decides that Willy must be released back into the wild.

By using a captive orca to present an anti-captivity narrative, Free Willy both proposes and undermines commonalities between the human and the animal. Most notably, the film subverts genre expectations in order to call attention to the coerced animal performance. As I argue in my previous chapters, historically, children and animals have been conflated in literature because of the alleged natural sympathy they have for one another. Just as even the misanthropic Dick the Little Pony can enter an affectionate relationship with a human child, so too is the miscreant Willy able to build a friendship with Jesse. The film, however, engages a secondary agenda, producing a 
dialectic of closeness and distance in order to avoid encouraging complacency towards cetacean captivity.

The friendship between Willy and Jesse is largely based on their common circumstances; both are caught between states of wildness and tameness, both are estranged from their families, and both lack legal recognition of their subjectivity. The opening scenes of the film stress how Willy and Jesse will come to represent a spectrum ranging from the wild to the civilized; this emphasis calls attention to the ways in which marine theme parks struggle to note the differences between humans and cetaceans in order to attract curious visitors, on one hand, and yet also put forward their similarities in order to encourage identification (albeit not to the point where the audience feels that the orcas are being exploited), on the other.

The film opens with documentary-like footage of an orca pod frolicking in the wild, cutting between close-ups of the whales' bodies and distance shots that situate the animal in its spacious ocean environment. The cross-cutting of close-up and long shots foreshadows the tension that will be created by the contrast between the closeness Willy and Jesse will develop and their actual species difference. This tension is also suggested by the naming of the tugboat that captures Willy - "the Pequod" - recalling Melville's own struggle to reconcile the subjectivity of the cetacean with its historically accepted status as natural resource. Though Willy is not intended for slaughter, his life is nonetheless exploitable for human economic gain. While he is neither as large nor as angry as Moby Dick, Willy is still able to engage in acts of resistance. In defiance of the species' reputation as gregarious, Willy proves surly and untrainable. He consistently 
splashes his trainer, Rae (Lori Petty), whenever she passes by his tank, or swims away when she summons him with a whistle. This rebelliousness is, paradoxically, also what defines the animal not simply as an individual, but as the type of independent hero that Hollywood has glamourized to the state of a cliché.

Jesse is similarly resistant to his own subordinate status as a child. He is belligerent and rude, and often runs away from Dwight, his case worker (Mykelti Williamson). His defiance leads him to engage in acts of destruction, such as vandalizing the marine park. The boy thus becomes adrift in the world without the kinship ties that are so integral not only to humans, but, importantly, also to orcas like Willy. Abandoned by his mother, the boy is caught up in the foster care system. Jesse has acquaintances with whom he teams up to scam the unsuspecting or gullible into giving them money, but no close relationships with anyone. He even appears to be moving along the spectrum toward the feral state of a wild animal, refusing all human physical contact and flinching when others try to touch him. Sent by Dwight to live with foster parents Annie and Glen Greenwood (Jayne Atkinson and Michael Madsen), the boy sees these forced ties as a form of captivity. Espousing a view of the world as a place in which everything, including care and altruism, is suspect by virtue of its potential for commodification, he cynically asks Glen, "how much are they paying you to be my jailer?" When contrasted with the gentle, playful and tactile orca family of the film's opening sequence, Jesse is positioned as being in desperate need of the deeper connections to nature that the contemporary conception of the whale seems to offer. 
The interspecies friendship between Jesse and Willy is portrayed as very much the orca's idea. Jesse, after playing his harmonica for the animal late one night, slips and falls into the pool, knocking himself unconscious. Instead of attacking him, as might be expected from its past antagonism to humans, the whale gently lifts Jesse to the surface and rolls him into a shallow spot to recover. After this episode, Willy makes several other friendly overtures to Jesse, including waving his fins, rolling in the water, and soliciting petting. The boy responds with his own collegial gestures, and they begin to play together. Jeffrey Mousaieff Masson and Susan McCarthy characterize this sort of "fellow-feeling" (168) as evidence of animal subjectivity. Being treated by the animal as one of its kind, as Willy's behaviour towards Jesse suggests he is doing, constitutes a particular "thrill" (168) for the human, situated in the commonalities between the two species. The film encourages this interpretation, but only then to wrench the vision apart by moving the situation into a commercial forum, with the orca's public debut as a performer.

Successfully performing before a crowd is considered by Rae to be in Willy's best interest, as Dial will not spend any money to expand the whale's small pool until the animal begins to generate income. Though the trainer does not agree with the orca's capture and confinement, neither does she envision a future for Willy in which he is set free. Unwilling to challenge Dial's ownership of the animal, she can only work towards making the whale's living conditions marginally less torturous. Rae sees Willy's positive attitude toward Jesse as an opportunity to prepare the whale for his role as the star of the 
animal show, and to this end, she is willing to exploit the mutual affection between the boy and orca.

Despite the whale and boy's bonds of affection, as well as their being framed in the film as both victims of abusive forces of the adult human world, their species difference is ultimately foregrounded specifically in order to undermine pat notions of interspecies sympathy. After an idealized training montage sequence, in which Jesse and Willy grow ever closer, and Willy is depicted as increasingly responsive to his human companion, the two are shown to be, in reality, only further apart.

In a scene of the two on a moonlit night, Jesse is positioned in the foreground, highlighting his importance as a human. With his back toward us and gazing down at the whale in his pool, the male youth takes on the position of both the park's attendees and that of the cinematic audience. The text, perhaps unintentionally, encourages the film's viewers to sense their own complicity in the consumption of the species as entertainment. Willy, in the distance, attempts a spy-hop manoeuvre. Swimming vertically with his head and eyes above the water, the orca is able to observe his environment for an extended period. His circumscribed view of the stadium seats and the walls around his pool distress him, which he conveys with a mournful wailing. Jesse, however, is confused as to why the orca is making such a "terrible noise," since they had had such a pleasant day playing together. Although the boy's vantage point includes both the pool and the open bay in the background, Jesse fails to recognize Willy's own distinction between captivity and freedom. The pool's water, moreover, calls attention to its artificial colour and form, as well as the enclosure's inadequate size. The proximity of 
the bay is a cruel reminder of all that the orca has lost in his forced transition to semitamed animal performer.

Despite the humans' expectations that the whale will successfully make the transition from wild creature to voluntary performer, Willy's debut turns out to be a disaster for both participants. Frightened by the noisy crowd, particularly a group of unsupervised children banging on the glass of the underwater viewing area, Willy swims in frantic circles in a futile effort to escape his torment. Such overwhelming auditory stimulus, as John Sorenson notes, is incredibly stressful to captive cetaceans (207). When Jesse summons him with a whistle to begin the show, Willy slinks away below the water, leaving Jesse furious and humiliated before the jeering crowd. Besieged by the additional noise, the orca becomes agitated enough to smash into the glass separating him from the misbehaving children. The whale's force is enough to cause a water leak, inciting a mass panic. By cross-cutting between Willy and Jesse's experience of the event, the film presents the youth here as a decidedly unsympathetic figure. Despite their closeness and species conflation, the boy is unable to empathize with his friend, considering Willy's violent refusal to participate to be a personal betrayal. As such, Jesse has fallen prey to what Desmond calls "the fantasy of species boundary crossing" (265). The boy believed that he and the orca were in perfect harmony, sharing the same goal of improving living conditions for the captive animal. In this configuration, the human overlooks or ignores completely the animal's distress in his imprisonment.

Moreover, as the film demonstrates, the two main characters are both bound by discourses around power imbalances between the human and the animal. Play activities, 
as Yi-Fu Tuan suggests, may not actually contribute to the "fellow-feeling" Masson and McCarthy describe, but instead can function to maintain inequalities between species. Through play, Tuan contends, "children learn to master a world[....] A child gains confidence and a sense of power as he manipulates the things around him" (163-64). Thus, in the film, training the orca is coded as fun for the youth, and a means by which the two could further develop their close friendship. What begins as mutual exploration between species, however, becomes subverted as the human develops a sense of the interaction as one not of significant otherness, or a companion species relationship such as that Haraway claims she and her dog experience in training, but of his mastery over the animal. This power imbalance in which Jesse is invested implies that the two are not the "soul mates" they are suggested to be.

In order to engage with Willy in significant otherness (described by Haraway as situated in mutual subjectivity), Jesse must make the cognitive leap from imagining an upgraded aquarium environment as the best outcome for his captive friend, to total freedom from captivity. Jesse is unable to make this conceptual shift until he is confronted with Willy's impending demise. The boy catches Dial attempting to murder the orca by sabotaging the repair to the aquarium's wall in order to drain the tank. Unsupported by water, the weight of the whale's body would compress his lungs, eventually causing the animal to suffocate. Interpreting the murder attempt as Dial's relinquishment of his possession of the whale, Jesse takes advantage of this opportunity to return his friend to the wild. With the assistance of Rae and Randall (August Schellenberg), the park handyman, Willy is successfully returned to the water, but in the 
meantime, boats have been dispatched to cut off the orca's escape route from the harbour to the open sea.

The only way Willy can escape is to obey Jesse's final command to jump over the marina's breakwater. Ironically, it is through the animal's self-subordination to the assumedly wiser guidance of the young human that the whale is able to evade re-capture. The very structure of the discipline against which Willy rebelled, threatening his life, proves to be what saves him, when enacted through the agency of Jesse. The film frames Willy's climactic leap as literally a leap of faith - the whale ostensibly has no idea what is on the other side of the rock barrier, only that he would rather risk death than be captured again. The spectacle of the orca's brave jump thus signifies the leap that viewers must take in granting the species an overt subjectivity, and the legal personhood rights that this acknowledgement would entail.

The film argues so persuasively for cetacean freedom that, upon the movie's release, viewers wanted Keiko, the killer whale playing Willy, returned to his own home waters. This endeavour, organized by the Free Willy Keiko Foundation, was subject to several obstacles, taking years and millions of dollars to accomplish. As with most captive marine mammals, Keiko's health was precarious. He needed medical attention and physical rehabilitation therapy to cure him of viral wart-like growths and to increase his lung capacity, which had been diminished by his inability to dive deeply in his shallow pool. Moreover, he had been kept in virtual isolation nearly his entire life, cut off from the familial ties so crucial to orca social development. ${ }^{48}$ These obstacles made even his supporters skeptical that he would ever be released back into the wild. 
Nevertheless, he was returned to Iceland in September 1998 after spending nearly 20 years in captivity. Over the next three and a half years, he was transitioned from his sea pen in a sheltered bay to the open ocean. He left Icelandic waters of his own volition in July 2002, accepted into a pod of wild orcas. Six weeks later, he turned up at Skaalvik Fjord in Norway, spending the next year periodically frolicking with tourists and children until his death of pneumonia in December 2003.

The attempt to release Keiko and train him to wild animal behaviour problematizes the traditionally accepted assumption that being wild and being civilized are binary states of existence. As Haraway contends, nature and culture are not mutually exclusive concepts. Her model of a natureculture, which conceptually encompasses both nature and culture, or wild and tame, provides a means by which to discuss Keiko's repatriation that does not position the whale's decision to commune with humans as a "failure" on the orca's part to become wild again (Brower 312). Like Opo the dolphin, or the canines Buck or White Fang, who similarly negotiate the slippages between wild and tame, so too is Keiko able to make his own decisions about his preferred companions. The orca's voyage to Norway, when viewed as part of the spectrum of choices the whale could make as part of a natureculture, evokes White Fang's own choice to follow Weedon Scott to California. By using the concept of a natureculture to sidestep an oppositional model of wild/civilized, the issue of whether Keiko's release was successful or not becomes moot. In this formulation, the spectrum to which wild and tame belong is continually in flux. Far from being "ruined" (n.p.) by prolonged human contact, as journalist Susan Orlean contends, Keiko's life is enhanced and enlarged to encompass 
his wild kindred as well as humans, a view of the whale that does not elide his established subjectivity.

\section{Interspecies Intimacy in Dolphin Tale}

The effort and resources expended to return Keiko to his home waters has had a lasting impact on forwarding the concept of cetacean personhood, ultimately benefiting other whales' rights to life. ${ }^{49}$ Many marine facilities and institutes, moreover, now recognize the animals' subjectivity and work to rehabilitate injured marine mammals to release them in the wild. Some animals, however, are too injured to be returned to their natural habitat and must, for their own survival, be maintained in captivity. Winter the dolphin is one such animal. As such, the dolphin's long-term residency at the marine hospital problematizes the assumption that captivity is always a negative experience for the animal. As Dolphin Tale, the film about Winter's experience suggests, when the cetacean's subjectivity and right to life are accounted for by the humans structuring her program of care, then a circumscribed existence is not necessarily akin to imprisonment or torture. Like Keiko's decision to stay in Norway, accounting for and honouring that subjectivity includes allowing the young dolphin the freedom of choice to prioritize her relationship with humans over the other injured dolphins who share her tank. The film proposes a uniquely inclusive model of cetacean rights, in which interspecies intimacy as a means by which to enrich the animal's life is as valid as grand gestures towards freedom from captivity. 
Dolphin Tale focuses on the friendship between Winter, a badly injured young dolphin, and Sawyer (Nathan Gamble), the boy who rescued her from entanglement in a crab trap line. Despite Sawyer's intervention, Winter's tail must be amputated, due to tissue necrosis caused by an extended loss of circulation. Winter teaches herself a new way to swim, and the two become close friends over the course of her healing process. Their relationship, however, is threatened by the physical damage Winter's new method of swimming causes to her spine. Left uncorrected, the damage will eventually lead to paralysis and death. Complicating Winter's rehabilitation is the imminent closure of the Clearwater Marine Hospital due to a lack of funds. Sawyer and Hazel (Cozi Zuehlsdorff), the head veterinarian's daughter, develop an ingenious plan to keep the aquarium open, broadcasting to an internet audience the dolphin's untroubled adaptation to her disability. The film portrays captivity positively, integral as it is to Winter's longterm survival.

Getting Winter to survive her ordeal initially involves extensive physical contact with Sawyer. He assists the veterinary staff by holding onto Winter for hours on end in order to keep her blowhole above water so as to prevent her from drowning. Through this prolonged physical intimacy, Winter regains her strength and will to live. In providing her with the strength to heal, Sawyer's bond with the dolphin develops into an intense affection for both parties. Not unlike the relationships between Thornton and Buck, or Scott and White Fang, the authenticity and intensity of the fellow-feeling between human and marine mammal forwards the notion that the cetacean's life can be enriched by human contact. Just as London proposes in his novels, the film links flesh 
and love in a way that transcends mere friendship to move beyond the power dynamics inherent to animal captivity.

Sawyer's affection for Winter is situated in the bonds of care that Haraway describes as integral to a companion species relationship, reinforced by the tactility and sensuality of Winter's reciprocal affection for the boy. The dolphin actively pursues Sawyer's interest and affection, often getting him to swim with her in the pool. As he spends more time in Winter's watery element, caressing her skin and allowing himself to be similarly explored by the dolphin, Sawyer is able to make a reality of what for Jesse, in Free Willy, does not go far beyond a fantasy of boundary crossing. Jesse and Willy are best friends, but Sawyer and Winter are engaging in an interspecies romance, the inevitable consequence of linking flesh and love, as I argue in my second chapter. ${ }^{50}$ Their play is coded as flirtation, as opposed to the more purposeful training activities in which Jesse and Willy engage. Moreover, the reciprocal affection between Sawyer and Winter, forwarded by playful flirtation, is a private activity and not intended for public consumption.

The two characters' intimacy is threatened, however, by the impending closure of the hospital. Sawyer must share Winter with a wider audience to secure the financial resources crucial to her ongoing care. To accomplish this goal, he and Hazel make Winter's amputated tail into a spectacle, installing a camera over the dolphin's pool. They then set up a website through which Winter can be viewed from anywhere at any time. Haraway posits that "crittercams" (250) of this nature promise an experience of otherness, a means by which to inhabit the other "as a new self" (252). What Sawyer and 
Hazel hope to accomplish by extending an invitation to anyone with internet access to intimately view the dolphin's experiences is to elicit the cross-species sympathy that will drive the collection of donations to her cause. The camera becomes integral to this process, constituting a "haptic-optic" means by which to engage with the animal other (Haraway 6). In Haraway's formulation, the viewer's eyes become configured by the camera into a means by which to touch the animal, evoking the physical relationship Sawyer and Winter experience together in real life. Haraway proposes that it is possible for the camera to reproduce the actual tactile experience of the animal body, by using the eyes as a proxy for the hands. The act of touching, moreover, "ramifies and shapes accountability" to the other (36), as it requires an acknowledgement of the animal's subjectivity. By watching Winter with "fingery eyes" (Haraway 5), the viewer can develop the same feelings of love and responsibility that Sawyer feels towards the dolphin. If the viewers do intimately experience Winter in this fashion, as Sawyer and Hazel hope, they will then understand the importance of generating the financial resources for her ongoing care.

The film delicately manoeuvres between the financial necessity of making Winter available to the public via webcam and at a fundraiser carnival, and maintaining the authenticity of the intimacy of her primary relationship with Sawyer. Sharing her, and his love for her, with a wider audience is a sacrifice the youth makes on her behalf. His sacrifice resonates with the public, justifying his fundraising efforts and securing his future with Winter. After opening their relationship up to include the public, however, the two must then reinforce their primary physical bonds to one another. 
In the last scene of the film, the camera voyeuristically circles around the pair as they hang suspended in the water. The pair's palpable relief over being able to be together in this manner for the foreseeable future is made manifest in the obvious sensuality of their physical attachment to one another. This sensuality echoes the lifereconfiguring intensity of the attachment between Thornton and Buck, or Scott and White Fang. The life-altering power of intense interspecies affections such as that displayed by Sawyer and Winter promotes a notion of intimacy that relies on equality and a respect for each other's subjectivity. By linking flesh and love in this manner, the film moves beyond the power dynamics inherent to cetacean captivity. In addition, by situating Winter's subjectivity in her right to live and, moreover, her right to choose this intimacy for herself, the dolphin's bond with Sawyer becomes an intimacy between equals. Most notably, the authenticity of the affectionate relationship between human and marine mammal presented in Dolphin Tale forwards the notion that captivity does not always undermine cetacean subjectivity.

As cetacean rights texts, Free Willy and Dolphin Tale present not only a spectrum of ways in which marine mammals can enact their subjectivity, including through erotically affectionate intimacy with other species, but also ways in which that subjectivity can be honoured and protected by humans. The notion of granting legal personhood to whales is still situated in a context of speciesism, in which rights are something that only humans have the authority to grant (Wolfe Animal Rites 34). As the complex cross-species intimacies celebrated in these two films suggest, however, the 
discussions developing around legal personhood for animals like cetaceans (or pets or the great apes), becomes most promising in the breakdown of speciesism as a fundamental institution, and the challenge to the currently common reduction of all nonhuman animals to "bare life." 


\section{Afterword}

Being owned by a dog, as I am, has predisposed me to acknowledging the autonomy of animals. Over the course of my research into the conflation of children with animals in children's literature and culture, my objective has been not unlike that of Victorian animal advocate Lewis Gompertz, "chiefly to support the claim of the brute creation to the mercy of man" (17) by emphasizing the animal's fundamental subjectivity. As such, I acknowledge the limitations of a model of expanded rights in which rights are still something the human can grant to the animal. Nevertheless, as I argue in my last chapter, the development of posthumanist approaches remains promising as a means of breaking down speciesism as a fundamental institution, and as a challenge to the still common reduction of all non-human animals to what Giorgio Agamben calls "bare life."

Although the earliest legislation prohibiting cruelty to animals was enacted to protect them from violence and abuse, as each generation of advocates was encultured to respect animals as individual beings, the cause itself has moved beyond demanding basic protection to arguing for legal personhood. I had assumed, as I conducted my

preliminary research, that children's literature would contribute to the subversion of an exclusively human notion of subjecthood, by encouraging child readers to identify so closely with animals. I was unprepared to discover exactly how subversive popular children's literature has been, and how overtly some texts, such as Dick the Little Pony, would argue for animal rights. 
Moreover, children's texts' espousal of rights for animals has proven notably nuanced and complex. Arising from disparate intentions and often aimed at different young audiences, authors developed original approaches that can be said in only a general sense to fulfill a collective aim. Jack London, for example, presents animal abuse as a necessary evil in order for Buck to learn to survive in incredibly harsh conditions, on one hand, and subverts his own position on this violence in White Fang, on the other. The eponymous canine hero is raised under the Law of Club and Fang that London describes in his previous Northland text. The abuse White Fang endures under such a "law" has detrimental effects, transforming his initial joyful interest in humans to suspicion and fear. London depicts this as a loss for the animal, which is only redressed by his intense companion species relationship with Weedon Scott.

E.B. White meanwhile prioritizes his companionable relationship with his pig, but in large part to complicate the assumption that animals are meant for human consumption (an issue London never addresses). Despite his eventual retreat from his radical stance on the killing of animals for meat as murder, White nevertheless opens up a space in which the sacrificial aspects of consuming animals are revealed. While White ultimately undermines an overarching subjectivity for all pigs and, by extension, all animals, Robert C. O'Brien addresses White's retreat by forwarding a notion of the subject that works on the level of a species, without prioritizing any one individual. His model can indeed effectively be adapted from his rats to propose an overarching subjectivity for all animals, an issue that I examine in my final chapter. 
In retrospect, perhaps the most obvious finding of my work is that human engagement with nonhuman animals is more unsettled, more unsettling, and - as Michael Lundblad suggests (498) - infinitely more complex than we generally assume it to be. As an analysis of the complex network of tensions in the relationships among humans and other animals depicted in works intended for a child audience, I hope that my dissertation picks up the threads left by White and others by further unsettling a model of human privilege and exclusivity.

As I suggest in my final chapter, there are still many aspects of culture not addressed in my dissertation that also reinforce the boundary between the human and the animal. One avenue that I feel requires closer consideration is the possibility that zoophilia is an extension of the intense mutual affection integral to a companion species relationship between equals. Peter Singer proposes that zoophilic activities forward a notion of animal subjectivity by removing it from a discourse of power dynamics or imbalances ("Heavy Petting" n.p.). The possibility is intriguing, although it does escape the paradoxically authoritative role of the scholar who establishes such a removal or articulates its argument. But does this suggest that the only pure act of equalization is one that is not articulated through a human mode of communication? Keiko's right to choose to ignore wild/civilized boundaries suggests otherwise. Posthumanist research will continue to undermine anthropocentric approaches to animal inter-relations, tantalizing us with the allusive possibility of an end to institutionalized speciesism akin to the perspective I see sustained, for the moment, by my daughter and my dog. 


\section{End Notes}

${ }^{1}$ For a thorough consideration of animal rights politics as they engaged with Stevenson's work, see Morgan Holmes’s “Donkeys, Englishman, and Other Animals: The Precarious Distinctions of Victorian Interspecies Morality” (2009).

${ }^{2}$ Benevolence toward animals also constitutes a feature of evangelical Christianity. In the same tradition as both John Wesley and William Cowper, Trimmer foregrounded animal welfare in the establishment of her own Sunday School programs (Prior n.p.)

${ }^{3}$ Martin Trevor Wild (2004) posits that the "squirearchy" (76), or landed gentry, sought to emulate the aristocracy, investing in local schools and parishes and architecturally improving the villages on their estates. Wild posits that their interest in maintaining social hierarchy stems from a closer class relationship to their tenants than the oftenabsent aristocratic landlord. For further history of the landed gentry and how they differed from the aristocracy and the middle class, see also John Burnett's $A$ Social History of Housing 1815-1970 (1978) and Felicity Heal and Clive Holmes's The Gentry in England and Wales 1500-1700 (1994).

\footnotetext{
${ }^{4}$ Rousseau uses pity and fellow-feeling interchangeably, but the two are not necessarily synonymous. Over the course of the French Revolution, compassion, or fellow-feeling was transmuted into a sense of pity, when revolutionaries were confronted by the volume of suffering and starvation the populace had to endure (Arendt 94). In this
} 
respect, pity becomes dangerous because it serves to glorify its own cause (Birmingham 50). More simply, feeling pity for the suffering is its own end; it does not require any further action on the part of the bystander. In this formulation, extending pity to the suffering animal was not enough. By encouraging children to identify with the animal, fellow-feeling could be engendered, spurring the compassionate individual to action on the behalf of animals.

${ }^{5}$ Recent scholarship on the Enlightenment and Romantic period has determined that the division between the two epochs is, in fact, quite fluid (Wallace 1). Marshall Brown in particular configures these overlaps into "an eighteenth-century pre-Romanticism and a Romantic post-Enlightenment", which retained many of the cultural forms of the Enlightenment, particularly the Neoclassicist influence in poetry and political thought, but reconfigured them into new literary forms (38).

${ }^{6}$ In this work, Descartes argues that the capability of human thought - what he calls cogito - proves human existence. A key proposition on which this claim is built is that animals do not feel pain as humans do. Rather, he argues, animals only go through the external motions of feeling pain, without the accompanying mental sensations that humans feel. These sensations presumably include physical discomfort as well as dread of the possibility of future pain. However, as Cary Wolfe points out, Descartes "insisted not that animals do not feel those sensations we call 'pain,' but only that they do not 
experience them as suffering because there is 'no one home,' no subject of the cogito to do the experiencing; and thus, the pain is not morally relevant" (Animal Rites 137).

${ }^{7}$ One of the first instances of the legal extension of human rights to animals occurred only in 2008, when Spain approved a law giving certain rights previously reserved for humans to apes. For more on this legislation, go to www.personhood.org.

${ }^{8}$ This rhetoric of slavery underscores the difference Haraway envisions between a companion species relationship and one based on hierarchy and forced service. If animals themselves can function within relations established through consent and respect, then the animalized human deserves no less. Britain was in the midst of debates about slavery at the time Dick the Little Pony was written, and the notion of animal rights was often tied to these other concerns. Lord Erskine is but one influential example of a proponent of animal rights who was also an anti-slavery advocate (Perkins 42). The British slave trade was abolished in 1807 , and slavery itself by 1833 . For an in-depth discussion of the relation of animal right politics and slavery, see Marjorie Spiegel's The Dreaded Comparison: Human and Animal Slavery (1996) and James Turner's Reckoning with the Beast: Animals, Pain and Humanity in the Victorian Mind (1980).

${ }^{9}$ A nuanced discussion of Black Beauty and audience can be found in "Riding Masters and Young Mares," chapter six of Coral Lansbury's The Old Brown Dog: Women, Workers and Vivisection in Edwardian England (1985). 
${ }^{10}$ Peter Stoneley furthers Dingley's argument, dispensing with any pretensions that Beauty is a servant and not a slave. To bolster his claim, he turns to Anne McClintock's notion of "articulated categories" (54), in which race, gender and class are interdependent, reciprocal and occasionally contradictory categories of experience. In accord with Halberstam's model, McClintock argues that, whenever we discuss a concept such as race, other common concepts and categories are also evoked.

${ }^{11}$ For a discussion of the horse as a Victorian symbol for the exploration of gender politics, see Gina M. Dorré's Victorian Fiction and the Cult of the Horse (2006). Other popular texts besides Black Beauty that enact this use include Mary Elizabeth Braddon's Lady Audley's Secret (1861) and George Moore's Esther Waters (1894).

${ }^{12}$ For an overview of "care-based" feminism and animal rights, see Alasdair Cochrane's An Introduction to Animals and Political Theory (2010). He outlines the connections between women's suffrage and animal rights. Cochrane notes further that "women comprise the bulk of campaigners" (115) in both of these movements.

${ }^{13}$ As the god Odin's wolf-familiars, "Ravener" and "Greed" were formidable beasts of battle. Fenrir, a supernatural wolf, was prophesized to kill Odin during Ragnarök, an apocalyptic final battle of the gods (Cavendish 251). 
${ }^{14}$ For more discussion of the history of the multiple versions of Little Red Riding Hood, see Robert Darnton (1984), Alan Dundes (1989) and Jack Zipes (1993).

${ }^{15}$ Judith Jesch provides a comprehensive comparison of how the wolf changed from a symbol of a glorious death on the battlefield to a fearsome beast of death and destruction, as Old Norse mythology transitioned to Old English poetry. As such, this is also an excellent case study of the shifting burdens of meaning that can be ascribed onto the animal body.

${ }^{16}$ According to the legends of the Kwakitul people of the Pacific Northwest region, for example, four wolves escaped a flood by climbing a mountain. Once there, they shed their skins to become human. The Kwakituls posit that they are then descended from those humans (Jones 6).

${ }^{17}$ In A Discourse on the Origin of Inequality (1755), Rousseau positioned himself against the Enlightenment's emphasis on science and reason, because he felt that those philosophers were overlooking human feeling and intuition. More importantly, he believed that civilization and its attendant rules, structures, habits and hierarchies quashed the creative impetus of the human soul, and as such, was an inhibitor of individual freedom. 
${ }^{18}$ For more discussion of late-nineteenth-century boy's literature as a medium for imperialist rhetoric, see Harvey Darton, Jeffrey Richards, and Jacqueline Rose.

${ }^{19}$ Seton draws upon the sentiments of animal rights advocate Henry Salt, who argued in Animals' Rights (1892) that it is "of little use to claim 'rights for animals' in a vague general way $[\ldots]$ so long as we regard them as beings of a wholly different order, and ignore the significance of their numberless points of kinship with mankind" (9).

${ }^{20}$ While London admired Kipling, there was no returned regard on Kipling's part. He loathed American capitalist expansion and its encroachment on the romance of the British empire (Hagiioannu 75). London, conversely, greatly admired British imperialism.

${ }^{21}$ After reading Darwin's On the Origin of Species (1859), Herbert Spencer was inspired to apply "survival of the fittest" to economic theories that privileged the "favoured races" (444) in capitalist economies. To accomplish this, Spencer deliberately elides Darwin's emphasis on the random nature of natural selection in order to equate "fittest" with concepts of physical (and racial) perfection, and individualist tropes like aggressiveness and violence.

${ }^{22}$ Labor notes further that Buck's casting aside of traditionally acceptable "Southland" morals and values to embrace the Law of Club and Fang "would necessarily affect us 
with revulsion" (116), in that such behaviour in a human would have been unpalatable to a Victorian readership.

${ }^{23}$ In “Jack London's Socialistic Social Darwinism," Jonathan Berliner debunks popular conceptions of London as "confused" (55) in his simultaneous espousal of individualist and collectivist philosophies. Berliner's central thesis is that London's overall body of work can only be understood by examining how these two elements are entwined. According to Berliner, London "presents nature as a brutal force, but crucially one that could be harnessed for socialistic purposes" (56).

${ }^{24}$ Additionally, animal behaviouralist Temple Grandin contends that our history with dogs dates back much further than earlier research suggests, and goes so far as to theorize that dogs and humans developed in tandem - that each would not exist as we are now without the other (176). Grandin concludes that "dogs and people belong together" (177).

${ }^{25}$ In London's short story "Bâtard" (1904), the human and canine protagonists are bound instead by mutual loathing. Bâtard and Leclère are locked in a cycle of violence and hatred, which leads to their deaths. Re-published between The Call of the Wild and White Fang, it problematizes simple binaries of good/evil and wild/civilized, in that both dog and man are both positioned as evil by birth and by nature, which points to a predestination that is lacking in both Call of the Wild and White Fang, though 
underwritten with a sympathy for the animal-human bond that Leclère corrupts. Bâtard is a proto-White Fang, in that he too is a wolf-dog who never experiences kindness, but unlike White Fang, he is too shaped by Leclère's hatred to access the "deeps" of his own nature and be redeemed. At the end of the story, Bâtard kills Leclère, and has to be shot in order to break his hold on the corpse.

${ }^{26}$ Peter Singer similarly contends that of all the meat animals, the pig is undoubtedly the most intelligent, making them a logical choice for George Orwell to cast as the leaders of the animal revolution in Animal Farm (Animal Liberation 119).

${ }^{27}$ Caras notes further that its meat value supercedes all of the pig's other skills and attributes, including cart-pulling and truffle-hunting. Contrasted to other livestock like sheep, goats, cattle and horses, the pig alone is solely valued for its edibility (111).

${ }^{28}$ Despite many advances in methods of killing animals (anaesthetic, chloroform, bullets), the actual killing was still performed by a human. Otter characterizes this interaction as "stubbornly resistant to full mechanization" (96).

${ }^{29}$ Notably, by the time Upton Sinclair wrote The Jungle in 1906, the conditions of the animals, the workers and the structure itself were so abysmal that readers were shocked and appalled that they overshadowed the plight of the immigrant families he intended to highlight (Adams 62-63; Lee 1). 
${ }^{30}$ As corporate conglomerates began buying land and driving down crop prices, smallscale operations and family farms could no longer compete and were driven out of business. By the early 1960s, CAFOs and packing plants were either housed together or owned by the same parent corporations, which made it increasingly difficult for independent farmers to survive. There was a $65 \%$ reduction in the number of hog farmers between 1975 and the mid-1990s (Grey 169). This drop-off in the number of independent hog farm operators had begun at a time when White himself was already nostalgic for a craftsman-like or companion-species relationship eroded by the increased mechanization of both farming and animal slaughter.

${ }^{31}$ Peter Singer (1975) and Dawn Coppin (2003) both outline in greater detail the inhumane confinement and treatment of the farrowing sow.

${ }^{32}$ Bentham, however, advocated the eating of animals, stating that humans should eat animals, because "we are the better for it, and they are never the worse" (311).

${ }^{33}$ John Griffith rightly points out that the most fantastical elements in Charlotte's Web stem from White's socioeconomic bracket, which insulated him from the realities of subsistence farming or fighting to retain land and make money in an increasingly corporatized industry. 
${ }^{34}$ In Animal Farm, Orwell similarly conflates human and animal at the end of his novel, albeit to call attention to the corrupting nature of political power and the plight of the working poor. According to Orwell, "men exploit animals in much the same way as the rich exploit the proletariat” (“Author’s Preface”405).

${ }^{35}$ Matthew Scully addresses this topic further in Dominion, in which he challenges the Judeo-Christian mythos that human rule over animals is not only granted by God, but includes the right of humans to inflict untold suffering upon them.

${ }^{36}$ Microsoft Word insists that it is incorrect to use "who" instead when referring to animals. Both grammar and technology are thus programmed to discourage the conflation of human and animal subjectivity.

${ }^{37}$ Women activists, many of whom were also lobbying for women's suffrage, were positioned as excessively sentimental, and censured for an over-identification with experimental animals largely because they, too, were at the mercy of medical men. Lower-class female patients in the charity wards of hospitals were exhibited as scientific curiosities, in violation of their personal modesty and bodily autonomy (Lansbury 8586). Upper-class women fared no better; often accused of hysteria and hypochondria, they too were subject to invasive procedures and even surgeries to cure "menstrual difficulties" (89). 
${ }^{38}$ Richard D. French characterizes the typical antivivisectionist as perceiving him or herself as the "“quasi-aristocratic' upholder of moral responsibility against the vulgar careerism, materialism, utilitarianism and even 'trades-unionism' of the provivisection medical profession" (236).

${ }^{39}$ For further reading on how Darwin assisted Frances Power Cobbe and other animal advocates in drafting antivivisection legislation, see David Allan Feller (2009).

${ }^{40}$ Diane Zahler notes in The Black Death (2009) that it is actually the fleas on the rats that cause the spread of the plague virus.

${ }^{41}$ Ramsden and Adams also contend that Calhoun believed that the main character, Mrs. Frisby, was named as a reference to the Frisbee disc hanging on the back of Calhoun's office door (781).

${ }^{42}$ Interestingly, current research has pinpointed the FOXP2 gene as the carrier of human language. When this gene is manipulated in laboratory rodents, they exhibit changed squeaking patterns and social organization (Wade n.p.)

${ }^{43}$ After stripping the blubber while the animal was still in the water, the body would then be hoisted on deck so that teams of men could disarticulate the cranium. If the victim were a right whale, its baleen plates would be removed; if it were a sperm whale, the 
spermaceti was extracted from the head, and its body was further eviscerated to remove valuable ambergris from the stomach and intestine. Fully rendering a whale into saleable materials would take days, or even weeks, particularly if the workers put to shore to boil the blubber down into oil for easier storage in casks. A profitable trip could take well over three years, if not longer, to return to the home port (Creighton 67).

${ }^{44}$ According to the Inuit whale hunters, the bowhead could only be killed by the very best hunters, who demonstrated the proper respectful attitude toward his quarry. By doing so, the hunter is "led to an attachment and reverence for the prey that can best be likened to the sentiments a man feels for his beloved" (Lynge 39).

${ }^{45}$ The North Atlantic right whale population has, to date, not rebounded, despite the best efforts of conservationists since 1930 . There are currently less than 500 whales in total (Trotter n.p.).

${ }^{46}$ Paul Watson $(1981,1994)$ and David Day (1987) detail the guerilla tactics espoused by Greenpeace and other environmental activists to call attention to illicit and unethical whaling activities in the 1970s and 1980s.

${ }^{47}$ In the early 1990s, film producer and environmentalist Richard Donner received a script about "a mute orphan boy who lives with nuns and befriends a whale at an amusement park[....] The boy is silent until the end of the movie, when he releases the 
whale into the ocean and cries out 'Free Willy!"” Donner and his wife, producer Lauren Shuler Donner, thought the story had potential, but substantially rewrote the script to make it less overtly saccharine. Green-lit by Warner Bros., they began auditioning orcas for the role of Willy. None of the Sea World or Marineland franchises would allow their whales to perform in an anti-captivity film, however, so the production team set their sights further afield. They found both Keiko and the dilapidated Reina Aventura in Mexico ideal for their purposes (Orlean n.p.).

${ }^{48}$ The emotional consequences of such social deprivation can be disastrous for the captive cetacean, including depression or increased aggression. Compulsive behaviours, such as repetitive swimming patterns, are also common, as is suicide. Captive dolphins in particular are prone to taking their own lives, hitting their heads repeatedly on the sides of their tanks until they die, or by sinking to the bottom of their pools and refusing to take another breath (Cochrane and Callen 144).

${ }^{49}$ People for the Ethical Treatment of Animals (PETA) recently filed a lawsuit on behalf of all the orcas held by the Sea World facilities in North America, on the grounds that Sea World is violating the $13^{\text {th }}$ Amendment to the US Constitution, which abolished slavery. (“Sea World" n.p.)

${ }^{50}$ Peter Singer proposes that human sexuality is fluid enough to encompass zoeophilia or bestiality. He contends that the taboo prohibiting sexual activities with animals is largely 
upheld to demarcate an exclusively human subjectivity. Moreover, arguments against sexual relations with animals situated in issues of power imbalance and the inability of the animal to verbally consent to these activities also prioritize human language as a privileged mode of communication, reinforcing species boundary. It is possible, in Singer's opinion, to have "mutually satisfying" experiences of this nature with animals in a way that does not involve cruelty ("Heavy Petting" n.p.). 


\section{Works Cited}

Adams, Carol J. The Sexual Politics of Meat: A Feminist-Vegetarian Critical Theory. 1990. NY: Continuum, 2000.

Agamben, Giogio. Homo Sacer: Sovereign Power and Bare Life. Trans. Daniel HellerRoazen. Stanford: Stanford UP, 1998.

Agosta, Lucien L. E.B. White: The Children's Books. NY: Twayne Publishers, 1995. Anonymous. Memoirs of Dick the Little Pony, Supposed to be Written by Himself. 1799. London: J. Walker, 1800.

Arendt, Hannah. On Revolution. NY: Viking Press, 1965.

Ariès, Phillipe. Centuries of Childhood: A Social History of Family Life. Trans. Robert Baldick. NY: Alfred A. Knopf, 1962.

Aristotle. "Nicomachean Ethics." Classics of Moral and Political Theory. Ed. Michael L. Morgan. Indianapolis: Hackett, 2005.

---. On the Parts of Animals I-IV. Trans. James G. Lennox. Oxford: Oxford UP, 2001.

Armstrong, Philip. "Moby-Dick and Compassion." Society and Animals 12.1 (2004): 19-37.

Audubon, John James. “The Pitting of Wolves.” Eds. Maria R. Audubon and Elliott Coues. Audubon and His Journals: Volume 2. 1897. Toronto: General, 1994.

Bailey, Peter. Leisure and Class in Victorian England: Rational Recreation and the Contest for Control, 1830-1885. NY: Routledge, 1978. 
Barbauld, Anna. “The Mouse's Petition.” The Works of Anna Laetitia Barbauld With A Memoir by Lucy Aiken. Vol. 1. Boston: David Reed, 1826. <http://www .archive.org/details/worksannaltitia00aikigoog> Accessed 18 December 2011.

Barnett, Samuel Anthony. The Story of Rats: Their Impact on Us, and Our Impact on Them. Crow's Nest, Australia: Allen \& Unwin, 2001.

Bentham, Jeremy. An Introduction to the Principles of Morals and Legislation. 1780. Oxford: Clarendon, 1879.

Bellanca, Mary Ellen. “Science, Sympathy, and Anna Barbauld's 'The Mouse's Petition." Eighteenth Century Studies 37.1 (Fall 2003): 47-67.

Berliner, Jonathan. “Jack London’s Socialistic Social Darwinism.” American Literary Realism 41.1 (Fall 2008): 52-78.

Birke, Lynda, Arnold Arluke and Mike Michael. The Sacrifice: How Scientific Experiments Transform Animals and People. West Lafayette: Purdue UP, 2007.

Birmingham, Peg. Hannah Arendt and Human Rights: The Predicament of Common Responsibility. Bloomington: Indiana UP, 2006.

Blake, William. "The Fly.” Songs of Experience. 1794. The Literature Network. N. date. <http://www.online-literature.com/blake/625/> Accessed 20 October 2010.

Brower, Kenneth. Freeing Keiko: The Journey of a Killer Whale from Free Willy to the Wild. NY: Gotham Books, 2005. 
Brown, Marshall. "Romanticism and Enlightenment." The Cambridge Companion to British Romanticism. Ed. Stuart Curran. Cambridge: Cambridge UP, 2010. 34-55.

Bryld, Mette and Nina Lykke. Cosmodolphins: Feminist Cultural Studies of Technology, Animals and the Sacred. London: Zed Books, 2000.

Burnett, D. Graham. The Sounding of the Whale: Science and Cetaceans in the Twentieth Century. Chicago: U of Chicago P, 2012.

Burnett, John. A Social History of Housing 1815-1970. Cambridge: Cambridge UP, 1978.

Caras, Roger. A Perfect Harmony: The Intertwining Lives of Animals and Humans Throughout History. West Lafayette, IN: NotaBell Books, 1996.

Carson, Gerald. "T.R. and the "nature fakers."” American Heritage Magazine 22.2 (February 1971). AmericanHeritage.com. N. date. <http://www.americanheritage.com/articles/magazine/ah/1971/2/1971_2_ 60.shtml> Accessed 6 December 2010.

Cavalieri, Paola. “Cetaceans: From Bare Life to Nonhuman Others.” Logos 10.1 (2011): $<$ http://www.logosjournal.com/cetaceans-bare-life-nonhumanothers.php\#_edn9> Accessed 5 April 2012.

Cavendish, Richard. The Powers of Evil in Western Religion, Magic and Folk Belief. London: W.J. Mackay, 1975. 
Chassagnol, Anne. "Darwin in Wonderland: Evolution, Involution and Natural Selection in The Water Babies (1863)." Miranda 1 (March 2010): n. pag. <www.mirandaejournal.eu/1/1/Miranda/article.xsp?numero=1\&id_article=article_03-1089> Accessed 29 March 2012.

Coats, Karen. "Lacan with Runt Pigs." Children's Literature 27 (1999): 105-28.

Cochrane, Alasdair. An Introduction to Animals and Political Theory. NY: Palgrave Macmillan, 2010.

Cochrane, Amanda and Karina Cullen. Dolphins: Their Power to Heal. Rochester, VT: Healing Arts Press, 1992.

Connolly, Paula T. "Frisby Turned Brisby: The Resolution of Ambiguity in The Secret of NIMH.” The Antic Art: Enhancing Children's Literary Experiences Through Film and Video. Ed. Lucy Rollin. Madison, WI: Highsmith Press, 1993. 73-82. Coppin, Dawn. "Hog Futures: The Birth of Mega-Hog Farms." Sociological Quarterly 44.4 (Autumn 2003): 597-616.

Crossley-Holland, Kevin. The Norse Myths. NY: Pantheon, 1980.

Creighton, Margaret S. Rites and Passages: The Experience of American Whaling, 18301870. Cambridge: Cambridge UP, 1995.

“Cruel and Improper Treatment of Cattle Act 1822." Animal Rights History, n. date. $<$ http://www.animalrightshistory.org/animal-rights-law/romanticlegislation/1822-uk-act-ill-treatment-cattle.htm?zoom_highlight $=$ martin $\% 27 \mathrm{~s}+$ act $>$ Accessed 16 December 2010. 
“Cruelty to Animals/Anti-Vivisection Act 1876." Animal Rights History, N. date. $<$ http://www.animalrightshistory.org/animal-rights-law/victorianlegislation/1876-uk-act-vivisection.htm> Accessed 12 December 2011.

D’Amato, Anthony and Sudhir K. Chopra. "Whales: Their Emerging Right to Life." American Journal of International Law 85 (January 1991): 21-62.

Darnton, Robert. The Great Cat Massacre and Other Episodes in French Cultural History. 1984. NY: Basic Books, 1999.

Darton, Harvey. Children's Books in England: Five Centuries of Social Life. 1932. London: Cambridge UP, 1982.

Darwin, Charles. The Expression of the Emotions in Man and Animals. 1872. Oxford: Oxford UP, 1998.

---. On the Origin of Species By Means of Natural Selection. Mineola, NY: Dover, 2006.

Davis, Susan G. Spectacular Nature: Corporate Culture and the Sea World Experience. Berkeley: U of California P, 1997.

Day, David. The Whale War. Toronto: Douglas \& McIntyre, 1987.

"Declaration of Cetacean Rights: Whales and Dolphins." Cetacean Rights: Fostering Moral and Legal Change. N. date. <www.cetaceanrights.org> Accessed 12 March 2012.

Deleuze, Gilles and Félix Guattari. A Thousand Plateaus: Capitalism and Schizophrenia. Trans. Brian Massumi. Minneapolis: U of Minnesota P, 1987. 
Derrida, Jacques. “'Eating Well,' or the Calculation of the Subject: An Interview with Jacques Derrida." Trans. Peter Connor and Avital Ronell. Who Comes After the Subject? Eds. Eduardo Cadava, Peter Connor and Jean-Luc Nancy. NY:

Routledge, 1991. 96-119.

---. The Animal That Therefore I Am. Trans. Marie-Louise Mallet. NY:

Fordham UP, 2008.

Descartes, René. "Discourse on the Method.” 1637. The Philosophical Works of Descartes. Translated by Elizabeth S. Haldane. Cambridge: Cambridge UP, 1967.

Desmond, Jane. Staging Tourism: Bodies on Display from Waikiki to Sea World. Chicago: U of Chicago P, 1999.

Desmond, John. “A Summons to the Consuming Animal.” Business Ethics: A European Review 19.3 (July 2010): 238-52.

Dingley, Robert. “A Horse of a Different Color: 'Black Beauty' and the Pressures of Indebtedness." Victorian Literature and Culture 25.2 (1997): 241-51.

Dolin, Eric Jay. Leviathan: The History of Whaling in America. NY: W.W. Norton \& Company, 2007.

Dolphin Tale. Dir. Charles Martin Smith. 2011. Warner Bros., 2011. DVD.

Dorré, Gina. 'Horses and Corsets: 'Black Beauty,' Dress Reform, and the Fashioning of the Victorian Woman.”Victorian Literature and Culture 30.1 (2002): 157-178.

---. Victorian Fiction and the Cult of the Horse. Aldershot: Ashgate, 2006. 
Dudzinski, Kathleen and Toni Frohoff. Dolphin Mysteries: Unlocking the Secrets of Communication. New Haven: Yale UP, 2008.

Dundes, Alan. Little Red Riding Hood: A Casebook. Madison: U of Wisconsin P, 1989.

Elledge, Scott. E.B. White: A Biography. NY: W.W. Norton \& Co., 1984.

Emerson, Ralph Waldo. Nature. 1836. Boston: James Monroe, 1844.

Faiella, Graham. Moby Dick and the Whaling Industry of the Nineteenth Century. NY: Rosen Publishing Group, 2004.

Fara, Patricia. "Educating Mary: Women and Scientific Literature in the Early Nineteenth Century.” Frankenstein's Science: Experimentation and Discovery in Romantic Culture, 1780-1830. Ed. Christa Knellwolf and Jane Goodall. London: Ashgate, 2008. 17-32.

Feller, David Allan. "Dog Fight: Darwin as Animal Advocate in the Antivivisection Controversy of 1875." Studies in History and Philosophy of Biological and Biomedical Sciences 40 (2009): 265-271.

Ferguson, Frances. “Anna Laetitia Barbauld.” The Oxford Encyclopedia of British Literature. Ed. David Scott Kastan. Oxford: Oxford UP, 2006. 119-122. Foucault, Michel. Discipline and Punish: The Birth of the Prison. 1975. Trans. Alan Sheridan. NY: Vintage, 1995.

Free Willy. Dir. Simon Wincer. 1993. Warner Bros., 2009. DVD.

French, Richard D. Antivivisection and Medical Science in Victorian Society. Princeton: Princeton University Press, 1975. 
Giles, James R. "Assaulting the Yeehats: Violence and Space in The Call of the Wild." Ed. Mary E. Papke. Twisted From the Ordinary: Essays on American Literary Naturalism. Knoxville: U of Tennessee P, 2003. 188-201.

Grandin, Temple. Animals in Translation: Using the Mysteries of Autism to Decode Animal Behavior. NY: Scribner, 2005.

Gompertz, Lewis. Moral Inquiries on the Situation of Man and Brutes. 1824. Sussex: Centaur Press, 1992.

Grey, Mark. “'Those Bastards Can Go to Hell!' Small Farmer Resistance to Vertical Integration and Concentration in the Pork Industry." Human Organization 59.2 (Summer 2000): 169-76.

Griffin, Emma. Blood Sport: Hunting in Britain Since 1066. London: Yale UP, 2007.

Griffith, John. “Charlotte's Web: A Lonely Fantasy of Love.” Children's Literature 8 (1980): 111-17.

---. Charlotte’s Web: A Pig's Salvation. NY: Twayne Publishers, 1993.

Guerrini, Anita. Experimenting with Humans and Animals: From Galen to Animal Rights. Baltimore: Johns Hopkins UP, 2003.

Hagiioannu, Andrew. The Man Who Would be Kipling: The Colonial Fiction and the Frontiers of Exile. NY: Palgrave, 2003.

Halberstam, Judith. Skin Shows: Gothic Horror and the Technology of Monsters. Durham: Duke University Press, 1995.

Haraway, Donna. The Companion Species Manifesto: Dogs, People, and Significant Otherness. Chicago: Prickly Paradigm Press, 2003. 
---. Simians, Cyborgs, and Women. NY: Routledge, 1991.

---. When Species Meet. Minneapolis: U of Minnesota P, 2008.

Hardy, Thomas. Jude the Obscure. 1895. NY: W.W. Norton \& Company, 1978.

Harrison, James. “Kipling's Jungle Eden.” Critical Essays on Rudyard Kipling. Ed. Harold Orel. Boston: G.K. Hall and Co., 1989. 151-64.

Heal, Felicity and Clive Holmes. The Gentry in England and Wales 1500-1700. Stanford: Stanford UP, 1994.

Hedgepeth, William. The Hog Book. Athens, GA: U of Georgia P, 1998.

Heidegger, Martin. The Fundamental Concepts of Metaphysics: World, Finitude, Solitude. 1929-1930. Trans. William McNeill and Nicholas Walker. Bloomington: Indiana University Press, 1995.

Helbig, Alethea K. “Robert C. O'Brien's Mrs. Frisby and the Rats of NIMH: Through the Eyes of Small Animals." Touchstones: Reflections on the Best in Children's Literature. Vol. 1. Ed. Perry Nodelman. West Lafayette, IN: Children's Literature Association, 1985. 204-11.

Holmes, Morgan. "Donkeys, Englishmen, and Other Animals: The Precarious Distinctions of Victorian Interspecies Morality." European Stevenson. Ed. Richard Ambrosini and Richard Dury. Newcastle upon Tyne: Cambridge Scholars, 2009. 109-126.

Horowitz, Roger. Putting Meat on the American Table: Taste, Technology, Transformation. Baltimore: Johns Hopkins UP, 2006. 
Howe, James. "Foxhunting as Ritual.” American Ethnologist 18.2 (1981): 278-300.

Jesch, Judith. "Eagles, Ravens and Wolves: Beasts of Battle, Symbols of Victory and Death." Ed. Judith Jesch. The Scandinavians from the Vendel Period to the Tenth Century: An Ethnographic Perspective. Rochester: The Boydell Press, 2002. 251-70.

Johnson, Samuel. English Dictionary. 1755. Boston: Nathan Hale, 1835.

Jones, Karen R. Wolf Mountains: A History of Wolves Along the Great Divide. Calgary: U of Calgary P, 2002.

Kalland, Arne. "Whale Politics and Green Legitimacy: A Critique of the Anti-Whaling Campaign.” Anthropology Today 9.6 (December 1993): 3-7.

Kean, Hilda. Animal Rights: Political and Social Change in Britain Since 1800. London: Reaktion, 1998.

Kinghorn, Norton D. “The Real Miracle of Charlotte’s Web.” Children's Literature Association Quarterly 11.1 (Spring 1986): 4-9.

Kipling, Rudyard. The Jungle Book and the Second Jungle Book. 1894. London: Wordsworth Classics, 2007.

Knellwolf, Christa and Jane Goodall. “Introduction.” Frankenstein's Science: Experimentation and Discovery in Romantic Culture, 1780-1830. Ed. Christa Knellwolf and Jane Goodall. London: Ashgate, 2008. 1-16.

Labor, Earle. “Jack London's Mondo Cane: 'Bâtard,' The Call of the Wild, and White Fang." Jacqueline Tavernier-Courbin, ed. Critical Essays on Jack London. Boston: G.K. Hall and Co., 1983. 114-30. 
Lansbury, Coral. The Old Brown Dog: Women, Workers, and Vivisection in Edwardian England. Madison: U of Wisconsin P, 1985.

Lee, Paula Young. "Introduction: Housing Slaughter." Meat, Modernity and the Rise of the Slaughterhouse. Ed. Paula Young Lee. Lebanon, NH: U of New Hampshire P, 2008. 1-12.

Levinas, Emmanuel. Totality and Infinity: An Essay on Exteriority. Trans. Alphonso Lingis. Pittsburgh: Duquesne University Press, 1969.

Lévi-Strauss, Claude. Totemism. Trans. Rodney Needham. London: Merlin Press, 1962. Lippit, Akira Mizuta. Electric Animal: Toward a Rhetoric of Wildlife. Minneapolis: U of Minnesota P, 2000.

Locke, John. An Essay Concerning Human Understanding. 1690. Oxford: Oxford UP: 2008.

---. Some Thoughts Concerning Education. 1693. NY: Dover Publications, Inc.: 2007.

London, Charmain. The Book of Jack London Part Two. 1921. Whitefish, MT: Kessinger Publishing, 2003.

London, Jack. "Bâtard." 1904. The World of Jack London. N. date. <http://www.jacklondons.net/writings/FaithMen/batard.html> Accessed 7 November 2010.

---. The Call of the Wild. 1903. Toronto: Penguin Books, 2008.

---. "Husky - The Wolf-Dog of the North.” 1900. The World of Jack London. N. date. <http://www.jacklondons.net/writings/Nonfiction/Journalism/husky.html> Accessed 8 November 2010. 
---. "The Other Animals." 1908. The World of Jack London. N. date.

$<$ http://www.jacklondons.net/writings/Revolution/animals.html>

Accessed 10 November 2010.

---. White Fang. 1906. Toronto: Penguin Books, 2008.

Lund, Thomas K. American Wildlife Law. Berkeley: U of California P, 1980.

Lundblad, Michael. "From Animal to Animality Studies." PMLA 124.2 (2009): 496-502.

Lynge, Finn. Arctic Wars, Animal Rights, Endangered Peoples. Hanover, NH:

University Press of New England, 1992.

Mackenzie, John M. "Hunting and the Natural World in Juvenile Literature.” Ed. Jeffrey

Richards. Imperialism and Juvenile Literature. Manchester: Manchester UP, 1989. 144-72.

---. Propaganda and Empire: The Manipulation of British Public Opinion, 1880-1960. Manchester: Manchester UP, 1984.

Maehle, Andreas-Holger and Ulrich Tröhler. "Animal Experimentation from Antiquity to the End of the Eighteenth Century: Attitudes and Arguments." Vivisection in a Historical Perspective. Ed. Nicholas Rupke. London: Routledge, 1987. 14-47.

Malcolmson, Robert and Stephanos Mastoris. The English Pig: A History. London: The Hambledon Press, 1998.

Marvin, Garry. "Unspeakability, Inedibility and the Structures of Pursuit in the English Foxhunt.” Ed. Nigel Rothfels. Representing Animals. Indianapolis: Indiana UP, 2002. 139-58. 
Masson, Jeffery Moussaieff. Dogs Never Lie About Love: Reflections on the Emotional World of Dogs. NY: Crown, 1997.

---. The Pig Who Sang to the Moon: The Emotional Lives of Farm Animals. NY:

Ballantine Books, 2003.

Masson, Jeffrey Mousaieff and Susan McCarthy. When Elephants Weep: The Emotional Lives of Animals. NY: Dell, 1995.

Mayer, Jed. "The Expression of Emotions in Man and Laboratory Animals." Victorian Studies 50.3 (Spring 2008): 399-417.

McCance, Dawn. “Anatomy as Speech Act: Vesalius, Descartes, Rembrant or, The Question of 'the animal' in the Early Modern Anatomy Lesson." Animal Subjects: An Ethical Reader in a Posthuman World. Ed. Jodey Castricano. Waterloo: Wilfred Laurier University Press, 2008. 63-96.

McClintock, Anne. Imperial Leather: Race, Gender and Sexuality in the Colonial Contest. NY: Routledge, 1995.

Melville, Herman. Moby-Dick, or The Whale. 1851. Hertfordshire: Wordsworth Editions Ltd., 2002.

“Metropolitan Slaughterhouses.” The Lancet (20 September 1873): 425.

Morrison, Robert. The Individuality of the Pig: Its Breeding, Feeding and Management. NY: E.P. Dutton \& Co., 1926. 
Morse, Deborah Denenholz and Martin A. Danahay. "Introduction." Victorian Animal Dreams: Representations of Animals in Victorian Literature and Culture. Ed. Deborah Denenholz Morse and Martin A. Danahay. Aldershot: Ashgate, 2007. $1-12$.

Murray, Robin L. and Joseph K. Heumann. That's All Folks? Ecocritical Readings of American Animated Features. Lincoln: U of Nebraska P, 2011.

Nash, Roderick Frazier. The Rights of Nature: A History of Environmental Ethics. Madison: U of Wisconsin P, 1989.

Nagtzaam, Gerry J. "The International Whaling Commission and the Elusive Great White Whale of Preservationism." William \& Mary Environmental Law and Policy Review 37533.2 (2009): 375-447.

Neumeyer, Peter. "What Makes a Good Children's Book? The Texture of Charlotte's Web.” South Atlantic Bulletin 44.2 (May 1979): 66-75.

Nodelman, Perry. "Text as Teacher: The Beginning of Charlotte's Web." Children's Literature 13 (1985): 109-27.

O'Brien, Robert C. Mrs. Frisby and the Rats of NIMH. Illus. Zena Bernstein. 1971. New York: Aladdin Paperbacks, 1986.

---. "Newbery Award Acceptance." Newbery and Caldecott Medal Books 1966-1975.

Ed. Lee Kingman. Boston: The Horn Book, Inc. 1975. 83-92.

O'Malley, Andrew. The Making of the Modern Child: Children's Literature and Childhood in the Late Eighteenth Century. NY: Routledge, 2003. 
Orlean, Susan. “Where's Willy?” The New Yorker 78.28 (23 September 2002): n. pag. <http://ezproxy.lib.Ryerson.ca/login?url=http://search.proquest.com/docview/23 3148152?accountid=13631> Accessed 12 January 2012.

Orwell, George. Animal Farm. 1945. Toronto: Penguin Books, 1989.

---. "Author's Preface to the Ukranian Edition of Animal Farm." Collected Essays, Journalism and Letters of George Orwell, Volume 3. Eds. Sonia Orwell and Ian Angus. NY: Harcourt, Brace and World, 1968.

Otter, Chris. "Civilizing Slaughter: The Development of the British Public Abattoir, 1850-1910." Meat, Modernity and the Rise of the Slaughterhouse. Ed. Paula Young Lee. Lebanon, NH: U of New Hampshire P, 2008. 89-106.

Pacyga, Dominic A. "Chicago: Slaughterhouse to the World." Meat, Modernity and the Rise of the Slaughterhouse. Ed. Paula Young Lee. Lebanon, NH: U of New Hampshire P, 2008. 153-66.

Perkins, David. Romanticism and Animal Rights. Cambridge: Cambridge UP, 2003.

Pickering, Samuel. John Locke and Children's Books in Eighteenth Century England. Knoxville: U of Tennessee P, 1981.

Plimpton, George A. and Frank H. Crowther. "The Art of the Essay, I: E.B. White." Paris Review 48 (Fall 1969): 65-88. <http://www.theparisreview.org/interviews /4155/the-art-of-the-essay-no-1-e-b-white> Accessed 1 June 2011.

Prior, Karen Swallow. “Animals and Evangelicals.” Liberty Journal. 18 October 2007. <http://www.liberty.edu/libertyjournal/index.cfm?PID=15758\&artid=13> Accessed 25 May 2012. 
Rahn, Suzanne. "Green Worlds for Children." The Lion and the Unicorn 19.2 (1995). 147-170.

Ramsden, Edmund and Jon Adams. "Escaping the Laboratory: The Rodent Experiments of John B. Calhoun and Their Cultural Influence.” Journal of Social History 42.3 (Spring 2009): 761-792.

Richards, Jeffrey. “Introduction.” Ed. Jeffrey Richards. Imperialism and Juvenile Literature. Manchester: Manchester UP, 1989. 1-11.

Ritvo, Harriet. "Learning from Animals: Natural History for Children in the Eighteenth and Nineteenth Centuries.” Children's Literature 13 (1985): 72-93.

Rose, Jacqueline. The Case of Peter Pan, or the Impossibility of Children's Fiction. 1984. Philadelphia: U of Pennsylvania P, 1993.

Rousseau, Jean-Jacques. Discourse on the Nature of Inequality. 1754. NY: Cosimo Classics, 2005.

---. Emile. Trans. Barbara Foxley. 1762. Charleston: BiblioLife, 2008.

Rushdy, Ashraf H.A. “"The Miracle of the Web': Community, Desire and Narrativity in Charlotte's Web." The Lion and the Unicorn 15 (1991): 35-60.

Salt, Henry. Animals’ Rights. 1892. Clarks Summit, PA: Society for Animal Rights, 1980.

Scholtmeijer, Marian. Animal Victims in Modern Fiction: From Sanctity to Sacrifice. Toronto: U of Toronto P, 1993.

Schuller, Kyla. "Specious Bedfellows: Ethnicity, Animality, and the Intimacy of Slaughter in Moby-Dick." Leviathan: A Journal of Melville Studies (2010): 3-20. 
Scoresby, William. Journal of a Voyage to the Northern Whale-Fishery. Edinburgh: Archibald Constable, 1923.

“Sea World sued over 'enslaved' killer whales.” BBC News 6 February 2012. <http://www.bbc.co.uk/news/world-us-canada-16920866> Accessed 8 April 2012.

Seiter, Richard. "Cinema Villain, Sequel Hero: Jenner and the Evolving NIMH Community." "Frisby Turned Brisby: The Resolution of Ambiguity in The Secret of NIMH." The Antic Art: Enhancing Children's Literary Experiences Through Film and Video. Ed. Lucy Rollin. Madison, WI: Highsmith Press, 1993. 83-91.

---. "Mrs. Frisby and the Rats go to Hollywood." Language Arts Journal of Michigan 5.3 (1990): 51-56.

Seton, Ernest Thompson. Wild Animals I Have Known. Project Gutenberg, October 2009. <http://www.gutenberg.org/files/3031/3031-h/3031-h.htm> Accessed 4 December 2010.

Scully, Matthew. Dominion: The Power of Man, the Suffering of Animals, and the Call to Mercy. NY: St. Martin's Press, 2002.

The Secret of NIMH. Dir. Don Bluth. 1982. Metro Goldwyn Mayer, 2007. DVD.

Sewell, Anna. Black Beauty: The Autobiography of a Horse. London: Jerrold \& Sons, 1877.

Shelley, Mary. Frankenstein. 1818. Toronto: Penguin Books, 1983.

Shepard, Paul. Traces of an Omnivore. Washington: Island, 1996. 
Sims, Michael. The Story of Charlotte's Web: E.B. White's Eccentric Life and the Birth of an American Classic. NY: Walker \& Company, 2011.

Singer, Peter. Animal Liberation. 1975. NY: HarperCollins, 2009.

---. "Heavy Petting." Nerve 2001. <http://utilitarian.net/singer/by/2001----.htm>

N. date. Accessed 12 May 2012.

Sorenson, John. "Monsters: The Case of Marineland." Animal Subjects: An Ethical Reader in a Posthuman World. Ed. Jodey Castricano. Waterloo: Wilfrid Laurier UP, 2008. 195-224.

Spiegel, Marjorie. The Dreaded Comparison: Human and Animal Slavery. NY: Mirror Books, 1996.

Spencer, Herbert. The Principles of Biology Volume Two. 1864. London: Williams and Norgate, 1867.

Spencer, Sanders. The Pig: Breeding, Rearing and Marketing. 1919. Cookhill, UK: Read Country Books, 2008.

Stevenson, Robert Louis. An Inland Voyage, Including “Travels with a Donkey.” 1879. NY, Cosimo Classics, 2007.

Stoneley, Peter. "Sentimental Emasculations: Uncle Tom's Cabin and Black Beauty." Nineteenth-Century Literature 54.1 (January 1999): 53-72.

Tavernier-Courbin, Jacqueline. “Introduction: Jack London: A Professional.” Ed. Jacqueline Tavernier-Courbin. Critical Essays on Jack London. Boston: G.K. Hall, 1983. 1-21.

---. The Call of the Wild: A Naturalistic Romance. Toronto: Twayne, 1994. 
Thierman, Stephen. “Apparatuses of Animality: Foucault Goes to a Slaughterhouse.” Foucault Studies 9 (September 2010): 89-110.

Trimmer, Sarah. Fabulous Histories Designed for the Instruction of Children, respecting their Treatment of Animals. 1786. London: C. and J. Rivington: 1826.

Trotter, Bill. “A whale of a task: Restoring the right whale population.” Bangor Daily News 8 August 2011. N. pag. <http://bangordailynews.com/2011/08/08/environment/a-whale-of-a-taskrestoring-the-right-whale-population/> Accessed 4 April 2012.

Tuan, Yi-Fu. Dominance and Affection: The Making of Pets. New Haven, CT: Yale UP, 1984.

Turner, Frederick Jackson. The Frontier in American History. Project Gutenberg. 14 October 2007. <http://www.gutenberg.org/catalog/world/readfile? fk_files=1530503> Accessed 8 December 2010.

Turner, James. Reckoning with the Beast: Animals, Pain and Humanity in the Victorian Mind. Baltimore: Johns Hopkins UP, 1980.

Twine, Richard. Animals as Biotechnology: Ethics, Sustainability and Critical Animal Studies. London: Earthscan, 2010.

Vint, Sherryl. Animal Alterity: Science Fiction and the Question of the Animal. Liverpool: Cambridge UP, 2010.

Wade, Nicholas. "A Human Language Gene Changes the Sound of Mouse Squeaks." The NY Times (28 May 2009). < http://www.nytimes.com/2009/05/29/science/ 29mouse.html> Accessed 8 November 2011. 
Wake, Lynn Overholt. “E.B. White's Paean to Life: The Environmental Imagination of Charlotte's Web." Wild Things: Children's Culture and Ecocritisism. Eds.

Sidney I. Dobrin and Kenneth B. Kidd. Detroit: Wayne State UP, 2004. 101-14.

Wallace, Miriam L. "Introduction: Enlightened Romanticism or Romantic Enlightenment?" Romancing the Enlightenment: British Novels from 1750 to 1832. Ed. Miriam L. Wallace. Aldershot: Ashgate, 2009. 1-20.

Watson, Paul and Cleveland Amory. Ocean Warrior: My Battle to End the Illegal Slaughter on the High Seas. Toronto: Key Porter Books, 1994. ---. Sea Shepherd: My Fight for Whales and Seals. NY: W.W. Norton \& Co., 1981. White, E.B. Charlotte's Web. 1952. Illus. Garth Williams. NY: HarperCollins, 1980.

---. "Death of a Pig." Essays of E.B. White. Ed. Dorothy Lobrano Guth. NY: Harper and Row, 1977.

---. Letters of E.B. White. Ed. Dorothy Lobrano Guth. NY: Harper and Row, 1976.

---. One Man's Meat. 1938. NY: Harper \& Brothers, 1944.

---. "Pigs and Spiders.” McClurg’s Book News (January 1953): 49.

Wild, Martin Trevor. Village England: A Social History of the Countryside. NY: Palgrave Macmillan, 2004.

Wilson, Margaret Dauler. “Animal Ideas.” Ideas and Mechanism: Essays on Early Modern Philosophy. Princeton: Princeton UP, 1999. 495-512.

Wintle, Sarah. "If Houyhnhms Were Horses: Thinking with Animals in Book IV of Gulliver's Travels." The Critical Review 34 (1994): 3-21. 
Wolfe, Cary. Animal Rites: American Culture, the Discourse of Species, and Posthumanist Theory. Chicago: U of Chicago P, 2003.

---. What Is Posthumanism? Minneapolis: U of Minnesota P, 2010.

Zipes, Jack, ed. The Trials and Tribulations of Little Red Riding Hood. $2^{\text {nd }}$ ed. NY: Routledge, 1993. 